UNIVERSIDADE DE BRASÍLIA - FACULDADE DA CEILÂNDIA PROGRAMA DE PÓS-GRADUAÇÃO STRITO-SENSU EM CIÊNCIAS E TECNOLOGIAS EM SAÚDE

\title{
EFEITOS DO TREINAMENTO RESISTIDO EM PACIENTES COM INSUFICÊNCIA CARDÍACA COM FRAÇÃO DE EJEÇÃO REDUZIDA - REVISÃO SISTEMÁTICA E METANÁLISE.
}

Francisco Valdez Santos de Oliveira Lima 
UNIVERSIDADE DE BRASÍLIA - FACULDADE DA CEILÂNDIA

PROGRAMA DE PÓS-GRADUAÇÃO STRITO-SENSU EM CIÊNCIAS E TECNOLOGIAS EM SAÚDE

\section{EFEITOS DO TREINAMENTO RESISTIDO EM PACIENTES COM INSUFICÊNCIA CARDÍACA COM FRAÇÃO DE EJEÇÃO REDUZIDA - REVISÃO SISTEMÁTICA E METANÁLISE.}

Francisco Valdez Santos de Oliveira Lima

Dissertação apresentada à Faculdade da Ceilândia da Universidade de Brasília, como requisito para obtenção do Grau de Mestre em Ciências e Tecnologias em Saúde.

Orientador: Prof. Dr. Gerson Cipriano Junior

Brasília, 2016 
Ficha catalográfica elaborada automaticamente, com os dados fornecidos pelo(a) autor(a)

Lima, Francisco Valdez Santos

Efeitos do treinamento resistido em pacientes com Insuficiencia Cardíaca com fração de ejeção reduzida: revisão sistemática e metanálise. / Francisco Valdez Santos Lima; orientador Gerson Cipriano Junior. -Brasília, 2016.

$165 \mathrm{p}$.

Dissertação (Mestrado - Mestrado em Ciências e Tecnologias em Saúde) -- Universidade de Brasília, 2016 .

1. Exercício. 2. Insuficiencia Cardíaca. 3.

Remodelamento Cardíaco. 4. Capacidade ao exercício. I Cipriano Junior, Gerson, orient. II. Título. 


\section{EFEITOS DO TREINAMENTO RESISTIDO EM PACIENTES COM INSUFICÊNCIA CARDÍACA COM FRAÇÃO DE EJEÇÃO REDUZIDA - REVISÃO SISTEMÁTICA E METANÁLISE.}

Dissertação aprovada como requisito para obtenção do Título de Mestre em Ciências e tecnologias em Saúde pelo Programa de Pós-graduação da Faculdade da Ceilândia da Universidade de Brasília

Banca Examinadora:

Prof. Dr. Gerson Cipriano Junior (presidente)

(Orientador - FCE/UnB)

Prof. Dr. Martim Francisco Bottaro Marques

(Examinador externo - FEF/UnB)

Profa. Dra. Graziella França Bernardelli Cipriano

(Examinador interno - FCE/UnB)

Prof. Dr. Sergio Ricardo Menezes Mateus

(Examinador Suplente - FCE/UnB) 


\section{AGRADECIMENTOS}

Inicialmente um agradecimento especial a Deus, por iluminar constantemente os meus caminhos, sempre me guiando e protegendo com sua presença divina no mais íntimo do meu ser. Pela sua graça, compaixão e bondade, que estão sempre presentes, sustentando-me nos momentos mais difíceis. E, finalmente, por não me deixar esquecer que ele habita em mim, e que ele somente é a força que dá vida ao meu espírito.

Agradecimentos não poderiam faltar a minha família, que sem dúvida é a base da personalidade de qualquer ser humano e de tudo que somos no presente e que poderemos ser no futuro. Aos meus pais e avós (in memoriam), e a minha querida tia Antônia (in memoriam), que nos deixou há poucos dias, personagens que passaram na minha vida para deixar a sua essência de bondade, coragem, perseverança, firmeza, amor e dignidade, que nunca me deixaram esquecer que acima de tudo devemos ser humildes e conscientes de que sem amor não somos absolutamente nada.

A minha querida e amada esposa, Katia Lima, os meus sinceros e amorosos agradecimentos, pois sem essa mulher guerreira eu não conseguiria continuar nessa jornada. Pelo apoio incondicional, pela paciência, pelo incentivo constante, pelo sorriso sempre bemvindo naqueles momentos em que eu mais precisei e acima de tudo, pelo profundo amor, sincero, absoluto a mim dispensado e que hoje é parte vital e necessária no meu dia-a-dia.

Ao Professor e orientador Dr. Gerson Cipriano Junior, a quem sempre admirei pela sua competência como profissional e porque não dizer pela sua competência em ser amigo, mesmo na distância física. Pela sua capacidade notória, que o torna uma excelência no que faz, conquistando sempre a admiração dos que os conhecem. Obrigado pela orientação, colaboração, compreensão e dedicação que me dispensou durante esta jornada. Seu profissionalismo é invejável e conquistado da forma mais honesta possível.

Ao Prof. Dr. Gaspar R. Chiappa, pelo suporte e contribuição indispensável para que este trabalho pudesse ser realizado. Obrigado pelos conselhos e discussões sempre pertinentes e pela demonstração de sua inteira disponibilidade nos momentos em que precisei. Sua capacidade profissional é incontestável e exponencialmente crescente.

Por fim, agradeço a todos os coautores do produto final desta dissertação, pelas contribuições sempre importantes e pertinentes, que acrescentaram mais robustez às evidencias cientificas do estudo. 
"Conhece-te a ti mesmo, torna-te consciente de tua ignorância e serás Sábio".

Sócrates

"Na vida, não vale tanto o que temos, nem tanto importa o que somos. Vale o que realizamos com aquilo que possuímos e, acima de tudo, importa o que fazemos de nós".

Chico Xavier

“Cuidemos no nosso coração porque é de lá que sai o que é bom e ruim, o que constrói e o que destrói”.

Papa Francisco 


\section{SUMÁRIO}

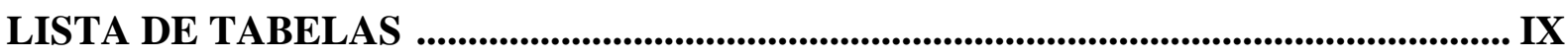

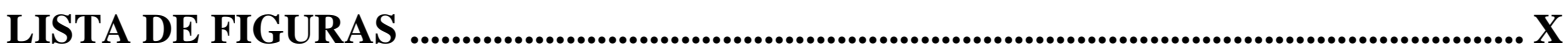

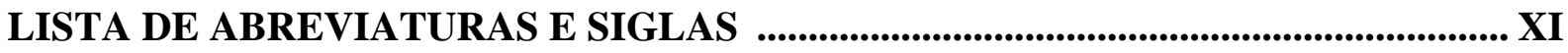

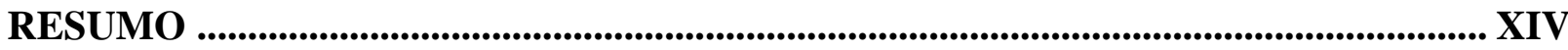

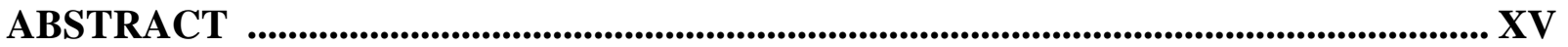

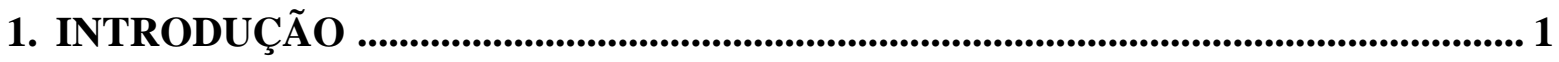

1.1. Contextualização geral ......................................................................................... 1

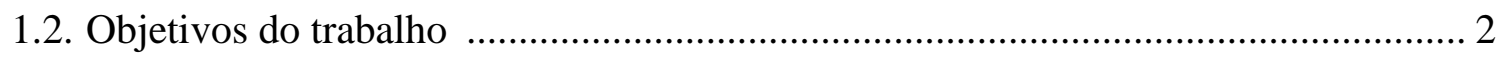

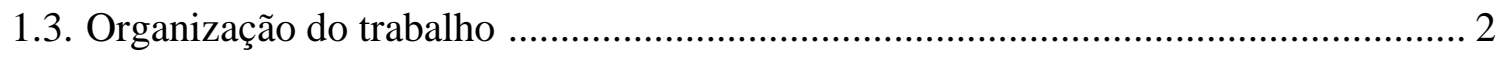

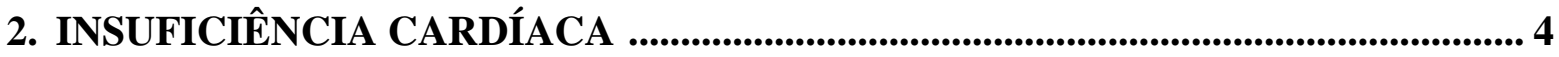

2.1. Referencial teórico …................................................................................. 4

2.1.1. Aspectos epidemiológicos da Insuficiência Cardíaca ..................................... 4

2.1.2. Aspectos clínicos da Insuficiência Cardíaca ................................................. 5

2.1.3. Intolerância ao exercício em pacientes com Insuficiência Cardíaca ................ 8

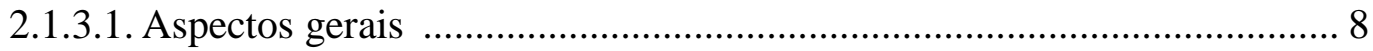

2.1.3.2. Mecanismos centrais de intolerância ao exercício ................................... 8

2.1.3.3. Mecanismos periféricos de intolerância ao exercício .............................. 12

2.1.3.4. Sistema respiratório e intolerância ao exercício ................................... 16

2.1.3.5. Sistema nervoso central e intolerância ao exercício ............................... 17

2.1.4. Remodelamento cardíaco em pacientes com Insuficiência Cardíaca .............. 17

3. REABILITAÇÃO CARDIOVASCULAR ...................................................... 24

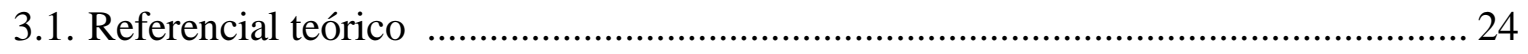

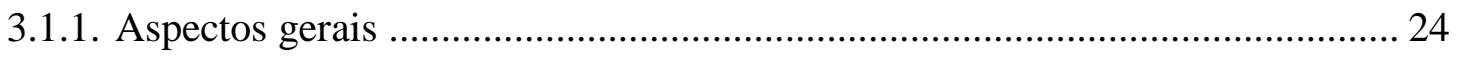

3.1.2. Atividade física como componente da reabilitação cardiovascular ................. 25

3.1.3. Segurança e adesão a programas de reabilitação cardiovascular ..................... 25

\section{EXERCÍCIO FÍSICO E SEUS EFEITOS NO REMODELAMENTO} CARDÍACO E CAPACIDADE AO EXERCÍCIO .......................................................... 27

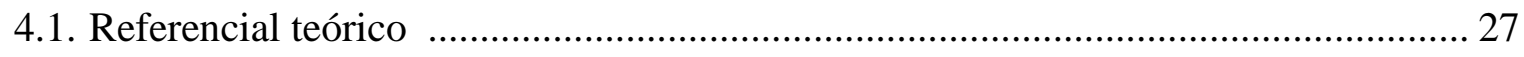

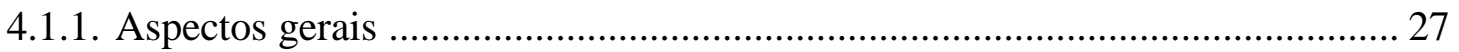

4.1.2. Exercício aeróbico em pacientes com Insuficiência Cardíaca .......................... 30 
4.1.3. Exercício resistido em pacientes com Insuficiência Cardíaca ......................... 33

4.1.3.1. Efeitos esperados do exercício resistido no sistema cardiovascular ...............34

4.1.3.2. Segurança cardiovascular durante exercício resistido ....................................34

4.1.3.3. Efeitos do exercício resistido isolado no consumo de oxigênio de pico ........36

4.1.3.4. Efeitos do exercício resistido isolado no remodelamento cardíaco .................38

4.1.3.5. Efeitos do exercício resistido combinado no consumo de oxigênio de

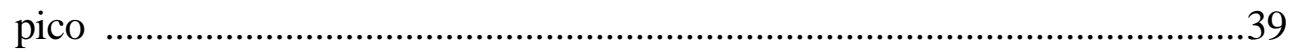

4.1.3.6. Efeitos do exercício resistido combinado no remodelamento cardíaco ................ 42

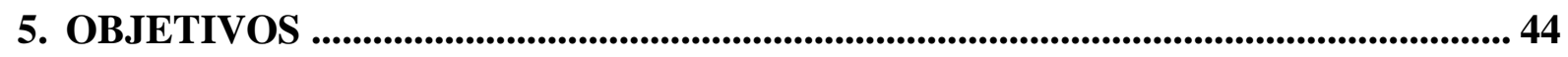

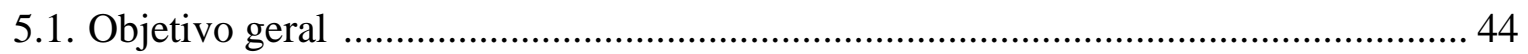

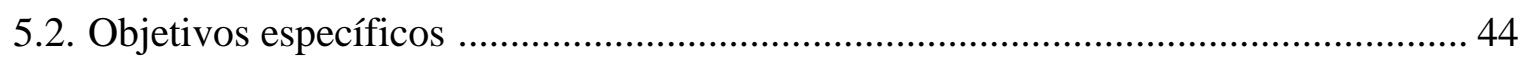

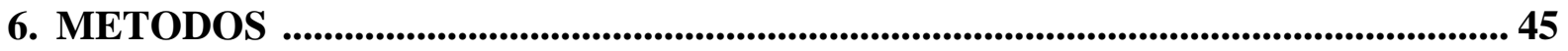

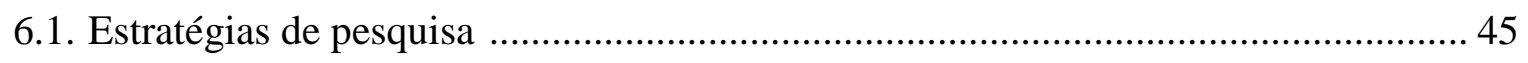

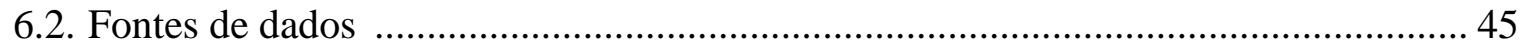

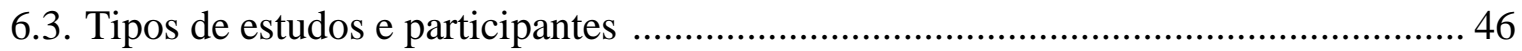

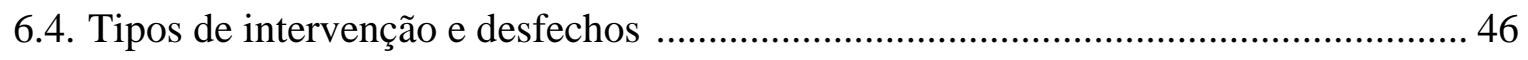

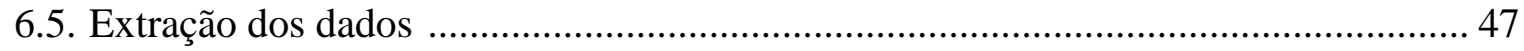

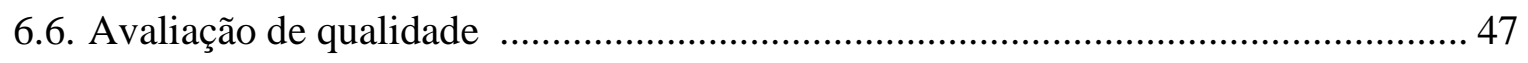

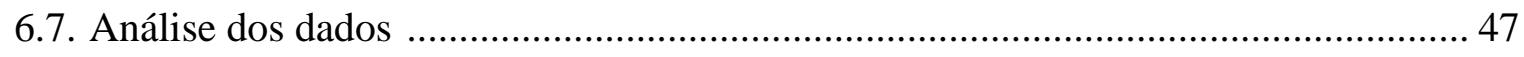

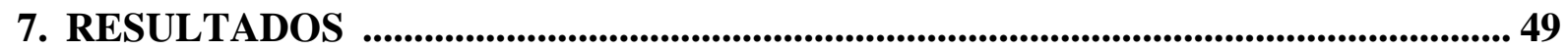

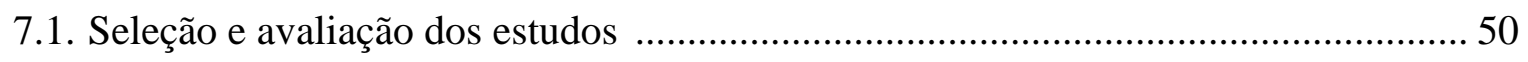

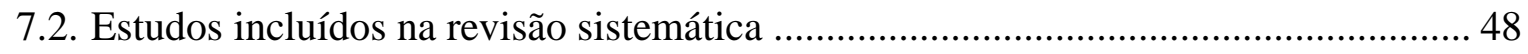

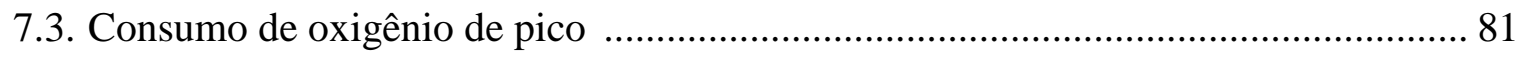

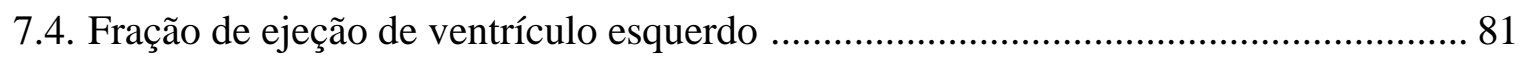

7.5. Volume diastólico final de ventrículo esquerdo ...................................................... 85

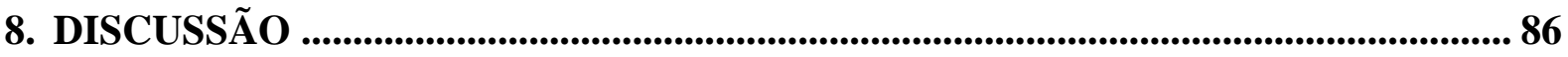

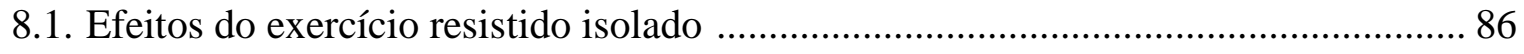

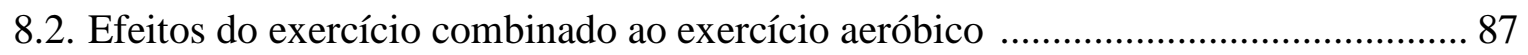

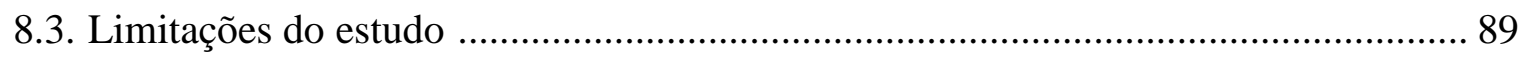

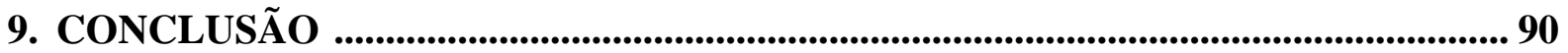

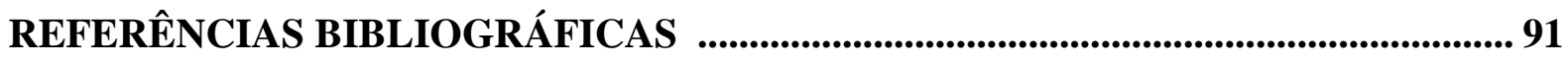


ANEXO B: Normas da revista: "The Journal of the American Medical Association"

ANEXO C: Parecer consubstanciado do CEP da Faculdade de medicina da Universidade de São Paulo

ANEXO D: Parecer consubstanciado do CEP da Universidade Federal de São

Paulo / Hospital São Paulo

\section{APÊNDICE}

APÊNDICE A: Contribuições Científicas Durante o Programa 148

Trabalhos em andamento 148

Artigos submetidos 148

Artigos em confecção 149 


\section{LISTA DE TABELAS E QUADROS}

Quadro 1 - Comparação entre os estágios de IC pela ACCF/AHA e a classificação funcional da IC pela NYHA

Quadro 2 - Principais efeitos do exercício aeróbico e resistido 29

Tabela 1 - Razões para exclusão de estudos 50

Tabela 2 - Descrição dos Estudos referentes ao Exercício Resistido isolado ou em combinação com Exercício Aeróbico incluídos no estudo

Tabela 3 - Descrição dos Estudos referentes ao Exercício Aeróbico incluídos no estudo 


\section{LISTA DE FIGURAS}

Figura 1 - O Metaboreflexo muscular respiratório

Figura 2 - Alterações do sistema nervoso central levando a intolerância ao exercício 18

Figura 3 - Hipertrofia ventricular concêntrica versus hipertrofia ventricular excêntrica

Figura 4 - A teoria da "Hipótese muscular" descrita por Coats e cols. 28

Figura 5 - Efeitos neuro-humorais do exercício em pacientes com Insuficiência Cardíaca 30

Figura 6 - Fluxograma de análise e seleção de estudos

Figura 7 - Análise de viés através de Funnel Plot para as análises de subgrupo. A) $\mathrm{VO}_{2}$ pico; B) FEVE; e C) VDFVE 82

Figura 8 - Análise de viés através de Funnel Plot para as comparações entre intervenções. A) EC vs EA para $\mathrm{VO}_{2}$ pico; B) $\mathrm{ER}$ versus $\mathrm{EA}$ para $\mathrm{VO}_{2}$ pico; e C) EC versus EA para FEVE 82

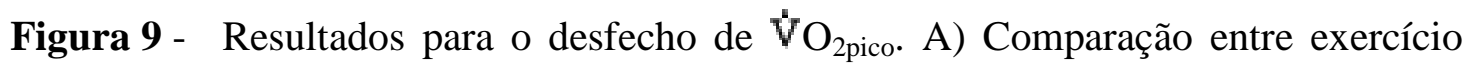
aeróbico, combinado e resistido isolado com grupo controle; e B) Comparações entre exercício combinado e resistido isolado com exercício aeróbico

Figura 10 - Resultados para o desfecho de fração de ejeção. A) Comparações entre exercício aeróbico, combinado e resistido isolado com grupo controle; e B) Comparações entre exercício combinado com exercício aeróbico 84

Figura 11 - Resultados para o desfecho de volume diastólico final. Comparações entre exercício aeróbico, combinado e resistido isolado com grupo controle 


\section{LISTA DE ABREVIATURAS E SIGLAS}

ACCF: American College of Cardiology Foundation

AE: Átrio Esquerdo

AHA: American Heart Association

AVC: $\quad$ Acidente Vascular Encefálico

CVM: Contração Voluntária Máxima

DAC: Doença Arterial Coronariana

DCV: Doença Cardiovascular

DM: $\quad$ Diabetes Mellitus

EA: $\quad$ Exercício Aeróbico

EC: $\quad$ Exercício Combinado

ER: $\quad$ Exercício Resistido

EUA: $\quad$ Estados Unidos da América

ET-1: Endotelina-1

FC: $\quad$ Frequência Cardíaca

FC $_{\text {máx }}$ : Frequência Cardíaca Máxima

FC $_{\text {pico: }}$ : Frequência Cardíaca de Pico

FC rep: $\quad$ Frequência Cardíaca de Repouso

FCR: Frequência Cardíaca de Reserva

FE: $\quad$ Fração de Ejeção

FEVE: Fração de Ejeção de Ventrículo Esquerdo

FNTa: $\quad$ Fator de Necrose Tumoral Alfa

FSC: Fluxo Sanguíneo Cerebral

FSP: $\quad$ Fluxo Sanguíneo Periférico

GC: $\quad$ Grupo Controle

HAS: Hipertensão Arterial Sistêmica 
HP: Hipertensão Pulmonar

IAM: Infarto Agudo do Miocárdio

IC: $\quad$ Insuficiência Cardíaca

ICFEp: Insuficiência Cardíaca com Fração de Ejeção Preservada

ICFEr: Insuficiência Cardíaca com Fração de Ejeção Reduzida

ICO: Insuficiência Coronariana

IRC: Insuficiência Renal Crônica

IVA: Índice de Volume Atrial

MET: Taxa de Equivalente Metabólico

MRM: Metaboreflexo Muscular

MS: $\quad$ Ministério da Saúde

NE: $\quad$ Norepinefrina

NYHA: New York Heart Association

OMS: $\quad$ Organização Mundial da Saúde

ON: $\quad$ Óxido Nítrico

PAP: $\quad$ Pressão de Artéria Pulmonar

PAS: $\quad$ Pressão Arterial Sistólica

PCR: $\quad$ Proteína C Reativa

PC resp: $\quad$ Ponto de Compensação Respiratória

PDFVE: Pressão Diastólica Final de Ventrículo Esquerdo

PEVE: Pressão de Enchimento de Ventrículo Esquerdo

PVC: $\quad$ Pressão Venosa Central

RC: $\quad$ Remodelamento Cardíaco

RCV: Reabilitação Cardiovascular

RV: $\quad$ Remodelamento Ventricular

RVP: $\quad$ Resistência Vascular Periférica 
$\mathbf{R V}_{\text {pulm: }}$ Resistência Vascular Pulmonar

RVS: Resistência Vascular Sistêmica

sãon: $\quad$ Saturação Arterial de Oxigênio

SBC: $\quad$ Sociedade Brasileira de Cardiologia

SUS: $\quad$ Sistema Único de Saúde

SNA: Sistema Nervoso Autonômico

SNP: $\quad$ Sistema Nervoso Parassimpático

SNS: $\quad$ Sistema Nervoso Simpático

SNC: $\quad$ Sistema Nervoso Central

TCP: Teste Cardiopulmonar

TC6 $_{\text {min }}$ : Teste de Caminhada de Seis Minutos

TMR: Treinamento Muscular Respiratório

VC: $\quad$ Volume Corrente

VCO $\mathrm{CO}_{2}$ Consumo de Gás Carbônico

VD: $\quad$ Volume de Espaço Morto

VDFVE: Volume Diastólico Final de Ventrículo Esquerdo

VE: Ventrículo Esquerdo

VFC: Variabilidade da Frequência Cardíaca

VM: $\quad$ Volume Minuto

VS: $\quad$ Volume Sistólico

VSFVE: Volume Sistólico Final de Ventrículo Esquerdo

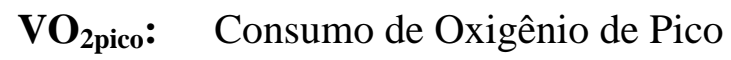

1-RM: Teste de uma Repetição Máxima 


\section{RESUMO}

Introdução: O Exercício Resistido (ER) melhora o Consumo de Oxigênio $\left(\mathrm{VO}_{2 \text { pico }}\right.$ ) de forma semelhante ao Exercício Aeróbico (EA). Por outro lado, os efeitos no Remodelamento Cardíaco (RC) não têm sido adequadamente avaliados. Objetivo: Comparar os efeitos do exercício no $\mathrm{VO}_{2 \text { pico }}$, Fração de Ejeção de Ventrículo Esquerdo (FEVE) e Volume Diastólico Final de Ventrículo Esquerdo (VDFVE) em pacientes com Insuficiência Cardíaca (IC). Fonte de dados e Seleção de Estudos: MEDLINE, EMBASE, Cochrane Library e CINAHL, AMEDEO e base de dados PEDro foram pesquisadas de 1990 à Março de 2016. Extração de dados: Dois revisores extraíram de forma independente as características e dados dos desfechos e tipos de exercício. Principais desfechos: $\mathrm{VO}_{2 \text { pico }}\left(\mathrm{ml} \bullet \mathrm{kg}^{-1} \bullet \mathrm{min}^{-1}\right), \mathrm{LVEF}(\%)$ e LVEDV (mL). Resultados: Dos 4919 artigos adquiridos, 59 estudos ( $\mathrm{n}=5046$ pacientes) foram incluídos. O ER (5 estudos) resultou em maior incremente do $\mathrm{VO}_{2 \text { pico }}\left(3.57 \mathrm{ml} \bullet \mathrm{kg}^{-}\right.$ ${ }^{1} \bullet \min ^{-1}$; 95\% Intervalo de Confiança [IC], 2.45 a 4.68; P<0,00001, $\mathrm{I}^{2}, 0 \%$ ). Da mesma forma, tanto o EA (2.63 $\mathrm{ml} \bullet \mathrm{kg}^{-1} \bullet \mathrm{min}^{-1} ; 95 \%$ IC, 1,96 a 3.29; $\left.\mathrm{P}<0,0001, \mathrm{I}^{2}, 58 \%\right)$ quanto o Exercício Combinado (EC) $\left(2.48 \mathrm{ml} \bullet \mathrm{kg}^{-1} \bullet \mathrm{min}^{-1}\right.$; IC, 0.88 a 4.09; $\left.\mathrm{P}<0,002, \mathrm{I}^{2}, 69 \%\right)$ foram também associados com aumento do $\mathrm{VO}_{2 \text { pico }}$ comparado com participantes do grupo controle. As comparações de Exercício Combinado (EC) e ER isolado com EA mostraram efeitos similares $\left(P=0.84 ; \mathrm{I}^{2}, 0 \%\right)$. O EA foi associado com maior ganho na FEVE $\left(P<0.008 ; \mathrm{I}^{2}\right.$, $79.4 \%$ ), com um aumento de (3.15\%; IC, 1.87 a 4.44; $\left.\mathrm{I}^{2}, 17 \%\right)$, enquanto o ER isolado ou EC foram similares comparados com participantes do grupo controle. De forma interessante, os efeitos do EC foram similares com os efeitos do EA na FEVE. A análise de subgrupo para VDFVE mostrou que o EA reduz significativamente o VDFVE (-10.21; 95\% IC, -17.64 a 2.77; $\left.\mathrm{P}<0,007, \mathrm{I}^{2}, 0 \%\right)$, no entanto o EC ou ER não mostraram efeitos quando comparados aos participantes do grupo controle. Conclusões e relevância: O ER resulta em maior ganho de pico de $\mathrm{VO}_{2}$, sem causar efeitos deletérios na função cardíaca em pacientes com IC.

Palavras-chave: Insuficiencia Cardíaca; Tolerância ao exercício; Exercício 


\begin{abstract}
Introduction: Recent literature suggests that resistance training (RT) improves peak oxygen uptake ( $\left(\mathrm{V}_{2}\right.$ peak), similarly to aerobic exercise (AE), but its effect on cardiac remodeling is controversial. Thus, we examined the effects of $\mathrm{RT}$ and $\mathrm{AE}$ on $\hat{\mathrm{V}}_{2}$ peak and cardiac remodeling in patients with heart failure (HF) via a systematic review and meta-analysis. Objective: To compare the effect of exercise training on $\mathrm{VO}_{2}$ peak, left ventricular ejection fraction (LVEF) and left ventricular end diastolic volume (LVEDV) in heart failure patients. Data sources and study selection MEDLINE, EMBASE, Cochrane Library and CINAHL, AMEDEO and PEDro databases were searched from January 1990 and March 2016. Data extraction and synthesis: Two reviewers independently extracted study characteristics and exercise type and vascular outcome data. Main outcomes and measures: $\mathrm{VO}_{2}$ peak $\left(\mathrm{ml} \bullet \mathrm{kg}^{-}\right.$ $\left.{ }^{1} \cdot \mathrm{min}^{-1}\right)$, LVEF (\%) and LVEDV (mL). Results: From 4919 articles retrieved, 59 RCTs $\left(\mathrm{n}=5046\right.$ patients) were included. RT (5 studies) produced a greater increase in $\grave{\mathrm{V}}_{2}$ peak (3.57 $\mathrm{ml} \bullet \mathrm{kg}^{-1} \bullet \mathrm{min}^{-1}, 95 \%$ confidence interval [CI] 2.45 to $\left.4.68 ; P<0.00001, \mathrm{I}^{2}=0 \%\right)$ compared to AE (28 studies) (2.63 ml•kg ${ }^{-1} \cdot \mathrm{min}^{-1}\left(95 \% \mathrm{CI}, 1.96\right.$ to $3.29 ; \mathrm{P}<0,0001, \mathrm{I}^{2}=58 \%$ ) while combined RT and AE (13 studies) produced a $2.48 \mathrm{ml} \bullet \mathrm{kg}^{-1} \bullet \mathrm{min}^{-1}$ increase $(95 \% \mathrm{CI}$, 0.88 to $4.09 ; \mathrm{I}^{2}=69 \%$ ) in $\mathrm{V}_{2}$ compared to control group. Comparison among the three forms of exercise reveal similar effects on $\hat{\mathrm{V}}_{2}$ peak $\left(P=0.84\right.$ and 1.00 respectively; $\mathrm{I}^{2}=$ $0 \%)$. In regard to cardiac remodeling, $\mathrm{AE}$ (16 studies) was associated with a greater gain in LVEF (3.15\%. CI, 1.87 to $4.44 ; P<0.00001, \mathrm{I}^{2}=17 \%$ ) compared to RT alone or combined RT and $\mathrm{AE}$ which produced similar gains compared to control groups (provide these gains as above for AE). Subgroup analysis revealed that AE reduces LVEDV (-10.21 ml. CI, -17.64 to -2.77; $\mathrm{P}=$ ???, $\mathrm{I}^{2}=0 \%$ ), while $\mathrm{RT}$ and combined $\mathrm{RT}$ and $\mathrm{AE}$ had no effect on LVEDV compared with control participants.. Conclusions and relevance: RT results in a higher gain in $\hat{\mathrm{V}}_{2}$ peak, and induces no deleterious effects on cardiac function in heart failure patients.
\end{abstract}

Key words: Ventricular Remodeling; Performance; Exercise capacity. 


\section{INTRODUÇÃO}

Este capítulo apresenta a contextualização geral do trabalho elaborado, os objetivos e a forma como foi organizada esta dissertação.

\subsection{Contextualização Geral}

As consequências estruturais e funcionais que se seguem um insulto agudo ou crónico para o miocárdio na Insuficiência Cardíaca (IC) pode desencadear vários mecanismos compensatórios, como a expressão de gene, a hiperestimulação simpática e aumento da atividade neuro-humoral ${ }^{(1,2-5)}$, apresentando-se clinicamente com intolerância ao exercício, sendo esta uma de suas características mais marcantes. As taxas de mortalidade em IC permanecem elevadas a despeito das estratégias terapêuticas atualmente administradas a estes pacientes ${ }^{(6)}$.

Estudos têm mostrado que o exercício físico é uma intervenção segura e eficaz para melhorar Consumo de Oxigênio de Pico $\left(\mathrm{VO}_{2 \text { pico }}\right)$ em pacientes com IC ${ }^{(7)}$. Esta resposta está ligada às mudanças favoráveis na função dos músculos cardíaco e esquelético ${ }^{(8)}$. Desta forma, diferentes estudos têm confirmado a eficácia do exercício sobre as consequências clínicas do remodelamento do ventrículo esquerdo e na capacidade de exercício, o que pode ter impacto direto sobre o prognóstico de pacientes com Insuficiência Cardíaca ${ }^{(9-13)}$. Entretanto, tais benefícios têm sido confirmados apenas com a administração de Exercício Aeróbico (EA), atingidos por meio de diversos mecanismos, mas principalmente por meio da atenuação da disfunção simpatovagal, levando a uma melhor resposta de vasodilatação periférica ${ }^{(4,13,14)}$. Adicionalmente, Haykowsky e colaboradores ${ }^{(4)}$ relataram que o Exercício Resistido isolado (ER) e Combinado ao exercício aeróbico (EC) melhorou a força muscular de membros superiores em comparação com o EA enquanto a mudança no $\mathrm{VO}_{2 \text { pico }}$ e força de membros inferiores não foram diferentes entre EA, EC e ER isolados. Além disso, os autores relataram que os efeitos do EA no Remodelamento Ventricular (RV) não ocorrem quando em combinação com ER devido ao aumento excessivo da pós-carga do Ventrículo Esquerdo (VE) causado por esta modalidade de exercício ${ }^{(4)}$.

Em contraste, recentes estudos ${ }^{(8,12,15)}$ demostraram que a adição do exercício resistido ao treinamento aeróbico apresenta efeitos semelhantes nas variáveis de remodelamento cardíaco e $\mathrm{VO}_{2 \text { pico }}$ quando comparados ao EA isolado, sem causar qualquer 
dano à função cardíaca em pacientes com IC. Adicionalmente, a literatura tem se mostrado bastante divergente a cerca do ER realizado isoladamente ou em combinação ao EA em tais variáveis. Além disso, no estudo de Haykowsky e colaboradores, não foram descritas nenhuma análise por meio de comparações entre exercício combinado e aeróbico ou mesmo entre exercício resistido e aeróbico ${ }^{(4)}$.

Portanto, não está claro na literatura se o ER isolado ou em combinação com EA podem ter efeitos favoráveis sobre o Remodelamento Cardíaco (RC) com base na melhora de trofismo muscular periférico ${ }^{(12,16-18)}$ sendo esta uma lacuna importante na literatura a ser preenchida. Para esclarecer esta questão, realizamos uma revisão abrangente dos efeitos do exercício combinado ou exercício resistido isolado no $\mathrm{RC}$ e na capacidade ao exercício de pacientes com Insuficiência Cardíaca com Fração de Ejeção Reduzida (ICFEr).

\subsection{Objetivos do Trabalho}

A presente dissertação possui os seguintes objetivos: (1) levantar, de forma metodológica, o estado de arte dos efeitos do exercício resistido dinâmico nas variáveis de remodelamento cardíaco e de $\mathrm{VO}_{2 \text { pico }}$ em pacientes com Insuficiência Cardíaca com fração de ejeção reduzida (revisão sistemática); e (2) comparar os resultados dos estudos encontrados a cerca desta temática (metanálise).

\subsection{Organização do Trabalho}

A presente dissertação, intitulada "Exercício resistido em pacientes com Insuficiência Cardíaca e fração de ejeção reduzida - Revisão sistemática e metanálise" têm como objetos centrais os seguintes temas: "Insuficiência Cardíaca", "Reabilitação cardiovascular" e "Exercício e efeitos sobre o remodelamento cardíaco e capacidade ao exercício". Desta forma, a presente dissertação foi devidamente organizada da seguinte maneira:

Neste Capítulo 1 foram apresentadas a contextualização geral, os objetivos e a organização da presente dissertação.

O Capítulo 2 refere-se ao tema Insuficiência Cardíaca. Neste capítulo será apresentado um referencial teórico acerca dos seguintes pontos: (1) aspectos epidemiológicos 
da Insuficiência Cardíaca, com o objetivo de atualizar os aspectos de incidência, prevalência e Mortalidade relacionados a esta síndrome no Brasil e nos principais centros mundiais; (2) aspectos clínicos da Insuficiência Cardíaca, onde serão abordadas as mais atuais formas de definição desta doença, bem como suas diversas formas de classificação; (3) intolerância ao exercício e Insuficiência Cardíaca, onde serão aprofundados os mecanismos centrais e periféricos de Intolerância nestes pacientes; e por fim (4) remodelamento cardíaco e Insuficiência Cardíaca, com uma abordagem acerca dos principais mecanismos de modificação das variáveis envolvidas neste processo, quais sejam: Fração de Ejeção de Ventrículo Esquerdo (FEVE), Volume Diastólico Final de Ventrículo Esquerdo (VDFVE) e Volume Sistólico Final de Ventrículo Esquerdo (VSFVE). Desta forma, este capítulo visa explorar todos os aspectos relacionados ao objeto de estudo e ser um facilitador do entendimento da relação entre a doença em questão e as variáveis verificadas no presente trabalho de dissertação.

O Capítulo 3 refere-se ao tema reabilitação cardiovascular. Neste capítulo será exposto o referencial teórico acerca da visão geral, assim como da atividade física como um componente da reabilitação cardiovascular. Além disso, serão abordados ainda, os aspectos relacionados à segurança e aderência em programas de reabilitação cardiovascular. Desta maneira, será possível adquirir maiores conhecimentos acerca do contexto no qual o exercício físico é inserido para o tratamento de doenças cardiovasculares, como no caso da Insuficiência Cardíaca.

No Capítulo 4, será abordado o tema exercício e seus efeitos no remodelamento cardíaco e capacidade ao exercício. Inicialmente, será feita uma abordagem geral com referencial teórico acerca dos efeitos do exercício aeróbico nestas variáveis. Posteriormente, o exercício resistido será abordado de uma forma mais detalhada, tendo em vista ser os efeitos desta intervenção o nosso objetivo principal nesta dissertação. Assim sendo, abordaremos os aspectos relacionados ao exercício resistido nos seguintes tópicos: (1) efeitos esperados do exercício resistido no sistema cardiovascular; (2) segurança cardiovascular durante o exercício resistido; (3) efeitos do exercício resistido isolado e combinado ao exercício aeróbico no Consumo de Oxigênio de pico $\left(\mathrm{VO}_{2 \text { pico }}\right)$; e (4) efeitos do exercício resistido isolado e combinado ao exercício aeróbico no remodelamento cardíaco. Este capítulo finaliza todo o arsenal teórico que fundamenta este trabalho e fornece melhor entendimento a respeito das principais formas de intervenção atualmente utilizadas em programas de reabilitação cardiovascular em pacientes com Insuficiência Cardíaca e fração de ejeção reduzida. 


\section{INSUFICIÊNCIA CARDÍACA}

\subsection{Referencial Teórico}

\subsubsection{Aspectos epidemiológicos da Insuficiência Cardíaca}

Segundo dados recentes da American Heart Association (AHA), estima-se que um a cada três americanos adultos (>18 anos) tenha algum tipo de Doença Cardiovascular (DCV). Destes, $49 \%$ possuem idade superior a 65 anos. Para 2030, estima-se que 40,5\% de toda a população americana tenha alguma forma de $\mathrm{DCV}^{(19)}$. A Organização Mundial da Saúde (OMS) demonstra que $31 \%$ de todas as mortes ao redor do mundo, o equivalente a 17,5 milhões de pessoas, são causadas em decorrência de DCV, sendo $75 \%$ destes óbitos ocorridos em países de baixa renda e $80 \%$ devido a Infarto Agudo do Miocárdio (IAM) e Acidente Vascular Cerebral (AVC) ${ }^{(20)}$. Dados do Ministério da Saúde (MS) de 2014 apontam para uma mortalidade de $29,4 \%$ por DCV, o equivalente a 308 mil pessoas predominantemente do sexo masculino (60\%) com idade média de 56 anos, que foram a óbito tanto por IAM quanto por AVC, colocando o país entre os dez maiores índices de mortes por DCV no mundo ${ }^{(21)}$. Esta mortalidade, que é crescente em todo o mundo está principalmente associada às modificações demográficas e à maior expectativa de vida da população mundial ${ }^{(22,23)}$.

Estima-se que 37 milhões de pessoas no mundo tenham IC. Nos países desenvolvidos a prevalência desta síndrome situa-se em torno de $2,2 \%$, o equivalente a cerca de 5,7 milhões de americanos, com perspectivas de aumento para próximo de 3\% até $2030^{(23)}$. No Brasil, cerca de dois milhões de pessoas têm IC atualmente. Com as perspectivas futuras de crescimento populacional de idosos até 2025 (aproximadamente 15\% da população do País será de idosos), há de se considerar uma resultante de aumento desta prevalência, já que o Brasil se tornará a sexta maior população de idosos do mundo ${ }^{(24)}$.

Nos países desenvolvidos, onde se concentram a maior parte dos estudos epidemiológicos a cerca de IC, a incidência desta síndrome têm apresentado uma tendência de estabilização, mostrando similaridade entre Estados Unidos da América (EUA) e Europa, com valores de 219 e 380/100.000 novos casos por ano de IC, respectivamente ${ }^{(23)}$. No Brasil, 240 mil casos de IC são diagnosticados anualmente ${ }^{(24)}$. Em um nível mundial, a incidência global de IC varia em torno de 100 a 900 casos / 100.000 habitantes, dependendo da população estudada e dos critérios para diagnóstico utilizados. Um estudo recente descreve um perfil de 
pacientes com IC predominantemente idosos, com média de idade em 64,1 anos, onde as etiologias isquêmica e hipertensiva perfazem mais de $50 \%$ destes ${ }^{(25)}$.

Em decorrência de a IC ser muitas vezes considerada como um estágio intermediário de uma doença considerada principal torna-se difícil a estimativa de mortalidade atribuída para esta síndrome. Ainda assim, grandes estudos de coorte nos EUA $^{(26)}$ e alguns países da Europa ${ }^{(27)}$ relatam uma mortalidade em cinco anos entre $48 \%$ e $57 \%$. Adicionalmente, observa-se um declínio nestes valores quando estes são comparados a estudos anteriores como a coorte de Framingham que observou taxas de mortalidade em torno de $70 \%$ na década de $60^{(28)(23,29)}$. Esta taxa de mortalidade possui similaridades com alguns tipos de câncer e AVC. No Brasil, dados extraídos do DATA-SUS de 2012 demonstram que a IC é responsável por $21 \%$ de todas as internações hospitalares por doenças do sistema cardiocirculatório, que ultrapassaram um milhão de internações neste mesmo ano, com 26.694 óbitos ocorridos por esta síndrome ${ }^{(30)}$. Estudo recente descreve uma mortalidade intrahospitalar no Brasil de aproximadamente $13 \%$, valor este muito acima dos demonstrados em estudos americanos e europeus onde não se ultrapassa $5 \%$ dos pacientes internados ${ }^{(25)}$.

\subsubsection{Aspectos Clínicos da Insuficiência Cardíaca}

De acordo com a American College of Cardiology Foundation (ACCF) e a American Heart Association (AHA), a IC pode ser definida como uma síndrome complexa resultante de qualquer dano seja estrutural ou funcional, que cause um prejuízo no enchimento ou na ejeção Ventricular ${ }^{(31)}$. A Sociedade Europeia de Cardiologia define IC como uma síndrome na qual os pacientes têm sinais (aumento de pressão venosa jugular, estertores pulmonares, deslocamento de ápice cardíaco, etc.) e sintomas (dispneia, edema, fatiga, etc.) resultantes de anormalidades estruturais e funcionais do coração ${ }^{(32)}$. No Brasil, a IC é definida pela Sociedade Brasileira de Cardiologia (SBC) como uma síndrome clínica complexa de caráter sistêmico, caracterizada como uma disfunção cardíaca que ocasiona inadequado suprimento sanguíneo para atender as necessidades metabólicas tissulares, na presença de retorno venoso normal, ou fazê-lo somente com elevadas pressões de enchimento ${ }^{(33)}$. Nota-se, portanto uma característica predominantemente fisiopatológica embebida nas definições acima mencionadas. A IC é a via final de todas as cardiopatias e, portanto pode resultar de anormalidades em quaisquer componentes estruturais pertencentes ao sistema cardiovascular, assim como também de alterações metabólicas diversas ${ }^{(31,34)}$. 
As manifestações hemodinâmicas em pacientes com IC ocorrem em função de uma resposta inadequada do Débito Cardíaco (DC), assim como da elevação da Pressão de Artéria Pulmonar (PAP) e da Pressão Venosa Central (PVC). Em situações onde o DC está prejudicado, ocorre redução da perfusão tecidual, que pode ser observada apenas durante o exercício em sua fase inicial, mas que com a progressão da doença pode chegar a ser detectada mesmo em situações de repouso. Por outro lado, podemos encontrar pacientes com DC preservado, como em situações de redução de pós-carga ventricular, onde os valores de FE encontram-se acima de 40\%, com alguns estudos descrevendo valores acima de 55\%. Assim, as anormalidades da função ventricular podem ocorrer tanto com diâmetro Ventricular normal e, portanto, com FE preservada, como com dilatação e/ou redução de fração de ejeção ${ }^{(33)}$. Adicionalmente, em alguns pacientes com IC podem coexistir déficit ventricular sistólico e diastólico, não estando na dependência, neste caso, de alterações da FE. Desta forma, esta variável torna-se uma ferramenta importante no processo de classificação da Insuficiência Cardíaca ${ }^{(31)}$.

As metodologias utilizadas para classificação de IC pela American College of Cardiology Foundation em conjunto com a American Heart Association e pela New York Heart Association (NYHA) se diferenciam pelos critérios utilizados em cada uma delas. A primeira fundamenta sua classificação em critérios de severidade e progressão da doença no decorrer do tempo, sendo classificada da seguinte forma: Estágio A (alto risco para desenvolvimento de IC, porém sem doença cardíaca estrutural detectada); Estágio B (alterações estruturais detectáveis, porém sem sinais e/ou sintomas de IC); Estágio C (pacientes com diagnóstico Clinico de IC prévio ou atual); e Estágio D (pacientes com IC refratária em estágio final). Sendo assim, o diagnóstico de IC está atribuído aos estágios C e D. Esta forma de classificação permite a inserção precoce de estratégias de prevenção para pacientes no estágio A, com foco nos fatores de risco para IC como, por exemplo, Hipertensão Arterial Sistêmica (HAS), Diabetes Mellitus (DM), obesidade e outros. Por outro lado, a NYHA classifica os pacientes com IC baseando-se em critérios de severidade de sintomas, em quatro diferentes classes funcionais, quais sejam: Classe funcional I (sem limitação à atividade física); Classe Funcional II (confortável em repouso, porem com discreta limitação à atividade física, apresentando sinais de IC no esforço); Classe Funcional III (confortável em repouso, porem com limitação importante à atividade física, exibindo sintomas de IC com esforços leves); e Classe Funcional IV (sintomas de IC em repouso ou incapazes de realizar atividade física sem desencadear sintomas de IC) $(\text { Tabela } 1)^{(31,35,36)}$. 
Quadro 1. Comparação entre estágios de IC pela ACCF/AHA e a classificação funcional da IC pela NYHA

\begin{tabular}{|l|l|}
\hline \multicolumn{1}{|c|}{ ACCF/AHA } & \multicolumn{1}{c|}{ NYHA Classificação Funcional } \\
\hline $\begin{array}{l}\text { A) Alto risco para desenvolvimento de IC, sem } \\
\text { doença cardíaca estrutural detectada ou }\end{array}$ & Nenhuma \\
sintomas. & \\
B) Doença cardíaca estrutural porem sem sinais & I-Sem limitação à atividade física \\
ou sintomas de IC & \\
C) Doença cardíaca estrutural com diagnóstico & I-Sem limitação à atividade física \\
clínico de IC, com presença de sinais e sintomas. & II - Confortável em repouso, com discreta \\
& limitação à atividade física, com sinais de IC ao \\
& esforço. \\
& III - confortável em repouso, com limitação \\
& importante à atividade física, com sintomas de \\
& IC aos esforços leves. \\
& IV - Sintomas de IC em repouso, incapazes de \\
& realizar atividades sem desencadear sintomas de \\
& IC. \\
& IV - Sintomas de IC em repouso, incapazes de \\
& realizar atividades sem desencadear sintomas de \\
& IC. \\
\hline
\end{tabular}

Legenda: ACCF: American College of Cardiology Foundation; AHA: American Heart Association; IC: Insuficiencia Cardíaca. Fonte: Yancy e cols. ${ }^{(31)}$

Em complemento às classificações dos Guidelines Americanos, a Sociedade Europeia de Cardiologia descreve uma terminologia para a Insuficiência Cardíaca baseada nas alterações de fração de ejeção, que tem sua importância fundamentada tanto no seu valor prognóstico, como também no fato de que esta variável tem sido cada vez mais utilizada em diversos ensaios clínicos na seleção de pacientes com IC. Desta forma, outra linha de classificação é baseada na presença ou não de alterações nos valores de FE, onde pacientes com sinais e sintomas de IC, com valores situados $\leq 35 \%$ ou $\leq 40 \%$ são classificados como IC com Fração de Ejeção Reduzida (ICFEr), enquanto pacientes com os mesmos sinais e sintomas de IC, porem com valores normais de FE (> 40\%-45\%) ou com discreta redução desta, são incluídos na classificação de IC com Fração de Ejeção Preservada (ICFEp). Pacientes com valores de fração de ejeção entre $40 \%$ e $50 \%$ estão em um grupo dito Intermediário, sendo o tratamento para os fatores de risco e comorbidades, assim como o tratamento farmacológico deste grupo, similar ao recomendado para os pacientes com $\operatorname{ICFEr}^{(31,32,35)}$. Por fim, torna-se importante salientar que os valores obtidos para medição da 
FE estão na dependência do operador, técnica empregada na mensuração e nos métodos para análise, estando, portanto, sujeitos a variações de resultados.

O principal fator de risco associado à ICFEr é a Doença Arterial Coronariana (DAC). Este fato gera um acometimento maior deste tipo de IC para o sexo masculino ${ }^{(32,35)}$. No Brasil, alguns preditores como a presença de edema, Insuficiência Renal Crônica (IRC), Escores de Boston mais elevados, etilismo, tabagismo e hospitalizações estão associados com a ICFEr ${ }^{(37)}$. Adicionalmente, um estudo de coorte incluindo indivíduos identificados com diagnóstico de ICFEr, fatores como obesidade, sexo masculino, IAM prévio, tabagismo, troponina $\mathrm{T}$ de alta sensibilidade e Peptídeo Natriurético Atrial tipo B foram identificados como importantes preditores para novo início deste tipo de IC, com tempo médio para novo diagnóstico em 6,6 anos dentro de um seguimento de 11,5 anos ${ }^{(38)}$.

\subsubsection{Intolerância ao exercício físico em pacientes com Insuficiência Cardíaca}

\subsubsection{Aspectos Gerais}

Pode-se definir a intolerância ao exercício físico como a presença de sintomas durante a realização de atividades dinâmicas que envolvam grandes grupos musculares, caracterizada principalmente por fadiga e dispneia e que impacta diretamente no prognóstico, assim como na piora da qualidade de vida destes pacientes ${ }^{(39,40)}$. O fato de que o indivíduo torna-se incapaz de realizar exercício sem desconforto pode ser considerado como um dos sintomas de IC, sendo essa intolerância ligada ao diagnóstico desta síndrome ${ }^{(39)}$. Os mecanismos envolvidos na intolerância ao exercício vão desde as disfunções centrais, que dizem respeito aos componentes cardíaco e pulmonar, até efeitos neuro-humorais desencadeados pela disfunção cardiopulmonar, que determinam significativas mudanças nos sistemas periféricos compreendendo principalmente os sistemas vascular e musculoesquelético, que contribuem significativamente para exacerbação e piora da tolerância ao exercício nestes pacientes ${ }^{(40)}$.

\subsubsection{Mecanismos centrais de intolerância ao exercício}

Apesar de uma fração de ejeção preservada em repouso, pacientes com ICFEp exibem um ajuste inadequado desta variável durante o exercício. Entretanto, esta não é de fato 
a única variável a fazer parte deste mecanismo. Desta forma, outros fatores podem ajudar a explicar a disfunção cardíaca que se encontra envolvida no mecanismo de Intolerância destes pacientes. O envolvimento dos Volumes Diastólico Final de Ventrículo Esquerdo (VDFVE) e do Volume Sistólico Final de Ventrículo Esquerdo (VSFVE) de reserva durante o exercício têm tido resultados conflitantes na literatura. De fato, enquanto alguns autores atribuem à disfunção cardíaca durante ao exercício nestes pacientes à queda nestes volumes ${ }^{(41)}$, outros estudos não tem suportado estes resultados, demonstrando valores de normalidade destas variáveis na mesma situação de aumento de demanda metabólica ${ }^{(42,43)}$. Ainda assim, este comportamento dito de normalidade não deve ser encarado como de integridade do Mecanismo de Frank-Starling nestes pacientes ${ }^{(40)}$.

Em estudo recente, Abudiab e colaboradores ${ }^{(44)}$ demonstraram de uma forma bastante clara o comportamento cardíaco central durante o exercício em pacientes com ICFEp. Neste estudo, os autores encontraram uma resposta de Débito Cardíaco (DC) de reserva atenuada nestes pacientes, estando diretamente relacionada ao déficit contrátil do VE e falha na resposta cronotrópica cardíaca. A atenuação do Volume Sistólico (VS) e, portanto, da FE é atribuída primariamente a uma perda de capacidade contrátil do VE acarretando aumento do Volume Sistólico Final de VE (VSFVE). Adicionalmente, apesar de os valores de VDFVE durante o exercício ter comportamento similar aos de indivíduos saudáveis, em pacientes com ICFEp estes valores são atingidos às custas de elevada Pressão de Enchimento Ventricular Esquerda (PEVE), resultando em níveis de Pressão de Artéria Pulmonar (PAP) elevados, gerando tanto um aumento na Pós Carga de Ventrículo Direito (VD) como Dispneia. Desta forma, a atenuação do DC durante o exercício é fator importante na redução dos níveis de Consumo de Oxigênio de pico $\left(\mathrm{VO}_{2 \text { pico }}\right)$ e, portanto no mecanismo central de intolerância ao exercício em pacientes com ICFEp ${ }^{(44)}$.

Pacientes com ICFEp apresentam-se com maior rigidez ventricular, que conferem a estes pacientes uma menor complacência e elevada elastância desta câmara cardíaca. Em uma análise dinâmica do mecanismo de Starling, Shibata em colaboradores ${ }^{(45)}$ demonstraram que, em comparação com indivíduos controle sedentários, pacientes com ICFEp apresentam uma maior variabilidade na Pressão Diastólica Final de Ventrículo Esquerdo (PDFVE). Esta situação se traduz em níveis elevados de PEVE batimento a batimento que ocorre pelo influxo de sangue a cada ciclo respiratório, para o interior de uma câmara ventricular de baixa complacência. Esta situação está presente em pacientes durante o repouso e se exacerbam 
durante o exercício, reforçando a ineficiência do mecanismo de Frank Starling na fisiopatologia da intolerância ao exercício, levando claramente estes pacientes a quadros variados de congestão e edema pulmonar em decorrência de Hipertensão Pulmonar (HP). Previamente, além de já terem demonstrado este mecanismo de disfunção cardíaca, Boularg e colaboradores ${ }^{(46)}$ expõem também a necessidade de uma avaliação minuciosa em fases precoces da IC (Classe funcional II pela NYHA), onde o sintoma de dispneia aos esforços pode ser confundido e relacionado a outras doenças não cardíacas que cursam com o mesmo sintoma como, por exemplo, na obesidade, doenças pulmonares crônicas, doenças vasculares e outras. Os autores demonstram que ainda em fases pouco avançadas da doença, as alterações de PEVE e PDFVE, assim como de PAP e atenuação do DC de reserva já ocorrem durante o exercício, reforçando a importância deste diagnóstico de forma precoce, gerando um impacto extremamente positivo no tratamento destes pacientes.

Outra variável não menos importante no mecanismo de intolerância ao exercício em pacientes com ICFEp é a disfunção de Átrio Esquerdo (AE). Neste contexto, a ineficiência contrátil atrial determina redução do volume de enchimento lento na fase tardia da diástole ventricular esquerda, contribuindo, portanto com a disfunção cardíaca encontrada nestes pacientes durante o exercício ${ }^{(40)}$. Tal disfunção, mensurada por meio do Índice de Volume atrial (IVA), é determinada pelos altos níveis de PEVE, levando a mecanismos de remodelamento atrial em longo prazo, sendo, portanto, a medida de tamanho atrial um preditor de anormalidade de PEVE. Adicionalmente, tanto a dilatação quanto o aumento da rigidez do AE são tradutores de efeitos cumulativos da PEVE em pacientes com ICFEp ${ }^{(47)}$.

Em pacientes com ICFEr, o DC atinge em torno de 50\% dos valores de referência para indivíduos saudáveis no pico de exercício. A redução do débito cardíaco máximo durante a atividade possui uma forte correlação com a capacidade funcional destes indivíduos, situando-se em torno de 10 a $20 \mathrm{ml} \cdot \mathrm{kg}^{-1} \cdot \mathrm{min}^{-1}$ comparado com indivíduos saudáveis com valores em torno de 30 a $40 \mathrm{ml} \cdot \mathrm{kg}^{-1} \cdot \mathrm{min}^{-1}{ }^{(39)}$. De modo semelhante aos pacientes com ICFEp, nos pacientes com FE reduzida ocorre redução do volume sistólico e da competência cronotrópica com redução da FC máxima durante o exercício. Nos pacientes onde a dilatação ventricular se faz presente, ocorre uma inabilidade para o ajuste de VDFVE durante o exercício. Isto ocorre em virtude de que já em repouso, este volume encontra-se próximo dos seus valores máximos e, por conseguinte com uma reserva reduzida para o exercício. Além disso, a alta elastância e baixa distensibilidade ventricular, assim como um maior VSFVE são 
fatores que restringem o enchimento ventricular em condições de repouso e exercício. Estas situações levam a uma maior PEVE em condições de imposição de atividade física, acarretando o aparecimento de HP e disfunção de VD por aumento de pós-carga. Por fim, surge a dispneia, que interfere diretamente no desempenho destes pacientes ao exercício acarretando em redução da sua tolerância ao esforço ${ }^{(40)}$. Em pacientes com IC e DAC associada, a presença de isquemia miocárdica devido desequilíbrio entre oferta e demanda de oxigênio durante o exercício leva a uma queda adicional do VS e do DC. Adicionalmente, situações de regurgitação valvar mitral durante o esforço podem ocorrer em virtude de dilatação do anel valvar respectivo, levando a redução do VS em decorrência do fluxo sanguíneo em direção retrógrada ao $\mathrm{AE}^{(40)}$.

Em resposta a redução significativa do DC, a cardio aceleração torna-se um fenômeno compensatório em pacientes com ICFEr. Em contrapartida, observa-se uma incompetência cronotrópica nestes pacientes, com um aumento da FC em Repouso ( $\left.\mathrm{FC}_{\text {rep}}\right)$, uma menor $\mathrm{FC}$ de reserva $(\mathrm{FCR})$ e finalmente, uma menor $\mathrm{FC}$ Máxima $\left(\mathrm{FC}_{\text {máx }}\right)$ em comparação com indivíduos saudáveis ${ }^{(39)}$. A incompetência cronotrópica pode ser definida por meio de uma Frequência Cardíaca de Pico $\left(\mathrm{FC}_{\text {pico }}\right)$ no exercício $<80 \%$ da $\mathrm{FC}_{\text {máx }}$ predita para idade e é diretamente relacionada à severidade da doença, estando, portanto mais evidente quanto mais intolerância ao exercício. As modificações na $\mathrm{FC}_{\text {rep }}$ são diretamente relacionadas a modificações na capacidade funcional com valores de $\mathrm{VO}_{2 \text { pico }} 14 \%$ menores em pacientes com ICFEr que cursam com incompetência cronotrópica independente do uso ou não de beta bloqueador ${ }^{(48)}$. Analisando-se a fase imediatamente após o exercício, observa-se um comportamento desfavorável da Frequência Cardíaca de Recuperação $\left(\mathrm{FC}_{\mathrm{rep}}\right)$ em virtude de uma disfunção do Sistema Nervoso Autonômico (SNA), caracterizada pela hiperatividade do Sistema Nervoso Simpático (SNS) com atenuação da velocidade de retirada desta atividade logo após o final do exercício, e uma menor atividade do Sistema Nervoso Parassimpático (SNP), com um retardo na entrada deste sistema também logo após o exercício $^{(40)}$. Adicionalmente, uma estimulação da atividade metaboreflexa, como demonstrado em modelos de oclusão circulatória pós-exercício, é capaz de demonstrar a atenuação na sensibilidade barorreceptora de pacientes com IC, com manutenção de elevados valores de FC pós-exercício em virtude mais uma vez, de um retardo para início da atividade parassimpática pós-esforço e consequente redução da $\mathrm{FC}_{\mathrm{rec}}{ }^{(49)}$. 


\subsubsection{Mecanismos periféricos de Intolerância ao exercício}

O aumento da atividade do SNS em repouso está presente em pacientes com ICFEr e é importante preditor de prognóstico nestes, com a sua presença ocorrendo independente do grau de disfunção do VE. Esta disfunção é diretamente relacionada à intolerância ao exercício e redução da capacidade física mensurada pelo $\mathrm{VO}_{2 \text { pico, }}$ com evidências de uma maior atividade simpática muscular em indivíduos com IC na vigência de baixa capacidade funcional quando comparados a pacientes também com IC, porém sem comprometimento da capacidade funcional, assim como com idosos e indivíduos jovens saudáveis ${ }^{(50)}$. Estudos prévios de Notarius e colaboradores foram primeiros a demonstrarem o fator neurogênico como limitante ao exercício nestes pacientes ${ }^{(51)}$, assim como a comprovar a especificidade desta relação apenas à atividade simpática em nível muscular ${ }^{(52,53)}$. Essa maior atividade simpática em repouso ocorre em sua grande maioria nos pacientes com IC de etiologia isquêmica, o que poderia explicar em partes uma menor capacidade ao exercício encontrada nestes indivíduos.

Existem fortes evidências de que a hiperatividade simpática cardíaca seja ocasionada pelos altos níveis de pressão e volume ventricular e HP aos quais são submetidos os pacientes com ICFEr. Nestes pacientes, observa-se fundamentalmente uma significativa atenuação do mecanismo de inibição de descarga simpática mediada por barorreceptores cardiopulmonares ${ }^{(50,54,55)}$. Azevedo e colaboradores ${ }^{(56)}$ demonstraram em estudo prévio com um modelo para indução de pressão negativa em MMII e consequente redução nas PEVE e HP sem causar hipotensão sistêmica em pacientes com ICFEr, uma atenuação importante da atividade simpática muscular eferente e dos níveis de norepinefrina cardíaca, provavelmente pela atenuação simultânea da descarga aferente provocada pela queda dos níveis de pressões ventricular e vascular pulmonar. Efeitos semelhantes tanto nos níveis de norepinefrina cardíaca quanto na atividade simpática muscular são observadas com outras formas de redução de PEVE e PAP, como uso de ventilação não invasiva e uso fármacos ${ }^{(54)}$. Não menos importante, quase metade dos pacientes com IC possuem um aumento na sensibilidade dos quimiorreceptores arteriais periféricos à hipóxia, causando um aumento da atividade do SNS, gerando vários distúrbios autonômicos como aumento plasmático da norepinefrina, queda da Variabilidade da Frequência Cardíaca (VFC), aumento de respostas ventilatórias ao exercício e maior propensão a arritmias cardíacas ${ }^{(54,57,58)}$. 
No decorrer do processo de evolução da IC, podemos observar modificações importantes no que diz respeito à morfologia, função e metabolismo muscular esquelético nestes pacientes. Do ponto de vista estrutural, a atrofia muscular esquelética parece ser a alteração mais explicita nestes pacientes. De fato, esta alteração é causa de redução de força muscular e de endurance e está relacionada ao desuso e consequente perda de massa muscular. Em uma análise de microestrutura, observam-se alguns fatores importantes no mecanismo fisiopatológico. Primeiro, um desequilíbrio entre os estados anabólicos e catabólicos musculares em direção a uma maior modulação no sentido de aumento de apoptose com consequente perda de massa muscular. Segundo, uma associação entre atrofia muscular e aumento da atividade do SNS e produção de angiotensina-II, um potente vasoconstrictor, ambos contribuindo para uma menor oferta de oxigênio para os músculos. Terceiro, uma redução na capilaridade muscular, causando um desequilíbrio entre a oferta e demanda de oxigênio para o musculo esquelético. Por fim e não menos importante, uma modificação do tipo de fibra muscular, passando de fibras tipo I, mais resistentes a fadiga chamadas de fibras oxidativas, para fibras tipo II ou IIb mais susceptíveis a fadiga chamadas de fibras glicolíticas. Esta modificação é fator importante na redução do desempenho durante o exercício e fadiga precoce, reduzindo significativamente a tolerância ao exercício nestes pacientes independente do aporte de fluxo muscular. Do ponto de vista metabólico, pacientes com IC apresentam uma menor capacidade oxidativa muscular com redução no número de mitocôndrias e de enzimas oxidativas, que associados a fatores já mencionados como uma menor capilaridade e uma menor produção de ON levam a um menor tempo de aerobiose e um início precoce do metabolismo anaeróbico, trazendo consequências graves que culminam com fadiga muscular e intolerância ao exercício ${ }^{(40,59)}$.

Todos estes aspectos supramencionados que se relacionam com a estrutura e metabolismo levam diretamente a uma limitação de funcionalidade muscular nestes pacientes, assim como uma propensão destes a maior incidência de quedas e incapacidade. Vale salientar aqui, que não somente os grandes grupos musculares esqueléticos estão em atividade no momento do exercício, mas também todos os músculos ditos respiratórios, que compartilham e competem pelo mesmo DC reduzido característico dos pacientes com IC. Adicionalmente, receptores mecânicos e metabólicos contidos nesses músculos podem amplificar a atividade do SNS que nestes pacientes pode ser mais exacerbada em virtude da miopatia que já se encontra instalada ${ }^{(59)}$. 
Dentre os vários fatores inerentes ao músculo esquelético desencadeando respostas inadequadas do SNS, podemos destacar o metaboreflexo muscular, que é desencadeado frente ao exercício isotônico ou isométrico, investigado frequentemente na literatura por meio do exercício de preensão palmar ou Handgrip. O mecanismo pelo qual se desencadeia este reflexo se dá inicialmente pelo acúmulo de metabólitos em nível intersticial muscular durante o exercício de alta intensidade, disparando um estímulo aferente em direção ao centro cardiovascular por meio de grupos de neurônios específicos (grupos II e III de mecanoreceptores e metaboreceptores), que culminam com uma resposta eferente produzindo um aumento da atividade do SNS com vasoconstricção arterial reflexa e aumento da Resistência Vascular Periférica (RVP) e Pressão Arterial Sistêmica (PAS) com redução do Fluxo Sanguíneo Periférico (FSP) e desequilíbrio da oferta e demanda de O2. Estas respostas visam aumentar o fluxo de sangue para os músculos em atividade, restaurando o desequilíbrio entre a demanda metabólica e a redução das tensões de oxigênio muscular ${ }^{(49,59)}$.

A magnitude das respostas hemodinâmicas mediadas por este reflexo é dose dependente com maior resposta em exercícios de moderada e alta intensidade, assim como tempo dependente, com as respostas hemodinâmicas atingindo sua maior plenitude a partir do primeiro minuto de atividade muscular isométrica ${ }^{(60-62)}$. Este reflexo torna-se exacerbado em pacientes com quadros de miopatia muscular, frequentemente encontrada em pacientes com IC, o que determina uma exacerbação destes metaboreflexo, tanto por uma aceleração no acúmulo de metabólitos produzidos por uma anaerobiose precoce nestes indivíduos, assim como pela maior potencialização da atividade simpática que já se encontra aumentada nestes pacientes. Por fim, tais pacientes demonstram uma resposta pressórica mais exagerada em relação a indivíduos saudáveis durante uma estimulação metaboreflexa. Assim, temos a chamada "hipótese muscular" para fundamentação da intolerância ao exercício nestes pacientes. Além da intolerância, é necessário ressaltar aqui, o aumento do trabalho miocárdico ocasionado pela sobrecarga pressórica derivada deste reflexo ${ }^{(49,63)}$. A intensidade deste está diretamente relacionada ao grau de decremento da capacidade funcional, estando mais evidente em pacientes com IC com valores de $\mathrm{VO}_{2}$ pico abaixo de $56 \%$ do predito ${ }^{(52,54)}$.

Em pacientes com IC e fraqueza muscular respiratória associada, a imposição de atividade física é capaz de causar anaerobiose precoce desta musculatura, desencadeando o Metaboreflexo Muscular Respiratório (MMR) pelo mesmo mecanismo descrito previamente, levando a parada precoce do exercício em virtude da redução do fluxo sanguíneo para os 
membros inferiores e aumento da RVP, com concomitante déficit de suprimento sanguíneo local (Figura 1).

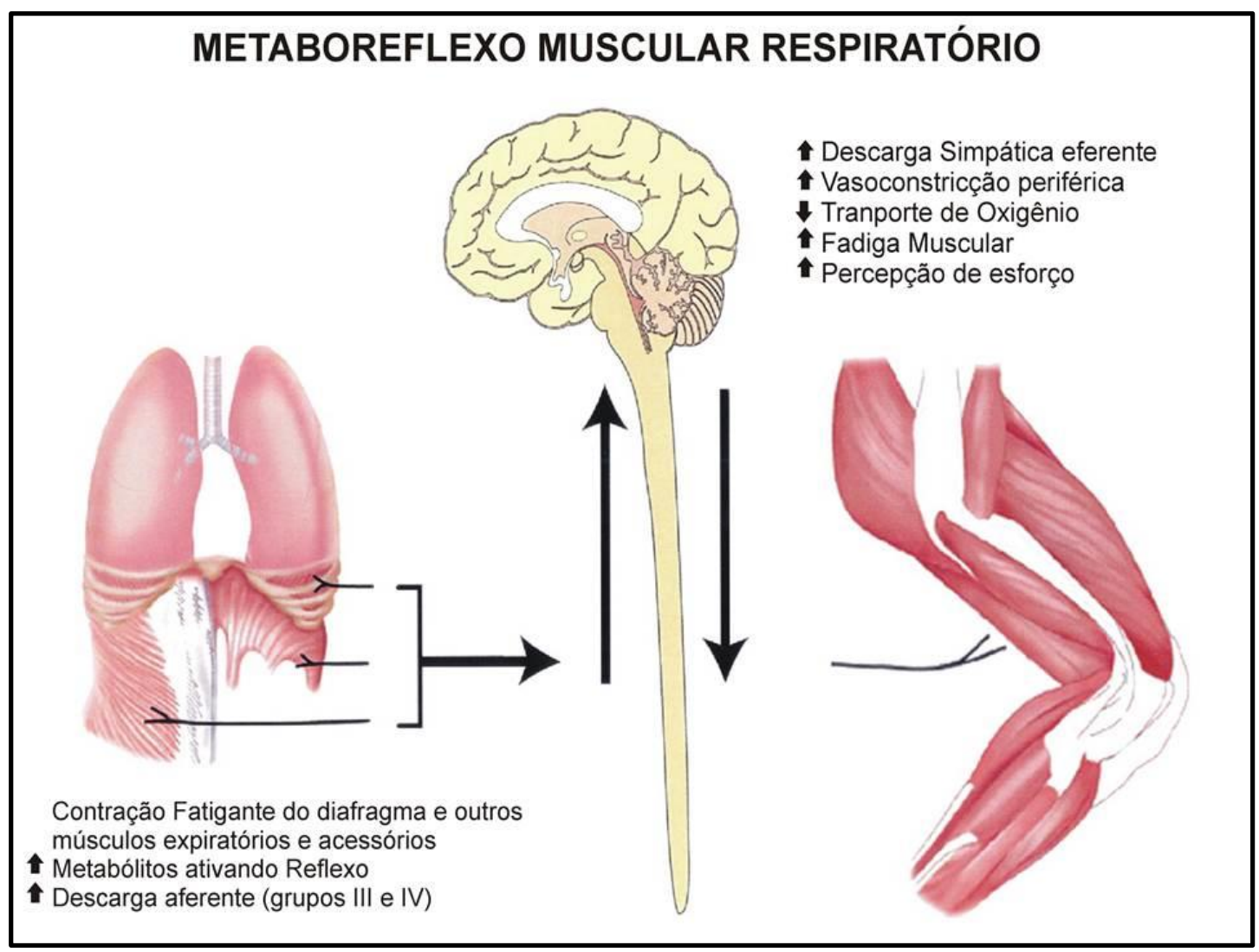

Figura 1. O Metaboreflexo muscular respiratório. Fonte: Phillips e cols. ${ }^{(40)}$

Durante o exercício, ocorre uma elevação fisiológica em mais de sete vezes do DC. É sabido que até $80 \%$ desse DC é direcionado para os músculos em atividade. Esta adaptação físiológica se dá pela extraordinária capacidade de vasodilatação dos vasos de resistência associado ao aumento do bombeamento de um maior volume de sangue para os músculos ativos no momento do exercício, com o intuito de suprir as demandas metabólicas necessárias naquele momento. Entretanto, na vigência da IC, a redução da capacidade de vasodilatação arterial reduz o suprimento sanguíneo para os músculos em atividade, levando estes pacientes a experimentarem uma redução no desempenho e consequente redução na tolerância ao exercício ${ }^{(40)}$. Vários fatores podem contribuir para essa disfunção vascular, como a hiperatividade do SNS, desencadeamento do sistema renina-angiotensina com resposta vasoconstrictora exacerbada, redução de vasodilatação dependente do endotélio, redução da área de secção transversa dos vasos musculares e aumento na tensão e rigidez endotelial. Vale salientar que alguns destes fatores fazem parte dos mecanismos 
compensatórios de pacientes com IC, que acabam por gerar respostas desfavoráveis ao exercício e um desequilíbrio entre oferta e demanda de Oxigênio no tecido muscular ${ }^{(40)}$.

A disfunção vascular endotelial ocorre de forma marcante em pacientes com IC e é um dos mecanismos fundamentais para aumento na rigidez destes vasos e aumento da RVP tanto em repouso quanto durante o exercício. Este fator tem papel fundamental nos aspectos relacionados à intolerância ao exercício em pacientes com IC tanto ICFEr como ICFEp. O principal aspecto relacionado à fisiopatologia desta disfunção diz respeito à biodisponibilidade do Óxido Nítrico (ON), uma substância vasodilatadora derivada do endotélio. Sua redução se dá pelas mudanças em direção à diminuição de seus processos de síntese, aumento na produção de substâncias vasoconstrictoras derivadas do endotélio (endotelina-1), aumento na concentração de substâncias inflamatórias como Fator de Necrose Tumoral Alfa (FNT $\alpha$ ) e Proteína C Reativa (PCR), assim como pela destruição em nível extracelular de ON por ação de radicais livres, como, por exemplo, o superóxido. Este último, denominado de stress oxidativo, tem forte correlação com disfunção endotelial e exacerbação da atividade do SNS, assim como com redução de capacidade cardiorrespiratória em pacientes com IC. A síntese de NO também sofre influência do stress da camada endotelial da artéria, que depende dentre outros fatores, do volume de sangue circulante. Em pacientes com IC e Insuficiência Coronariana (ICO), a redução do fluxo sanguíneo nessas artérias diminui o stress em suas paredes, com consequente redução na síntese de ON e, portanto, produzindo uma via adicional de disfunção e lesão miocárdica nestes pacientes. Adicionalmente, a associação entre a perda da capacidade vasodilatadora do endotélio e o aumento da produção de substâncias vasoconstrictoras neste, ocasiona um aumento do tônus da musculatura lisa endotelial. Esta modificação gera uma aceleração na onda de pulso na fase de diástole ventricular, o que confere uma menor pressão aórtica nesta fase, com consequente contribuição direta na atenuação da perfusão coronariana e potencialização da lesão miocárdica já presente em pacientes com IC. Além disso, o aumento da RVS na vigência de aumento de rigidez arterial e arteriolar contribui para aumento na Pós-carga de VE, o que também é contribuinte de disfunção na fisiopatologia da IC ${ }^{(64)}$.

\subsubsection{Sistema respiratório e intolerância ao Exercício}

A relação entre o sistema respiratório e a limitação ao exercício em pacientes com IC é bastante descrita na literatura. Do ponto de vista de ventilação pulmonar, o que se 
observa é o edema pulmonar e a queda na complacência dos pulmões, assim como a fraqueza muscular respiratória. Em um Teste Cardiopulmonar (TCP) em pacientes com IC estas alterações podem ser confirmadas por meio da redução da relação entre Volume Corrente e Volume Minuto (VC/VM) à custa de redução do VC e aumento do VM, aumento da relação Volume de Espaço Morto e VC (VD/VC) à custa do aumento do VC, aumento da relação entre o VE e Consumo de Dióxido de Carbono $\left(\mathrm{VM} / \mathrm{VCO}_{2}\right)$ à custa de um aumento do $\mathrm{VE} \mathrm{e}$ redução dos níveis de $\mathrm{VCO}_{2}$ e por fim, uma redução do Consumo de Oxigênio $\left(\mathrm{VO}_{2}\right)$. Destas variáveis podemos destacar a relação $\mathrm{VM} / \mathrm{VCO}_{2}$ (Índice de Eficiência ventilatória com valor de normalidade abaixo de 34) e o $\mathrm{VO}_{2 \text { pico }}$ como variáveis fortemente relacionadas à redução da capacidade funcional e prognóstico de pacientes com IC. A capacidade de difusão de gases por meio da membrana alvéolo-capilar de pacientes com IC encontra-se alterada. Este comprometimento pode ser observado pela redução da capacidade de difusão de monóxido de carbono, tanto em repouso quanto durante o exercício. Adicionalmente, as atenuações na difusão de oxigênio podem ser compensadas pelo mecanismo de recrutamento de áreas de troca adicionais durante o exercício, o que pode em alguns casos menos graves de IC, reduzir a queda na Saturação Arterial de Oxigênio $\left(\mathrm{SaO}_{2}\right)$ mesmo na vigência de baixo fluxo sanguíneo pulmonar ${ }^{(64)}$.

Em pacientes com IC, a limitação da circulação pulmonar é determinada pelo desempenho do Ventrículo Direito (VD) assim como dos níveis de PAP. Adicionalmente, o trabalho muscular do VD aumenta em relação direta ao aumento da PAP, elevando seu nível de metabolismo também em proporção direta. $\mathrm{O}$ índice de eficiência ventilatória $\mathrm{VM} / \mathrm{VCO}_{2}$ possui forte correlação com Resistência Vascular Pulmonar $\left(\mathrm{RV}_{\text {pulm }}\right)$ e, portanto pode ser diretamente relacionada ao metabolismo oxidativo de VD como demonstrado por Ukkonen e colaboradores ${ }^{(65)}$ em estudo prévio. Desta forma, a medida de $\mathrm{RV}_{\text {pulm }}$ é uma importante variável no mecanismo de intolerância ao exercício em pacientes com IC.

\subsubsection{Sistema nervoso central e intolerância ao exercício}

O Fluxo Sanguíneo Cerebral (FSC) é determinado pela pressão arterial, regulação neural vascular, gases arteriais e SNA. Em virtude do baixo DC em pacientes com IC, o FSC nestes pacientes encontra-se reduzido, atenuando o aumento desta variável durante o exercício. Adicionalmente, a disfunção autonômica presente na IC toma papel importante no aumento da norepinefrina em regiões cerebrais subcorticais e é responsável pelo 
desencadeamento de vasoconstricção da vasculatura cerebral, reduzindo o FSC e desequilibrando a relação entre a oferta e demanda de $\mathrm{O}_{2}$ em nível cerebral. Associado a isso, durante o exercício, a resposta exacerbada do sistema respiratório com hiperventilação em virtude de uma reduzida eficiência ventilatória e redução dos níveis de pressão arterial de $\mathrm{CO}_{2}$, se relaciona com uma menor perfusão e consequente redução da oxigenação do tecido cerebral. Estas modificações durante o exercício são responsáveis tanto pela redução do drive motor central, como pelo aumento da percepção de fadiga e de maior esforço percebido pelo paciente $^{(66)}$. Desta forma, as modificações ocorridas em nível do Sistema Nervoso Central (SNC) e suas consequências tem também uma participação fundamental nos mecanismos de limitação e intolerância ao exercício em pacientes com IC (Figura 2).

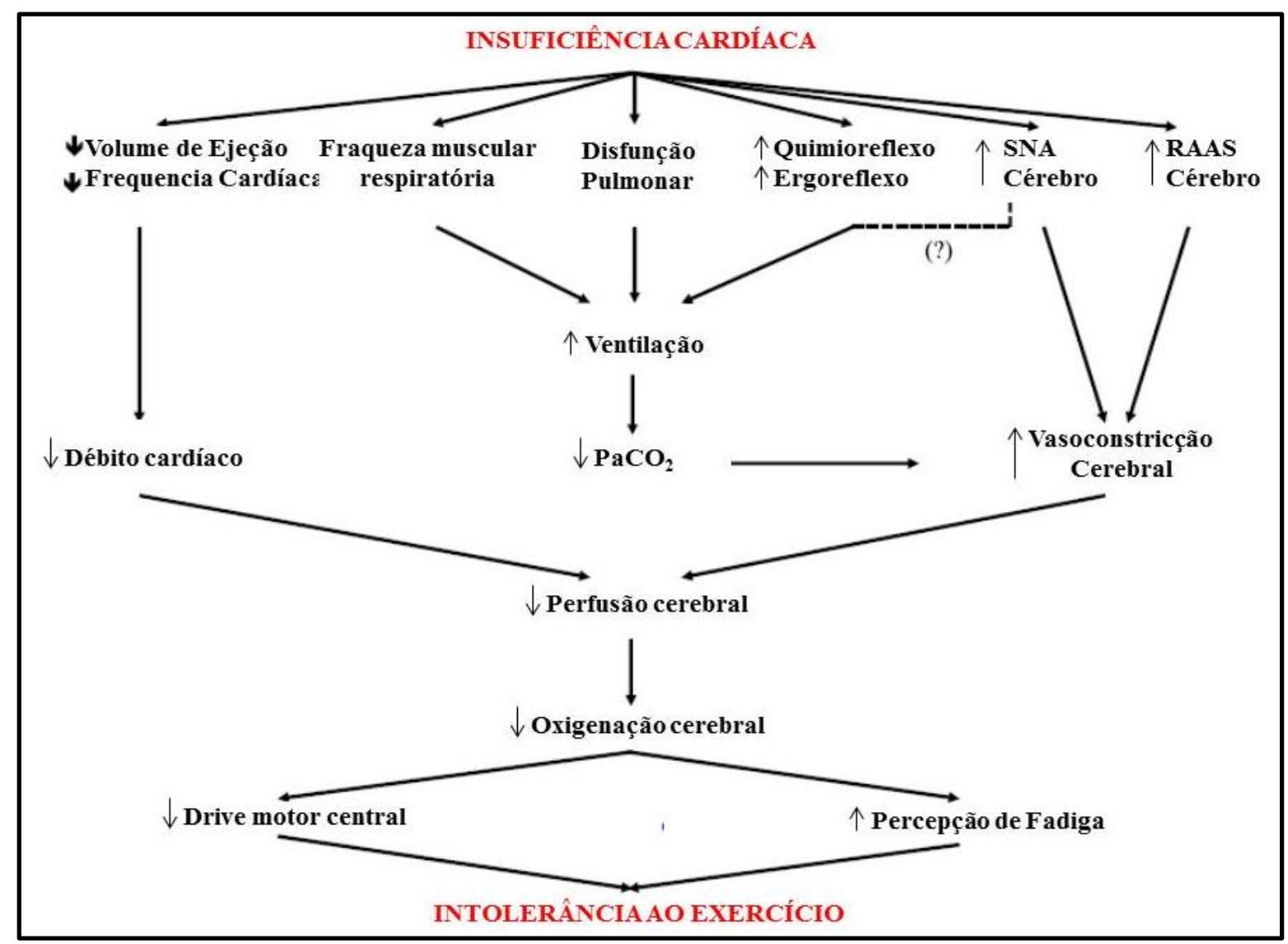

Figura 2. Alterações do Sistema Nervoso Central levando a Intolerância ao exercício em IC. Fonte: Brassard e cols. ${ }^{(66)}$

Várias modificações podem ocorrer no coração em resposta a situações de aumento de demanda. Dentre essas modificações podemos observar o aumento das câmaras cardíacas e a deterioração da função cardíaca, resultado de modificações nos componentes celulares e moleculares do coração assim como da perda parcial do controle homeostático. A 
este processo podemos denominar Remodelamento Cardíaco (RC). Por definição, o RC consiste nas mudanças moleculares, celulares, intersticiais e de expressão de genoma manifestadas clinicamente pelo aumento no tamanho, forma e função do coração, que ocorre após uma determinada lesão cardíaca. Este remodelamento sofre influências do nível de sobrecarga a qual é exposto o coração, assim como ativação neuro-hormonal e outros fatores, sendo os miócitos o principal componente afetado neste processo, porem afetando também outros componentes, como o interstício, fibroblastos, colágeno e vasculatura coronariana. A despeito das várias causas que podem levar ao remodelamento cardíaco, os mecanismos envolvidos são os mesmos ${ }^{(67)}$. É importante salientar que em indivíduos que desenvolvem IC, o processo de remodelamento torna-se muito mais agressivo e prejudicial quando comparados com indivíduos que cursam sem evolução para IC ${ }^{(68)}$.

O remodelamento do VE ocorre por meio de uma via inicial de estiramento ou stress de uma célula de miócitos. A partir deste ponto, ocorre um aumento na concentração de substâncias vasoconstrictoras, quais sejam: norepinefrina, angiotensina e a endotelina. Em seguida, observa-se uma estimulação de expressão de proteínas alteradas e da hipertrofia destes miócitos, gerando como resultado final uma deterioração significativa do desempenho ventricular e uma maior ativação do sistema neuro-hormonal. Em paralelo, a ativação de aldosterona e citoquinas promove uma maior síntese de colágeno e fibrose intersticial com remodelamento da matriz extracelular e proliferação de fibroblastos. Estes últimos determinam a formação de fibrose tanto na área onde ocorreu a lesão isquêmica quanto em áreas não acometidas. São também resultantes deste processo a necrose tecidual e apoptose celular. Adicionalmente, a ativação de uma enzima denominada colagenase cardíaca, ativada em situações de lesão de tecido miocárdico, promove degradação do tecido conectivo de sustentação de miócitos promovendo a dilatação da câmara cardíaca. Finalmente o que se observa é uma dilatação progressiva do VE que funcionalmente resulta em um aumento do VSFVE e uma redução da $\mathrm{FE}^{(56,67)}$.

Dentro dos fatores neuro-hormonais envolvidos no mecanismo de remodelamento ventricular, podemos destacar a atuação da angiotensina II e da aldosterona. A primeira favorece algumas alterações, quais sejam: Aumento de síntese de proteínas em fibroblastos e miócitos; e aumento de permeabilidade arterial coronariana, favorecendo a infiltração de fatores de crescimento para o interior do interstício miocárdico causando necrose e fibrose celular. A aldosterona tem seus efeitos concentrados na estimulação da síntese de colágeno e 
no processo de morte celular por via eletrolítica. Outros fatores ligados à modificação morfofuncional do VE são outras citoquinas como o Fator de Necrose Tumoral Alfa (FNT $\alpha$ ) e as interleucinas, assim como o aumento do stress oxidativo, todos convergindo para a via de necrose celular e apoptose gerando importante agravamento da função ventricular ${ }^{(56,67)}$.

Levando-se em consideração o papel fundamental do Miócito como a célula contrátil do musculo ventricular, a lesão miocárdica inicial levando a necrose e apoptose reduz o número destas células, fazendo com que as células remanescentes alterem a sua conformação assim como também se hipertrofiem. Esta resposta compensatória à redução do VS é também acompanhada por uma maior expressão de genes relacionados à hipertrofia, que são percussores neste contexto de síntese de novas proteínas contráteis e consequentemente da formação de novos sarcômeros.

A hipertrofia ventricular é um fator importante no processo de remodelamento. Esta situação quando adjacente a situações adversas como doença valvar e IAM, são acompanhadas por modificações no padrão metabólico, desorganização de sarcômeros, perda de miócitos com substituição por tecido fibrótico, disfunção sistólica e/ou diastólica, e alterações de condução elétrica cardíaca. A hipertrofia concêntrica é ocasionada por sobrecarga pressórica, onde ocorre aumento na espessura da parede miocárdica assim como da sua massa, porem com pouca ou nenhuma alteração do volume interno do VE. A hipertrofia excêntrica tem como fatores predisponentes a sobrecarga volumétrica e a imposição de exercício isotônico, e caracteriza-se por uma espessura da parede miocárdica que pode ou não estar aumentado, porem com massa e volume de VE aumentados. No primeiro tipo de hipertrofia os sarcômeros estão dispostos paralelamente com crescimento lateral de cardiomiócitos, enquanto no segundo tipo a disposição dos sarcômeros está em série e há um crescimento longitudinal dos seus cardiomiócitos (Figura 3) ${ }^{(67,68)}$. 


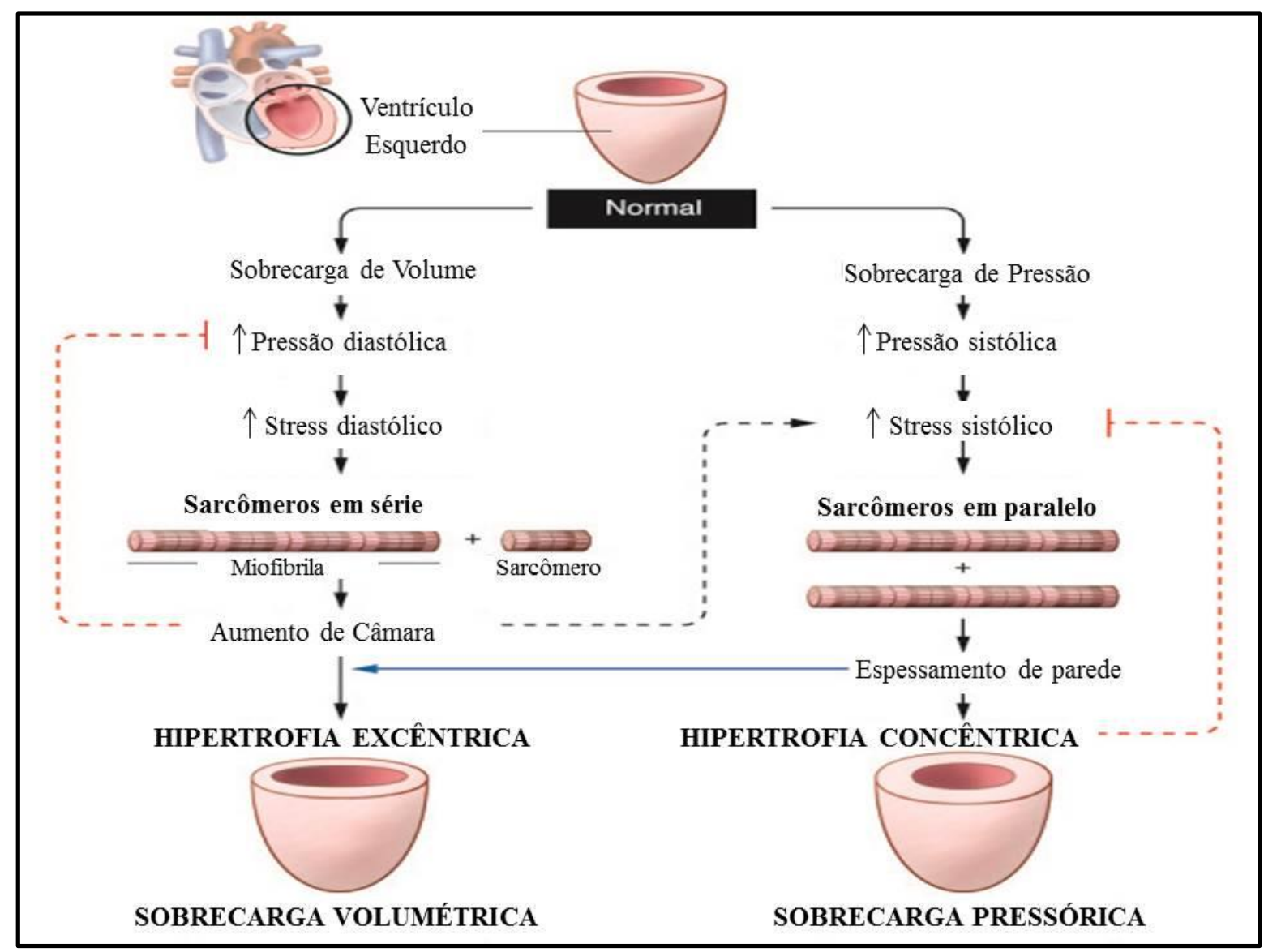

Figura 3. Hipertrofia ventricular concêntrica versus Hipertrofia ventricular excêntrica. Fonte: baseada em Hill e cols. ${ }^{(67)}$

O remodelamento do VE tem sido atribuído ao prognóstico de pacientes com IC, possuindo uma correlação direta com mortalidade e morbidade cardiovascular, estando associado a um maior risco de morte não só em IC, mas também em pacientes com DAC e pós IAM ${ }^{(69)}$. O curso de tempo do remodelamento patológico cardíaco também reforça a sua importância prognóstica. De fato, a síntese de cadeia pesada de Miosina aumenta em 35\% dos pacientes em poucas horas após exposição a sobrecargas volumétricas ou pressóricas. Adicionalmente, fatores genéticos podem aumentar a massa miocárdica em $60 \%$ em poucas semanas. Com a manutenção de uma sobrecarga constante, o coração é acometido por uma descompensação aparentemente irreversível. Esta fase mais tardia do remodelamento está associada a alterações no equilíbrio celular de $\mathrm{Ca}^{2+}$ e de alterações de correntes iônicas, acompanhadas por fibrose, apoptose e dilatação de câmaras, quadro compatível com IC com disfunção sistólica presente. Esta modificação é também caracterizada por uma redução da espessura da parede ventricular de causa multifatorial, podendo estar associada à proteólise, necrose de cardiomiócitos, isquemia celular, fibrose e alteração de proteínas contráteis ${ }^{(67)}$. 
Clinicamente, o RC pode ser detectado por meio de mudanças morfológicas, com análise de diâmetro, espessura de massa miocárdica, geometria e áreas de fibrose e infiltrados inflamatórios ${ }^{(56)}$. As principais variáveis que podem ser avaliadas e medidas para monitoramento do grau de remodelamento cardíaco são: dimensão e forma cardíaca; FEVE; VDFVE; e VSFVE. A variação de técnicas e avaliações para mensuração de morfologia ventricular determina uma baixa detecção da presença de hipertrofia de VE ${ }^{(70)}$. Outras técnicas como Eletrocardiografia $(E C G){ }^{(71)}$ e exames radiológicos são também importantes na predição de prognósticos e da presenta de Hipertrofia. O VDFVE fornece importantes informações acerca das modificações estruturais causadas pelo remodelamento e do Volume de enchimento ventricular, que se relaciona com o grau de distensão do miócito. O VSFVE é influenciado principalmente pelo VDFVE e pelo grau de encurtamento muscular. A FE é função principalmente do VDFVE, apesar de também estar na dependência da FC e grau de encurtamento muscular. Esta variável tem papel importante na predição de prognóstico e curso clínico em pacientes com IC. De fato, a medida do índice de VSFVE e FE após IAM pode predizer fortemente o desenvolvimento subsequente de IC, uma vez que pacientes com baixa FE e altos valores de VSFVE tem maiores chances de desenvolver IC e maior risco de morte do que pacientes em pós IAM com valores normais destas variáveis ou próximos da normalidade. Adicionalmente, pacientes com diagnóstico de ICFEr que cursam com maiores diâmetros de VE apresentam menor sobrevida do que pacientes com diâmetro de VE menor (49\% vs $75 \%$ de risco de morte em 2 anos, respectivamente). É importante lembrar que altos valores de VDFVE tem concomitante menores FE. Assim, esta última variável se torna um importante marcador do processo de remodelamento ventricular ${ }^{(72)}$.

A disfunção cardíaca após o remodelamento é modulada por diversos fatores decorrentes deste processo. Um fator importante é o déficit de disponibilidade de energia para o miocárdio com desequilíbrio entre oferta e consumo de oxigênio. Isto se dá pela modificação na via metabólica com redução dos ácidos graxos e da beta oxidação, aumentando o acúmulo de triglicerídeos e a lipotoxicidade, assim como atrofia mitocondrial com alteração de sua função. O resultado final é aumento da ATPase, maior liberação de radicais livres e aumento do stress oxidativo. Este último é fator causal de um desequilíbrio entre a produção de radicais livres e de seus tamponantes, gerando diversas alterações como peroxidação lipídica, lesão de DNA, disfunção celular, proliferação de fibroblastos, indução de apoptose, ativação de vias para hipertrofia ventricular, dentre outras ${ }^{(56)}$. 
É importante salientar que estratégias que possam cessar ou atenuar o processo de remodelamento de VE, sejam farmacológicos, ou por meio da imposição de exercício, podem interferir nos desfechos envolvidos na história natural da IC, impactando positivamente na sobrevida destes pacientes, assim como em uma melhor qualidade de Vida. 


\section{REABILITAÇÃO CARDIOVASCULAR}

\subsection{Referencial Teórico}

\subsubsection{Aspectos gerais}

De uma forma geral, o processo de Reabilitação Cardiovascular (RCV) consiste em uma atividade multidisciplinar, que envolve desde uma avaliação médica detalhada e prescrição de exercício, até intervenções para modificações nos fatores de risco cardiovascular, comportamento e educação de pacientes com DCV. De uma forma bastante efetiva, uma equipe multidisciplinar atua ao nível de Prevenção Secundária em diversos fatores, como na atenuação dos mecanismos fisiológicos e psicológicos, redução do risco de morte súbita e de novo infarto, estabilização de sintomas da doença e interferência no processo de aterosclerose, além de promover um melhor status psicossocial destes pacientes $(74,75,76)$.

No que diz respeito à indicação, podemos dividir de forma apropriada os candidatos a um programa de RCV em blocos clínicos e cirúrgicos. Entre os pacientes cirúrgicos, podemos citar as intervenções coronarianas abertas e por via hemodinâmica, cirurgias valvares e o transplante cardíaco, associado ou não ao transplante de pulmão. No bloco de pacientes clínicos, podemos incluir os pacientes com IAM, Doença Arterial Periférica (DAP), doenças valvares e IC ${ }^{(76)}$.

Segundo a American Heart Association e Associação Americana de Reabilitação Cardiovascular e Pulmonar, os programas de RCV devem ter os seus principais focos no aumento da tolerância ao exercício e do hábito de realiza-lo, assim como na correção dos fatores de risco coronarianos, claramente descritos como perfil lipoproteico, redução de peso corporal e dos níveis de glicose e pressão arterial, assim como na cessação do tabagismo. Não menos importantes no processo de RCV, são os aspectos emocionais resultantes das DCV, a exclusão social e as consequências destas doenças no aspecto ocupacional destes pacientes. Neste contexto, a RC pode atuar na modificação e aderência a um novo estilo de vida e maior motivação por parte dos pacientes, levando os mesmos a se beneficiarem por uma recuperação substancial da sua funcionalidade, com impacto positivo em todos os aspectos fisiológicos e psicossociais envolvidos na evolução das DVC ${ }^{(76)}$. 


\subsubsection{Atividade Física como componente da reabilitação cardiovascular}

Dentre os componentes que fazem parte de um programa integral de RCV, destacamos aqui o componente de atividade física. Neste âmbito, podemos subdividir este componente nos seguintes subitens: Orientações para realização de atividade física e o treinamento físico. O primeiro visa estimular a inserção da atividade física de forma habitual, modificando desta forma à disposição dos indivíduos para a realização de atividades ocupacionais e recreacionais. Deve-se nesse contexto, estimular a realização de atividade física por pelo menos 30 minutos em quase todos, senão todos os dias da semana com aumento gradual da frequência e intensidade de exercício. Adicionalmente, o segundo componente se refere à prescrição de exercício de forma personalizada, baseada na maioria das vezes em um teste de esforço limitado por sintomas para garantir a segurança na realização de exercícios no que diz respeito ao risco de complicações cardiovasculares e de eventos fatais e não fatais durante o decorrer do programa, assim como para determinar o nível de supervisão durante o mesmo. Uma sessão de exercícios deve incorporar além da fase de atividade propriamente dita, fases de aquecimento, desaquecimento assim como de exercícios de flexibilidade. As modificações dos parâmetros de prescrição de exercícios devem ser realizadas de acordo com as variações no status clínico no decorrer do programa de $\mathrm{RCV}^{(76)}$.

\subsubsection{Segurança e adesão a programas de reabilitação cardiovascular}

Um aspecto de grande importância no âmbito da RCV se refere à segurança dos pacientes em programas de treinamento. De acordo com a literatura, a incidência de eventos durante sessões de exercícios tem sido extremamente baixa, variando de um evento a cada 50.000 a 100.000 pacientes por hora de exercício supervisionado. Esta baixa incidência de complicações se deve principalmente ao fato destes pacientes se submeterem a uma classificação prévia de risco cardiovascular para o exercício, inserindo os pacientes em cada um dos níveis que se seguem: Classe A, aparentemente saudáveis e sem risco cardiovascular ao exercício; Classe B, cardiopatas estáveis com baixo risco de complicações durante exercício vigoroso; Classe C, incluídos na classe Funcional NYHA III e IV, com história de múltiplos IAM e Parada Cardiorrespiratória e com capacidade funcional abaixo de 6 Equivalentes Metabólicos (MET), com moderado a alto risco de complicações durante o exercício; e Classe D, em vigência de instabilidade da DCV com contraindicação para realização de exercício de qualquer intensidade. Desta forma, pacientes incluídos nas 
classificações B e C são frequentemente encaminhados a programas de RCV e devem ser supervisionados até que níveis de segurança durante o exercício possam ser atingidos ${ }^{(76)}$.

De uma maneira geral, embora a literatura seja extremamente farta no que diz respeito a indicações, contraindicações e aos benefícios da RCV, nos EUA menos de 30\% dos pacientes com critérios para inclusão participam efetivamente de programas supervisionados de RCV. Parâmetros de sexo, idade e raça são descritos na literatura como menos beneficiados destes programas. Adicionalmente, maior numero de comorbidades, nível socioeconômico, grandes distâncias, baixa motivação, falta ou inadequado reembolso por seguradoras de saúde e falta de encaminhamento médico são fatores adicionais que reduzem substancialmente o número de pacientes que deveriam se submeter a programas de RCV e que, no entanto, não o fazem. Segundo King e colaboradores pacientes com mais de 70 anos, do sexo feminino, residentes de áreas rurais, que não tinham o domínio da língua inglesa e que se submetiam a procedimentos por via hemodinâmica, eram menos prováveis de fazerem parte de programas de RCV. De forma interessante, os idosos argumentam o não estímulo para participação nesses programas pelo fato de acharem que tais afecções estão ocorrendo em função de sua idade avançada e que pouco teria a acrescentar de benefícios a sua entrada em tais programas. ${ }^{(73)}$

Adicionalmente, apesar de pacientes submetidos a procedimentos hemodinâmicos gerarem menos impacto na recuperação destes, a sua inclusão em programas de reabilitação seria amplamente justificada pelos focos nas modificações de estilo de vida e de fatores de risco relacionados a DCV. Por fim, mas talvez de importância grandiosa ainda na questão da baixa taxa de participação e adesão, está o reduzido comprometimento por parte de profissionais médicos no encaminhamento para programas de $\mathrm{RCV}$, seja pela descrença de que tais programas possam efetivamente provocar modificações reais de estilo de vida, ou porque os referidos profissionais acreditam que apenas o próprio tratamento, clínico ou cirúrgico, tornam desnecessária a realização de qualquer terapia reabilitativa nos seus pacientes, o que nos parece ser o mais grave em relação ao tema principal abordado neste momento. É notória, portanto a necessidade de um incremento nos níveis de conhecimento a respeito dos benefícios da $\mathrm{RCV}$, assim como em um maior encorajamento por parte das equipes médicas para maior frequência de encaminhamento a estes programas, já que a recomendação médica é hoje sem dúvida alguma, um fator de extrema importância na motivação para procura da RCV por parte dos pacientes, independente de quaisquer outros fatores mencionados que podem interferir na participação destes pacientes ${ }^{(74)}$. 


\section{EXERCÍCIO FÍSICO E SEUS EFEITOS NO REMODELAMENTO CARDÍACO E CAPACIDADE AO EXERCÍCIO}

\subsection{Referencial Teórico}

\subsubsection{Aspectos gerais}

Até o início da década de 90, pacientes com IC eram orientados a se manterem em repouso, com a justificativa de que a imposição de atividade física poderia gerar aumento de sobrecarga ventricular e induzir uma sintomatologia induzida pelo exercício. A partir do estudo de Coats e colaboradores ${ }^{(1)}$, com o conceito da chamada "hipótese muscular", que fundamenta de forma bastante robusta a indicação de exercício físico em pacientes com IC e disfunção de VE, baseado na presença de uma miopatia esquelética e respiratória com sintomatologia secundária e exacerbação da atividade ergoreflexa ao exercício, vários fatores periféricos como disfunção vascular periférica, redução de força muscular e alterações nos componentes funcionais, metabólicos e estruturais do musculo esquelético tornaram-se por assim dizer, alvos terapêuticos, que poderiam ser passíveis de reversão por meio da realização de exercício físico (Figura 4) ${ }^{(75)}$.

Os benefícios do exercício nas mais diversas DCV já são bem descritos na literatura. Atualmente, existem poucas afecções cardíacas nas quais está contraindicada a realização de exercício, quais sejam: Angina instável, IAM recente, arritmias não controladas, estenose aórtica severa, IC descompensada, miocardites e pericardites. Após a exclusão das condições supramencionadas, podemos englobar as principais indicações para realização de exercício como parte de um programa de RC, grandes grupos de pacientes que perfazem a grande maioria dos que efetivamente participam de tais programas. Dentre eles, podemos citar a DAC, o IAM e a IC, seja com fração de ejeção reduzida ou preservada. A partir deste ponto, destacaremos o papel do exercício em pacientes com IC e com fração de ejeção reduzida (ICFEr), objeto direto do estudo em questão ${ }^{(75)}$. 


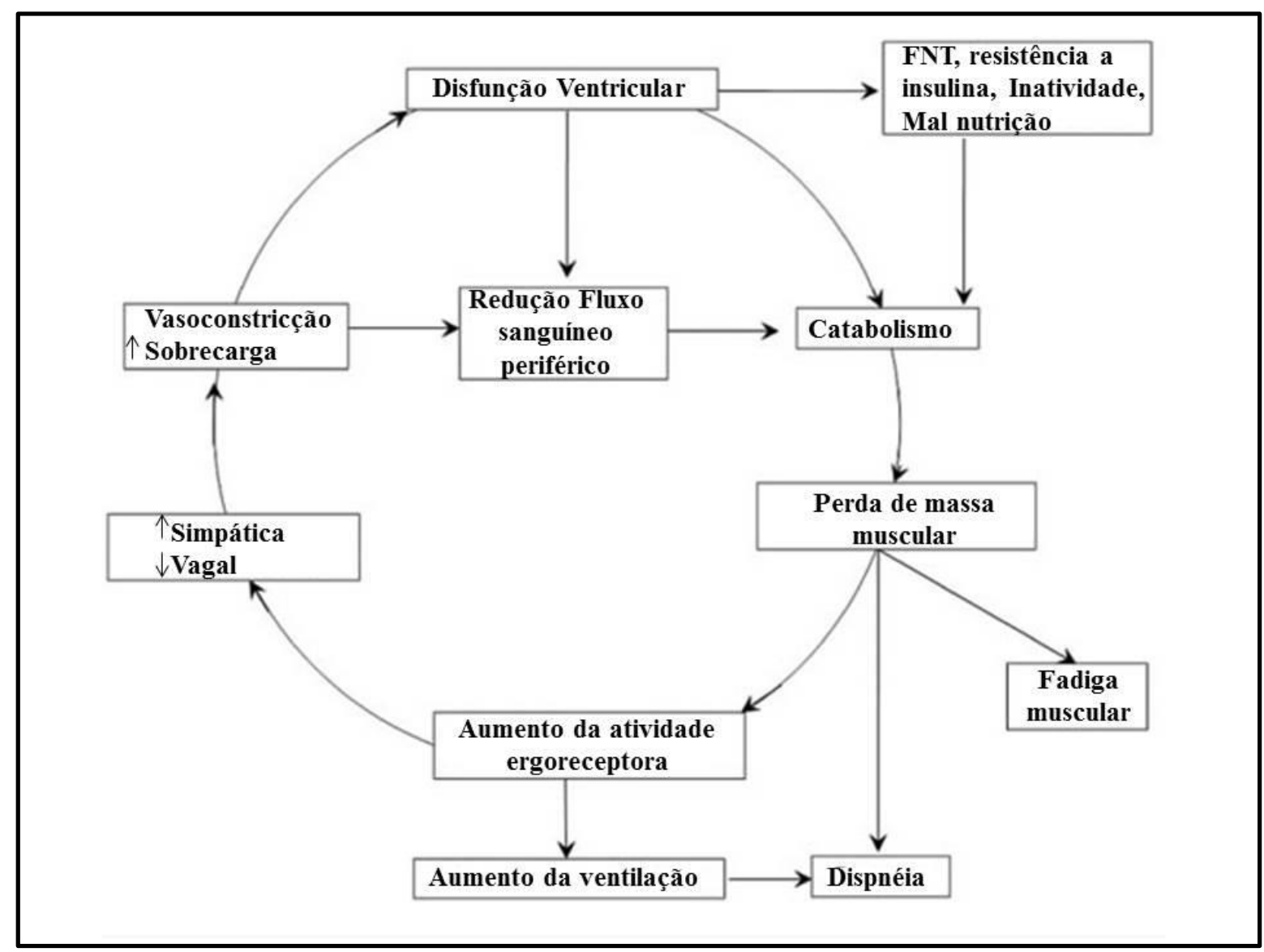

Figura 4. A teoria da "hipótese muscular" descrita por Coats e cols. Fonte: Coats e cols. ${ }^{(1)}$

De uma maneira geral, tanto o exercício aeróbio quanto o exercício resistido podem produzir melhora importante em diversas variáveis de condicionamento físico e qualidade de vida relacionada à saúde (Tabela 2). Entretanto, a magnitude de efeito resultante destas intervenções nestas variáveis é o que diferencia estas modalidades de exercício, estando o exercício aeróbico mais relacionado a modificações na capacidade aeróbica e modificação de fatores de risco, enquanto o exercício resistido se relaciona ao aumento de massa e força muscular e ganho de endurance ${ }^{(76)}$. Adicionalmente, a partir destas duas modalidades de aplicação de exercício, podemos observar na literatura uma variação de formas de suas aplicações, como por exemplo, a modalidade de exercício aeróbico de alta intensidade ou High intensity training (HIT), exercício aeróbico intervalado e uma combinação entre exercício aeróbico com exercício resistido. Desta forma, a partir deste ponto em diante, iremos discutir acerca dos dois principais tipos de exercício, quais sejam: exercício aeróbico, exercício resistido e sua combinação, denominada de exercício combinado. 
Quadro 2. Principais efeitos do exercício aeróbico e resistido

\begin{tabular}{|c|c|c|}
\hline Composição corporal & Exercício aeróbico & Exercício resistido \\
\hline Densidade mineral óssea & $\uparrow \uparrow$ & $\uparrow \uparrow$ \\
\hline$\%$ de massa gorda & $\downarrow \downarrow$ & $\downarrow$ \\
\hline$\%$ de massa magra & $\leftrightarrow$ & $\uparrow \uparrow$ \\
\hline Força muscular & $\leftrightarrow \uparrow$ & $\uparrow \uparrow \uparrow$ \\
\hline \multicolumn{3}{|l|}{ Metabolismo de Glicose } \\
\hline Níveis basais de insulina & $\downarrow$ & $\downarrow$ \\
\hline Sensibilidade à insulina & $\uparrow \uparrow$ & $\uparrow \uparrow$ \\
\hline \multicolumn{3}{|l|}{ Lipídeos plasmáticos e lipoproteínas } \\
\hline HDL colesterol & $\uparrow \leftrightarrow$ & $\uparrow \leftrightarrow$ \\
\hline LDL colesterol & $\downarrow \leftrightarrow$ & $\downarrow \leftrightarrow$ \\
\hline Triglicerídeos & $\downarrow \downarrow$ & $\downarrow \leftrightarrow$ \\
\hline \multicolumn{3}{|l|}{ Dinâmica cardiovascular } \\
\hline Frequência cardíaca de repouso & $\downarrow \downarrow$ & $\leftrightarrow$ \\
\hline Volume de ejeção (repouso e máximo) & $\uparrow \uparrow$ & $\leftrightarrow$ \\
\hline Débito cardíaco repouso & $\leftrightarrow$ & $\leftrightarrow$ \\
\hline Débito cardíaco máximo & $\uparrow \uparrow$ & $\leftrightarrow$ \\
\hline Pressão arterial sistólica repouso & $\downarrow \leftrightarrow$ & $\leftrightarrow$ \\
\hline Pressão arterial diastólica repouso & $\downarrow \leftrightarrow$ & $\leftrightarrow$ \\
\hline VO2 máximo & $\uparrow \uparrow \uparrow$ & $\downarrow \leftrightarrow$ \\
\hline Tempo de endurance submáxima e máxima & $\uparrow \uparrow \uparrow$ & $\uparrow \uparrow$ \\
\hline Duplo produto submáximo & $\downarrow \downarrow \downarrow$ & $\downarrow \downarrow$ \\
\hline Metabolismo basal & $\uparrow \leftrightarrow$ & $\uparrow$ \\
\hline Qualidade de vida relacionada à saúde & $\uparrow \leftrightarrow$ & $\uparrow \leftrightarrow$ \\
\hline
\end{tabular}

Fonte: Adaptado de Williams e cols. ${ }^{(76)}$ 


\subsubsection{Exercício Aeróbico em pacientes com Insuficiência Cardíaca}

Os benefícios do Exercício Aeróbico em pacientes com IC são bem descritos na literatura. Dentre eles, podemos citar a melhora da Capacidade de exercício, mensurada e representada pelo $\mathrm{VO}_{2}$, atenuação da disfunção endotelial, redução dos níveis séricos de catecolaminas circulantes, melhora do comportamento autonômico cardiovascular, redução da atividade do sistema renina-angiotensina-aldosterona, melhora da Função e estrutura cardíaca mensurada principalmente pela FEVE e VDFVE, atenuação do processo de degradação muscular, melhora do desempenho cardiorrespiratório, melhora da qualidade de vida e impacto direto na mortalidade (Figura 5) ${ }^{(8,77-80)}$.

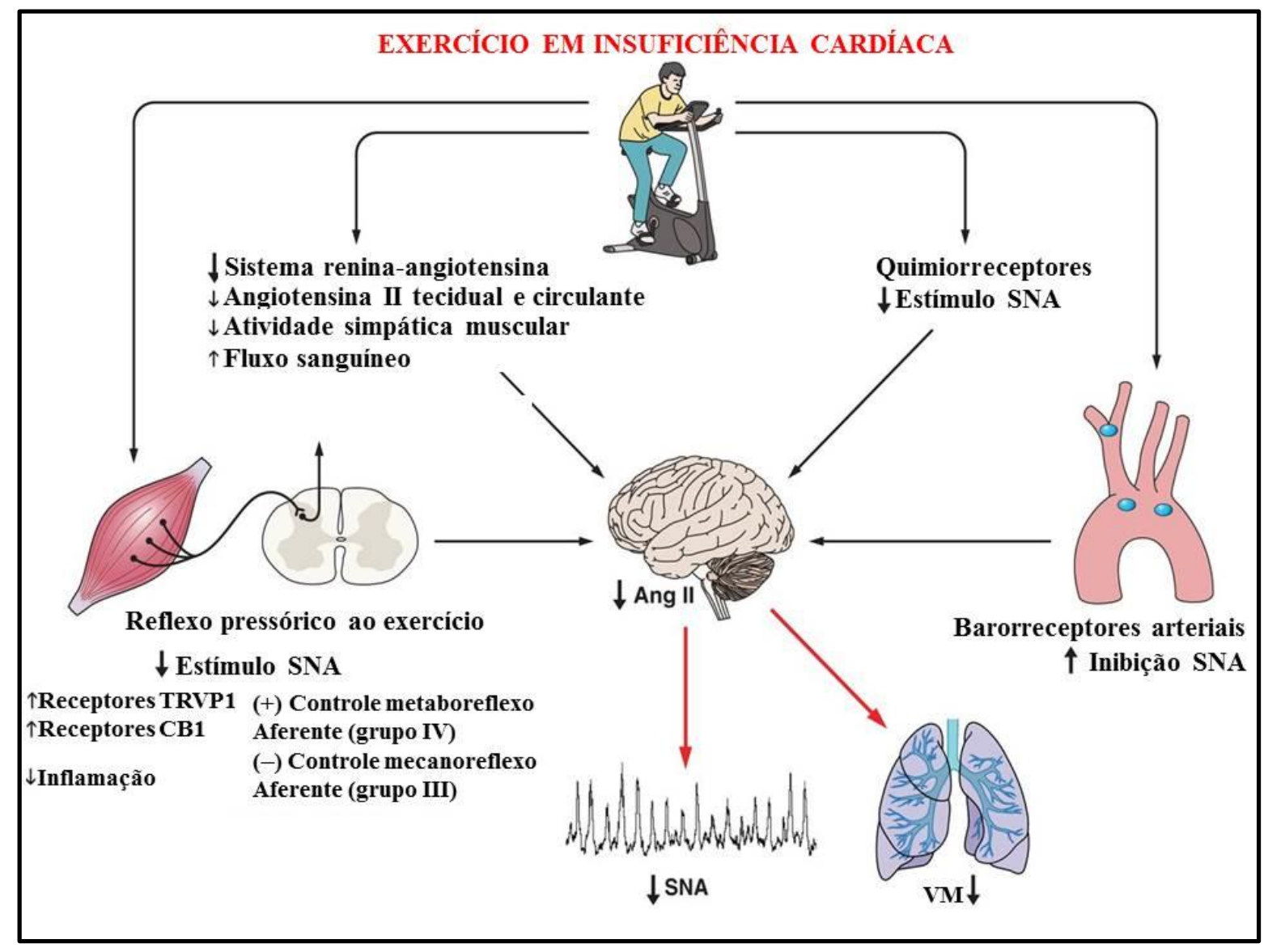

Figura 5. Efeitos neuro-humorais do exercício em pacientes com Insuficiência Cardíaca.

Fonte: Adaptado de Negrao e cols ${ }^{(80)}$.

Trata-se atualmente uma forte ferramenta para melhora de prognóstico em pacientes com ICFEr $^{(81)}$. Existem hoje dois grandes estudos na literatura que suportam esta evidência ${ }^{(75)}$. O primeiro deles é a metanálise EXTRA-MATCH ${ }^{(82)}$, constituída de Ensaios Clínicos Randomizados (ECR), principalmente europeus, abrangendo um total de 801 
pacientes com ICFEr, que demonstrou uma melhora na sobrevida destes pacientes em relação a indivíduos alocados em grupo controle, com redução de $35 \%$ na mortalidade por qualquer causa e redução de $28 \%$ para os end-points combinados de morte e internação hospitalar. O segundo é o HF-ACTION ${ }^{(83)}$, um estudo multicêntrico, que apesar de ter a maior amostra reunida de pacientes com ICFEr até os dias atuais, não obteve êxito em demonstrar efeitos favoráveis na mortalidade destes pacientes. A principal justificativa para tal resultado seria a reduzida taxa de adesão dos pacientes ao programa de tratamento proposto no estudo, em torno de $60 \%$, que foi posteriormente confirmada a partir de uma sub-análise destes resultados em um subsequente estudo feito por Keteyian e colaboradores ${ }^{(84)}$, que demonstraram uma relação dose-resposta de exercício com mortalidade nestes pacientes com um volume mínimo necessário de exercício de 3 a 7 MET’s para que sejam visualizados benefícios clínicos.

De uma maneira geral, os efeitos do EA nas variáveis de RC são bem descritas na literatura. Recentemente, Haykowsky e colaboradores publicaram uma metanálise analizando os efeitos desta modalidade de exercício em pacientes com ICFEr. Incluindo um total de 14 estudos, sendo 10 estudos envolvendo EA, os autores demonstram um efeito significativamente favorável o EA em todas as variáveis de remodelamento analisadas, quais sejam: FEVE, VDFVE e VSFVE. Os autores atribuem estes efeitos a uma atenuação da atividade neurohormonal e redução da sobrecarga cardíaca com o treinamento. Dentre os vários mecanismos responsáveis por estas respostas podemos citar os que se seguem: Redução dos níveis de várias substâncias como angiotensina II, aldosterona, catecolaminas e Peptídeo Natriuretrico Atrial e Cerebral ${ }^{(85)}$, redução da atividade simpática e aumento da atividade parassimpática ${ }^{(86)}$. Estas modificações culminam com queda significativa da RVP e redução da pós-carga de VE. Efeitos adicionais podem ser descritos como aumento da contratilidade miocárdica e de reserva vascular, aumento da dilatação mediada por fluxo, redução dos níveis de FNT- $\alpha$ e neovascularização foram encontradas por Erbs e colaboradores após 12 semanas de exercício aeróbico de moderada intensidade ${ }^{(87)}$. Estes resultados estão diretamente relacionados à maior biodisponibilidade de ON resultando em uma menor RVP e redução de pós-carga de VE, o que justifica os efeitos favoráveis nas variáveis de RC e do aumento da capacidade ao exercício ocorrido neste estudo. Adicionalmente, os efeitos antiinflamatórios observados são contribuintes para uma atenuação no mecanismo de lesão endotelial característica nestes pacientes ${ }^{(87,88)}$. Malfatto e colaboradores adicionam às evidencias já encontradas, uma melhora do índice de massa de VE e melhora da complacência ventricular, variáveis também relacionadas ao processo de $\mathrm{RC}^{\left({ }^{89}\right)}$. Contudo, em uma análise 
individual dos estudos que se relacionam as variáveis de $\mathrm{RC}$, encontramos resultados conflitantes, que vão desde melhora significativa destas variáveis, até resultados favoráveis que aumentam o desempenho de VE destes pacientes. Mesmo nos estudos onde não ocorreram efeitos favoráveis nos desfechos de RC, a indicação para RC nestes pacientes torna-se de extrema importância clínica, tendo em vista os seus efeitos na interrupção da piora da disfunção cardíaca em virtude da evolução desfavorável desta Síndrome.

A influência do EA na melhora da capacidade ao exercício de pacientes com ICFEr tem sido descrita na literatura a décadas. Recentemente, Vromen e colaboradores fizeram uma análise por meta-regressão das características envolvidas no processo de prescrição de EA e sua influência nos resultados de capacidade de exercício. Os autores concluíram que tanto o número quanto a duração das sessões de treinamento são diretamente correlacionadas com este desfecho, ficando a intensidade como um fator secundário nos resultados do estudo ${ }^{(90)}$. Estes resultados contrariam os achados de Ismail e colaboradores, que demonstraram que o volume e intensidade do treinamento seriam os fatores mais importantes na prescrição de EA em pacientes com IC ${ }^{(91)}$.

Os mecanismos envolvidos no aumento da capacidade ao exercício com o EA podem ser descritos a partir de modificações na estrutura e função cardiovascular ${ }^{(88)}$, assim como no metabolismo muscular ${ }^{(92)}$. Os impactos clínicos resultantes da melhora do $\mathrm{VO}_{2 \text { pico }}$ em pacientes com ICFEr podem ser vistos na redução da ansiedade e depressão, assim como na qualidade de vida relacionada a saúde destes pacientes ${ }^{(11,12,93,94)}$. Estudo prévio de Belardinelli e colaboradores relacionou o ganho obtido no $\mathrm{VO}_{2 \text { pico }}$ após um programa de EA de baixa intensidade por um período de oito semanas, ao aumento na densidade mitocondrial e de capacidade oxidativa muscular ${ }^{(95)}$. Posteriormente, o mesmo grupo de pesquisadores demonstrou que o aumento do enchimento ventricular tanto em repouso quanto durante o exercício também pode contribuir com a melhora de $\mathrm{VO}_{2 \text { pico }}$ nestes pacientes. Estes resultados são confirmados adiante por Malfatto e colaboradores e adicionam outros achados como um aumento da complacência de VE após o treinamento ${ }^{\left({ }^{(9)}\right.}$. Entretanto alguns estudos não foram capazes de demonstrar melhora nesta variável, apesar desta modalidade de treinamento ter efeito benéfico na capacidade submáxima e melhora dos sintomas relacionados à IC durante o exercício ${ }^{(97-101)}$. A melhora do comportamento cronotrópico é também fator importante envolvido no mecanismo de melhora da capacidade ao exercício, com melhora dos componentes de FC de repouso e de reserva após o programa de treinamento ${ }^{\left({ }^{(8)}\right.}$. 
Sturm e colaboradores demonstram uma correlação inversa entre capacidade aeróbica antes do início do programa de treinamento e uma melhora significativa do $\mathrm{VO}_{2 \text { pico }}$ induzida pelo EA de moderada intensidade ${ }^{(102)}$. Além de demonstrar melhora significativa do $\mathrm{VO}_{2 \text { pico }}$ e do Slope $\mathrm{VM} / \mathrm{VCO}_{2}$ após um programa de EA de moderada intensidade em pacientes com ICFEr, Gademan e colaboradores também foram capazes de forma pioneira o aumento no slope de eficiência de consumo de oxigênio ${ }^{(81)}$, uma variável obtida similarmente obtida no TCP que possui um corpo de evidências como preditor de performance cardiorrespiratória ${ }^{(103,104)}$, sugerindo adaptações musculares periféricas ao treinamento. Estes achados foram recentemente corroborados por Myers e colaboradores com EA de alta intensidade em pacientes com $\operatorname{ICFEr}^{(105)}$. A relação entre a redução de peptídeo Natriuretrico cardíaco e cerebral foi demonstrada em estudo recente publicado por Guazzi e colaboradores e confirmado por estudo posterior de Sandri e colaboradores ${ }^{(85)}$. Adicionalmente, em um estudo que analisou os efeitos da $\mathrm{RCV}$ com $\mathrm{EA}$ o $\mathrm{VO}_{2 \text { pico }}$ dentre outras variáveis demonstrou um aumento significativo desta variável após um mês de treinamento, no entanto, após seis anos os valores de $\mathrm{VO}_{2 \text { pico }}$ retornaram para valores próximos dos basais. Mesmo assim, os pacientes mantiveram-se envolvidos em níveis de atividade física acima do que é recomendado por guidelines para manter saúde cardiovascular ${ }^{(106)}$.

\subsubsection{Exercício resistido em pacientes com Insuficiência Cardíaca}

A correlação entre as alterações da função muscular e a redução da capacidade ao exercício em pacientes com IC é um dos pilares na fundamentação da prescrição de exercício nestes pacientes. Adicionalmente, o estudo de revisão de Braith e colaboradores fornecem informações extremamente importantes com evidências científicas claras que fundamentam o ER em pacientes com IC. Estas evidências se baseiam em dois pontos importantes. Primeiro no que diz respeito ao fenótipo muscular, que se refere às alterações de redução de massa muscular, mudanças histoquímicas com anormalidades na capacidade oxidativa muscular e por fim a modificação no tipo de fibra muscular destes pacientes. Todas estas alterações são convergentes para retroalimentação dos mecanismos de intolerância ao exercício em IC e tem impacto direto no prognóstico destes pacientes. Como segundo ponto não menos importante que o primeiro, encontra-se a redução da força muscular, principalmente de membros inferiores, que tomam papel importante como melhor preditor de desfecho em longo prazo do 
que variáveis não menos importantes como $\mathrm{VO}_{2}$ pico dentre outras. Desta forma, torna-se clara as razões para inclusão do ER no arsenal terapêutico de pacientes com IC ${ }^{(107)}$.

\subsubsection{Efeitos esperados do exercício resistido no sistema cardiovascular}

Os efeitos do exercício resistido na estrutura e função do sistema cardiovascular estão na dependência de múltiplos fatores, que vão desde o tipo, duração e intensidade do exercício, até fatores inerentes aos indivíduos que o realizam, como idade, sexo, raça e componente genético. É importante salienta que as respostas que ocorrem ao ER são uma combinação entre sobrecarga volumétrica e pressórica, resultantes do exercício aeróbico e isométrico, respectivamente ${ }^{(76)}$. A magnitude destas respostas estão em função do nível de intensidade administrada por meio de porcentagem do Teste de uma Repetição Máxima (1RM); do tamanho do musculo exercitado; e da duração da contração muscular em relação ao período de repouso entre cada repetição ${ }^{(107)}$. Do ponto de vista estrutural, os resultados obtidos com a realização de ER em indivíduos saudáveis se relacionam a um aumento da espessura da massa miocárdica de VE, sem modificações no seu diâmetro, sendo esta espessura equivalente à de indivíduos saudáveis destreinados. Esta hipertrofia, ocasionada por sobrecarga pressórica de VE diferentemente da hipertrofia causada pelo EA, tem características simétricas, consistentes com o tipo de hipertrofia fisiológica, sem modificações na estrutura miocárdica quando comparados a miocárdio de indivíduos com DCV. Adicionalmente, a normalidade das funções sistólicas e diastólicas após o treinamento com ER fundamenta ainda mais a hipertrofia fisiológica causada por esta modalidade de exercício. Por fim, reduções na FC e PAS ocorridas em longo prazo em consequência de efeitos prolongados do ER determinam redução concomitante do duplo produto (FC x PAS), um determinante indireto de consumo de $\mathrm{O}_{2}$ pelo miocárdio.

\subsubsection{Segurança cardiovascular durante exercício resistido}

Do ponto de vista de segurança cardiovascular durante a realização de ER, as evidências encontradas na literatura são consistentes com um risco relativo, que tem sua dependência em variáveis também relacionadas ao EA, como idade, nível prévio de condicionamento físico, presença de DCV associada e intensidade do exercício. De forma bastante paradoxal ao que se racionaliza neste conceito, Featherstone e colaboradores ${ }^{(108)}$ 
sugerem um risco cardiovascular de maior montante durante o EA, uma vez que o ER proporciona um maior equilíbrio na relação oferta e consumo miocárdico, já que o aumento de pós-carga inerente a este tipo de exercício ocasiona um aumento na pressão de perfusão coronariana e, portanto maior perfusão miocárdica, reduzindo os riscos de isquemia e de produção de angina ou alterações de segmento ST. Adicionalmente, um estudo prévio com uma amostra de mais de 6.000 indivíduos saudáveis, demonstrou ausência total de eventos cardiovasculares adversos com a realização de teste $1-\mathrm{RM}^{(109)}$. Em pacientes com IC, a imposição de ER de até 60\% de 1-RM gera respostas hemodinâmicas de menor magnitude se comparadas a um teste cardiopulmonar em esteira ${ }^{(107)}$ ou durante exercício à $70 \%$ de 1-RM quando comparado a exercício em cicloergômetro à $70 \%$ do $\mathrm{VO}_{2 \text { pico }}{ }^{(110)}$. Além disso, Meyer e colaboradores demonstraram em estudo prévio com monitoração hemodinâmica invasiva por meio de cateter de artéria pulmonar um aumento do DC e do índice de trabalho sistólico de VE, assim como uma redução da RVP durante ER com intensidade de $80 \%$ de 1-RM, deixando clara a adaptabilidade do VE durante esta modalidade de exercício ${ }^{(111)}$. De uma forma complementar, a utilização de uma técnica de respiração adequada e a orientação para que se evitem manobras de valsalva são formas eficazes de reduzir o risco cardiovascular

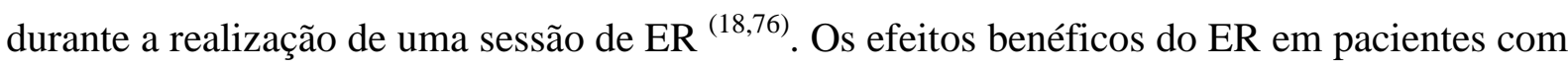
DAC têm sido acompanhados de uma ausência de efeitos colaterais adversos como eventos isquêmicos e arritmias simples ou complexas, sugerindo que esta modalidade terapêutica pode ser incorporada com segurança em programas de $\mathrm{RC}^{(76)}$. Adicionalmente, em pacientes com IC, as respostas agudas do ER têm sido consideradas sem anormalidades mesmo com níveis de intensidades elevadas como $80 \%$ da Contração Voluntária Máxima $(\mathrm{CVM}){ }^{(111)}$. Desta forma, o ER parece ser bem tolerado em pacientes com ICFEr desde que compensados e estáveis, uma vez que se mantiveram também estáveis a função de VE e as demais variáveis hemodinâmicas.

De uma maneira geral, três metanálises prévias analisaram os efeitos do ER isoladamente e por meio do EC em pacientes com ICFEr. Haykowsky e colaboradores tem demonstrado a incapacidade destas duas modalidades de exercício em melhorar tanto a capacidade ao exercício, como as variáveis de RC analisadas no estudo, tendo atribuído tais resultados negativos aos efeitos hemodinâmicos deletérios na função cardíaca já deteriorada nestes pacientes ${ }^{(4)}$. Posteriormente, apesar de Hwang e colaboradores não conseguirem obter êxito em demonstrar resultados favoráveis em nenhum dos desfechos em questão, um achado interessante em sua metanálise foi que o ER conseguiu ter um efeito favorável na capacidade 
de exercício submáxima, avaliada pelo Teste de Caminhada de Seis Minutos (TC6 $6_{\min }$ ). Adicionalmente, ao contrário de Haykowsky, os autores em seu estudo não relatam efeitos adversos da função cardíaca ao ER em qualquer de suas formas de aplicação ${ }^{(13)}$. Por fim, em uma publicação recente, Van de Meer e colaboradores demonstraram os efeitos favoráveis do EA e do EC na melhora do $\mathrm{VO}_{2 \text { pico }}$ em pacientes com ICFEr em relação a pacientes de grupo controle. Entretanto, o estudo não analisou separadamente os dois tipos de exercício e, portanto, ficam obscuros ainda os reais efeitos da modalidade de EC nestes pacientes. Além disso, os autores analisaram os efeitos apenas na capacidade ao exercício, sem análise das variáveis de $\mathrm{RCV}^{(7)}$. Tendo em vista, parecem ainda pouco claras as reais respostas cardiovasculares e funcionais de indivíduos com ICFEr ao ER isolado e EC. A seguir, iremos descrever de uma forma mais detalhada os resultados dos principais estudos publicados na literatura com estas intervenções e seus efeitos nas variáveis de $\mathrm{VO}_{2 \text { pico }}$ e de RCV. Assim, tornar-se-ão mais claras as evidências a este respeito.

\subsubsection{Efeitos do exercício resistido isolado no consumo de oxigênio de pico}

Para verificar os efeitos do ER na capacidade ao exercício em pacientes com ICFEr, Tynni-Lenné e colaboradores desenvolveram um protocolo de oito semanas de treinamento, utilizando-se de bandas elásticas (therabands) com intensidade ajustada pelo Índice de percepção de esforço de BORG entre 13 a 16 para esforço muscular e abaixo de 13 para percepção central de esforço. A aplicação de tal protocolo foi capaz de reduzir os níveis de catecolaminas circulantes durante atividades submáximas, assim como aumentar os níveis de $\mathrm{VO}_{2 \text { pico }}$ e o desempenho no $\mathrm{TC}_{\text {min }}{ }^{(12)}$. Este estudo reforça estudos prévios ${ }^{(113,114)}$ e seria posteriormente corroborado por Palevo e colaboradores em seu estudo ${ }^{(18)}$. Por meio de uma análise de variáveis consistentes, Selig e colaboradores fizeram inferências importantes em decorrência dos achados de seu estudo. A partir da aplicação de um protocolo de ER de moderada intensidade em pacientes com ICFEr, os autores conseguiram demonstrar um aumento de força muscular e endurance $(20 \%), \mathrm{VO}_{2 \text { pico }}(10 \%)$, fluxo sanguíneo em antebraço tanto em repouso como durante realização de contração isométrica em várias porcentagens da CVM e redução do componente espectral de baixa frequência da VFC (44\%). Os resultados destes autores demonstram os efeitos em cascata da redução da atividade autonômica na vasculatura periférica, com decremento da RVP, associando-se a estes fatores a melhora da 
força muscular, levando a um resultado final de melhora do desempenho destes pacientes traduzidos pelo aumento da endurance e do $\mathrm{VO}_{2 \text { pico }}{ }^{(115)}$.

Posteriormente, o mesmo grupo de pesquisadores, agora liderados pelo Dr. Andrew Williams e utilizando o mesmo protocolo de ER previamente descrito, demonstraram de forma pioneira, que tal modalidade de exercício foi capaz de aumentar a capacidade oxidativa do musculo esquelético por meio do aumento da citrato sintase, uma enzima fundamental no primeiro passo do ciclo de Krebs, e na taxa de produção de ATP muscular. Estas respostas foram correlacionadas diretamente com os achados de aumento significativo de $\mathrm{VO}_{2 \text { pico }}$ e de limiar de lactato em pacientes com ICFEr e comprovaram que a melhora funcional do musculo esquelético com a imposição de ER é um forte preditor de melhora da capacidade ao exercício nestes pacientes ${ }^{(76)}$. Em outro estudo, Feiereisen e colaboradores demonstraram um aumento significativo do $\mathrm{VO}_{2 \text { pico }}$ com o ER em pacientes com ICFEr (FE < $35 \%$ ) com magnitude de melhora em $16 \%$, valor este considerado elevado tendo em vista valores médios de aumento desta variável em torno de $3 \%$ em indivíduos saudáveis sedentários. Estes valores tiveram uma tendência de estarem mais elevados, apesar de estatisticamente não significativos, quando o componente resistido estava presente, do que nos pacientes submetidos a apenas o EA. Outro dado importante é que o ganho de força muscular nestes pacientes parece ter ocorrido de forma concomitante à melhora de $\mathrm{VO}_{2 \text { pico }}$ durante o estudo, podendo esta melhora na capacidade de exercício estar relacionada fortemente ao incremento de força muscular resultante do ER ${ }^{(76)}$. Estes resultados corroboram estudos que correlacionam à fraqueza muscular esquelética à limitação de exercício em pacientes com IC ${ }^{(116)}$.

Os achados de Feiereisen, confirmam achados prévios de Koch e colaboradores ${ }^{(16)}$, que obtiveram um aumento de $34 \%$ no desempenho durante o teste cardiopulmonar após três meses de um programa de ER o qual atribuem esta melhora aos efeitos desta modalidade de exercício nos vasos periféricos. Todavia, Estes resultados contrastam com os achados de Jakovljevic e colaboradores, que não observação benefícios do ER no $\mathrm{VO}_{2 \text { pico. }}$ Os autores afirmam que apesar da perda de massa muscular ser uma característica marcante em pacientes com IC, a melhora da capacidade de exercício parece estar mais relacionado a adaptações centrais do que periféricas ao exercício, já que uma melhora significativa do DC à custa de um maior Volume Sistólico (VS) ocorreu apenas no grupo de EA e esta se correlacionou positivamente a melhora do $\mathrm{VO}_{2 \text { pico }}{ }^{(117)}$. No entanto, algumas considerações tornam-se pertinentes aos resultados deste estudo. Em primeiro lugar 
não estão descritas de forma clara as estratégias de prescrição de ER como, por exemplo, nível de intensidade e nem tampouco os autores fazem uma análise de ganho de força muscular dos participantes do estudo. Segundo, apesar do estudo de Jakovljevic ter sido realizado em cinco dias da semana, apenas uma sessão do programa de treinamento foi realizada de forma supervisionada, o que pode ter interferido nos resultados do estudo. Adicionalmente, apesar de não ter sido o foco principal do estudo, Maiorana e colaboradores ${ }^{(118)}$ obtiveram aumento significativo do $\mathrm{VO}_{2 \text { pico }}$ e de magnitude equivalente ao EA com o ER em pacientes com ICFE que foram submetidos a 12 semanas de treinamento com até $70 \%$ de 1-RM. Achados adicionais foram de que a redução da espessura da artéria braquial e aumento de força muscular foram obtidos apenas com ER, demonstrando novamente uma relação entre a melhora do componente periférico na recuperação da capacidade funcional em pacientes com ICFEr.

\subsubsection{Efeitos do exercício resistido isolado no remodelamento cardíaco}

O efeito anti-remodelamento foi demonstrado por Feiereisen e colaboradores ${ }^{(12)}$ por meio da imposição de ER, com aumento significativo da FEVE e redução do VDFVE de $18 \%$ e $-11 \%$, respectivamente. De forma bastante interessante, o fato de que o ganho de FEVE no grupo de EA tenha sido duas vezes maior em relação ao ER, este aumento não se traduziu em uma melhora proporcionalmente maior do $\mathrm{VO}_{2 \text { pico }}$ no grupo de aeróbico, ainda sendo maior nos pacientes submetidos à ER. Esta observância de resultados nos leva a uma inferência de que o ganho de capacidade de exercício pode estar mais relacionado a fatores periféricos, do que em benefícios obtidos em componentes centrais resultantes do treinamento Físico. Resultados similares de ganho de função ventricular foram descritos por Palevo e colaboradores. Utilizando um método semelhante de prescrição de ER, os autores demonstraram um incremento na FEVE e VS da ordem de $16 \%$ e $15 \%$ respectivamente. Adicionalmente, apesar de não ter sido mensurada capacidade de exercício por meio do $\mathrm{VO}_{2 \text { pico }}$ neste estudo, esta melhora na função de VE se correlacionou com aumento da distância caminhada no TC6 $_{\min }$ e com o aumento de Força muscular esquelética superior a $20 \%{ }^{(18)}$. Estes resultados reforçam a hipótese da interferência do componente periférico na melhora dos índices de capacidade funcional. Um achado interessante tinha sido obtido por Levinger e colaboradores em 2005, quando os autores analisaram os efeitos do ER em um programa mais curto de treinamento. Eles observaram um ganho na FEVE, que apesar de 
consistente $(13,4 \%)$, não foi estatisticamente significativo na comparação entre os valores basais e de pós-treinamento. Entretanto, na comparação com o grupo controle, os valores desta variável eram estatisticamente significativos após o programa de exercício. Adicionalmente, uma perda de pouco mais de $12 \%$ em relação aos valores basais no grupo controle, deixa claro que mesmo que não haja um aumento significativo das variáveis de remodelamento, tal modalidade de exercício possui papel fundamental na inibição da piora da função de VE em pacientes com ICFEr ${ }^{(17)}$. Os autores atribuem esta estabilidade cardíaca funcional a uma possível redução da RVP e consequente redução da sobrecarga ventricular esquerda.

4.1.3.5. Efeitos do exercício resistido combinado no consumo de oxigênio de pico

O Exercício Combinado (EC) tem sido associado a modificações importantes na Capacidade de Exercício e parâmetros funcionais do VE. Achados de Stolen e colaboradores aumentam as evidências de que este tipo de treinamento aumenta a eficiência miocárdica por meio de uma redução do metabolismo oxidativo ventricular. Este melhor desempenho metabólico se dá em virtude da modificação do substrato energético utilizado pelo musculo miocárdico, passando de uma utilização de ácidos graxos para a oxidação de glicose. Outros mecanismos de melhora do desempenho ventricular se relacionam a redução da pós-carga de VE e redução da atividade adrenérgica para o coração e vasos de resistência. Adicionalmente, observa-se uma melhora na FEVE com uma forte correlação com o desempenho durante o exercício e aumento de $\mathrm{VO}_{2 \text { pico }}{ }^{(119)}$. Um grande estudo delineado para verificar os efeitos do EC em um protocolo longo de tratamento, com três meses iniciais de RC supervisionada seguido de nove meses de treinamento não supervisionado, com EA com intensidade de 60 a $70 \%$ da FC máxima, associado ao ER com intensidade de 40 a 70\% de 1-RM em 181 pacientes com ICFEr, demonstraram melhora significativa no $\mathrm{VO}_{2 \text { pico }}$ em $14 \%$ e da força muscular esquelética ${ }^{(120)}$. Os efeitos do EC na atividade simpática de pacientes com ICFEr foram estudados previamente por Roveda e colaboradores por meio da monitoração da atividade nervosa simpática muscular com Microneurografia. Após um programa de dezesseis semanas com intensidade ajustada em 10\% abaixo do Ponto de Compensação Respiratória $\left(\mathrm{PC}_{\text {resp }}\right)$, o estudo demonstrou valores tão baixos de atividade simpática muscular quanto os encontrados em indivíduos saudáveis ${ }^{(121)}$. Apesar de os autores não especularem de forma mais aprofundada os mecanismos responsáveis por este achado, os mesmos excluem os 
mecanismos centrais, tendo em vista uma não mudança significativa dos valores de FEVE após o programa de exercícios. Esta afirmação nos faz atribuir estes efeitos a mudanças periféricas provocadas pelos efeitos do ER como parte do treinamento. Estes achados estão em conformidade com os resultados de Antunes-Correia e colaboradores, que reduziram a atividade simpática muscular de repouso de pacientes com ICFEr após um programa de EC com intensidade ajustada em $70 \%$ do $\mathrm{VO}_{2 \text { pico, }}$, melhorando o controle do metaboreflexo e mecanoreflexo nestes pacientes reforçando a hipótese da interferência da miopatia característica de pacientes com ICFEr no controle reflexo do SNA durante o exercício ${ }^{(122)}$. No entanto, Sabelis e Colaboradores, não obtiveram sucesso em demonstrar redução dos níveis de Endotelina-1 (ET-1) após 26 semanas de EC com 50\% do programa realizado de Forma não supervisionada a uma intensidade de $50 \%$ da capacidade de exercício atingida no TCP. Os resultados também abrangem uma não modificação do $\mathrm{VO}_{2 \text { pico. Entretanto, os }}$ autores demonstraram um comportamento favorável do EC após o período de treinamento na liberação de Fator de Von Willebrand, um polímero com papel importante no mecanismo de adesão plaquetária no subendotélio ${ }^{(123)}$. Estes achados estão de acordo com os encontrados por De Meirelles e colaboradores, que demonstraram uma redução da agregação plaquetária com benefícios antioxidantes e anti-inflamatórios com o EC em relação ao grupo controle, além de um aumento significativo do $\mathrm{VO}_{2 \text { pico }}{ }^{(124)}$. Posteriormente, o mesmo protocolo de treinamento foi repetido por Senden e colaboradores, demonstrando melhora da força e massa muscular, assim como da endurance, porem novamente sem melhora significativa do $\mathrm{VO}_{2 \text { pico }}{ }^{(125)}$, demonstrando apenas o efeito positivo da adição do ER no programa de EA. De Mello Franco e colaboradores observaram que os ganhos no $\mathrm{VO}_{2 \text { pico }}$ e de que queda na atividade simpática muscular em um programa de 16 semanas de EC ajustados à $10 \%$ do $\mathrm{PC}_{\text {resp }}$ não puderam ser mantidos após mais 16 semanas de exercício não supervisionado. De forma semelhante, a realização de EC no estudo de Dracup e colaboradores ${ }^{(126)}$ de forma não supervisionada mesmo com supervisão semanal, não conseguiu melhorar as variáveis de capacidade de exercício em pacientes com ICFEr, reforçando o estudo de Mello Franco. Estes resultados despertam para o desafio imposto pela $\mathrm{RC}$ não supervisionada em conseguir manter os mesmos níveis de intensidade obtidos pelo treinamento supervisionado e desta forma perdurar seus efeitos em longo prazo. Em contrapartida, os efeitos de redução na RVP e melhora da qualidade de vida se mantiveram após oito meses, porem isso não repercutiu na manutenção da melhora da capacidade de exercício. Adicionalmente, Mandic e colaboradores, condicionam a melhora do $\mathrm{VO}_{2 \text { pico }}$ após EC a uma adesão ao treinamento acima de $80 \%$ e salientam a importância do componente resistido do exercício na melhora da força e 
endurance muscular ${ }^{(8)}$. Segundo Jónsdóttir e colaboradores, apesar da não significância dos valores de $\mathrm{VO}_{2 \text { pico }}$ após um programa de $\mathrm{EC}$, a adição do ER, mesmo com intensidade leve a moderada, gerou um aumento significativo da força muscular e isso influenciou diretamente a melhora de outras variáveis de capacidade de exercício, como a distância no TC6 e o maior tempo e carga obtida durante o teste em cicloergômetro ${ }^{(127)}$. Estes resultados corroboram com os achados obtidos por Beckers e colaboradores, com similaridades encontradas nos valores de $\mathrm{VO}_{2 \text { pico }}$ tanto após EA quanto após $\mathrm{EC}$, mas com melhora significativamente maior na força muscular esquelética, capacidade funcional submáxima e da qualidade de vida somente após EC. Por fim, os autores ressaltam a segurança da adição do ER ao programa de EA ${ }^{(10)}$.

Adicionalmente, Feiereisen e colaboradores conseguiram demonstrar em seu estudo que a intensidade tanto do EA quanto do ER combinados pode ser fatores importantes na geração de bons resultados em todas as variáveis cardiovasculares. Desta forma, a aplicação de EA e ER de alta intensidade $\left(75 \%\right.$ do $\mathrm{VO}_{2 \text { pico }}$ e $70 \%$ de 1-RM, respectivamente) ocasionou aumento de $\mathrm{VO}_{2 \text { pico }}$ na magnitude de $14 \%$, com aumento proporcional da Força muscular e impacto direto na qualidade de vida ${ }^{(12)}$. Estes achados corroboram com estudo posterior de Bouchla e colaboradores, onde o aumento do $\mathrm{VO}_{2 \text { pico }}$ no grupo de $\mathrm{EC}$ apesar de estatisticamente não significativo, foi de uma magnitude de quase o dobro do aumento no EA (variação entre pré e pós treinamento de $1,3 \mathrm{ml} \cdot \mathrm{Kg}^{-1} \cdot \mathrm{min}^{-1}$ e $2,3 \mathrm{ml} \cdot \mathrm{Kg}^{-1} \cdot \mathrm{min}^{-1}$, respectivamente). Um achado adicional consistiu no aumento de Força muscular esquelética, mais uma vez presente apenas no grupo de $\mathrm{EC}^{(128)}$. De uma forma bastante semelhante, a imposição de EC com componente aeróbico intervalado de alta intensidade associado à ER gerou uma magnitude de elevação duas vezes maior no $\mathrm{VO}_{2 \text { pico, }}$ em relação ao EA também intervalado e de alta intensidade (variação entre pré e pós treinamento de $1,3 \mathrm{ml} \cdot \mathrm{Kg}^{-1} \cdot \mathrm{min}^{-1} \mathrm{e}$ 2,8 $\mathrm{ml} \cdot \mathrm{Kg}^{-1} \cdot \mathrm{min}^{-1}$, respectivamente), porém sem significância estatística na comparação inter grupos Adicionalmente, o referido estudo enfatiza a relação entre os efeitos benéficos do ER na capacidade de exercício por meio de reestabelecimento da microcirculação periférica, força muscular esquelética, vasoreatividade endotelial e variáveis de recuperação após TCP ${ }^{(129)}$. Estas últimas, mensuradas no estudo de Georgantas e colaboradores, demonstraram ter uma forte correlação com a força muscular esquelética de membros inferiores ${ }^{(130)}$. Um achado não menos importante foi o de um aumento significativo no fluxo sanguíneo miocárdico de reserva em pacientes com ICFEr após EC quando comparados com um grupo controle. Os autores sugerem uma ligação entre o aumento do fluxo miocárdico e a melhora significativa de $\mathrm{VO}_{2 \text { pico }}$ obtida após EC nestes pacientes ${ }^{(131)}$. Em estudo recente, Anagnostakou e 
colaboradores enfatizam os efeitos do ER em adição ao EA intervalado de alta intensidade na maior magnitude de aumento no $\mathrm{VO}_{2 \text { pico }}$ em relação ao EA isolado. Adicionalmente, os efeitos na capacidade de exercício no grupo de EC sugere uma relação com o maior incremento de dilatação mediada pelo fluxo decorrente de maior concentração de vasodilatador dependente do endotélio. Os autores reforçam a importância da inserção do ER em programas de RC para pacientes com ICFEr ${ }^{(129)}$. Um outro mecanismo para melhora do $\mathrm{VO}_{2 \text { pico }}$ foi descrito por Chrysohoou e colaboradores, que relacionaram o aumento significativo desta variável em seu estudo à uma redução na velocidade de onda de pulso que se traduz em redução da rigidez arterial permitindo uma melhor performance tanto do coração quanto do vaso, resultando em um sistema arterio-ventricular mais funcional ${ }^{(132)}$. A adição de treinamento muscular respiratório (TMR) ao EC com componente aeróbico de moderada intensidade (70\%-80\% $\mathrm{FC}_{\text {máx }}$ ) elevou o $\mathrm{VO}_{2 \text { pico }}$ em um nível de significância maior quando comparada ao grupo de EA. Além disso, outras diferenças significativas foram obtidas com EC, como na força muscular respiratória e esquelética, estando esta última mais relacionada ao componente de ER do treinamento ${ }^{(15)}$. Recentemente, Keast e colaboradores testaram os efeitos em pacientes com ICFEr da Nordic walking, uma técnica que utiliza a caminhada sincronizada com movimentos de membros superiores por meio de bastões de caminhada fazendo serem ativados praticamente todos os músculos do corpo de forma harmônica. A aderência destes bastões ao solo e sua posterior liberação atribuem um componente resistivo ao componente aeróbico. Esta modalidade de EA foi comparada a EC consistindo de caminhada convencional associado ao ER com pesos livres e Therabands, por um período de 12 semanas com intensidade ajustada em até $75 \%$ da FC de reserva (FCR) em ambos os grupos. Apesar de factível, não houve diferenças significativas desta modalidade de EA em relação ao grupo de EC na variável de $\mathrm{VO}_{2 \text { pico, }}$ com uma diferença a favor do grupo de EA na força de preensão palmar à direita, porém sem significância clínica importante ${ }^{(133)}$.

\subsubsection{Efeitos do exercício resistido combinado no Remodelamento Cardíaco}

Apesar de não observarem modificações favoráveis ao EC no desfecho de FEVE, McKelvie e colaboradores puderam demonstrar em seu estudo, conhecido como EXERT (Exercise Rehabilitation Trial), que a inclusão do ER ao programa de EA não traz efeitos adversos para a função de VE, como se pode observar por meio das variáveis de FEVE e pela segurança verificada durante todo o programa de treinamento ${ }^{(120)}$. Os resultados pouco 
expressivos nas variáveis de RCV podem ter suas justificativas nas dificuldades encontradas pelos autores no que diz respeito à adesão ao tratamento e pelo fato de a maior parte do programa ter sido realizado de forma não supervisionada. Resultado semelhante foi atribuído a dois estudos publicados posteriormente com a aplicação de protocolo de EC ajustado em $50 \%$ do desempenho atingido no $\mathrm{TCP}^{(123,125)}$. É provável que também a intensidade do exercício possa interferir nos resultados obtidos de capacidade de exercício.

De modo semelhante, os efeitos de inibição de piora do RCV com o exercício físico são reforçados nestes pacientes, apesar de não serem obtidos melhora significativa nas variáveis de função ventricular ${ }^{(8,127,134)}$. Contrariamente a estes resultados, o parâmetro de intensidade de exercício parece ter papel importante também nas variáveis de RC. Isto é demonstrado em estudo prévio onde a aplicação de exercício de alta intensidade, acima de $70 \%$ do $\mathrm{VO}_{2 \text { pico }}$ e de $70 \%$ de 1-RM proporcionam incremento significativo da ordem de quase $30 \%$ na FEVE e de decremento dos VDFVE e VSVE da ordem de $21 \%$ e $15 \%$, respectivamente. Estas modificações parecem ser mais evidentes no EC do que quando os dois componentes são realizados isoladamente ${ }^{(12)}$. Adicionalmente, apesar de não ter sido foco principal do estudo, Antunes-Correia e colaboradores alcançaram um incremento na FEVE da ordem de $15 \%$ com exercício combinado, porém não estatisticamente significativo a despeito de ser quase três vezes maior do que a modificação ocorrida no grupo controle ${ }^{(122)}$. Para Chrysohoou e colaboradores, mesmo não sendo capazes de demonstrar efeitos estatisticamente significativos na FEVE, o seu estudo conseguiu mais uma vez reforçar a hipótese de segurança e de inibição de piora de função e estrutura ventricular, além de obter modificações importantes na função diastólica de VE e complacência arterial com impacto direto na qualidade de vida destes pacientes em virtude de um aumento da capacidade ao exercício ${ }^{(132)}$. 


\section{OBJETIVOS}

\subsection{Objetivo Geral}

Analisar os Efeitos do ER e EC na capacidade ao exercício e remodelamento cardíaco em pacientes com Insuficiência cardíaca com Fração de Ejeção Reduzida

\subsection{Objetivos Específicos}

5.2.1. Investigar os efeitos do ER nas variáveis de $\mathrm{VO}_{2 \text { pico, }}$ FEVE e VDFVE em relação ao grupo controle;

5.2.2. Verificar os efeitos do $\mathrm{EC}$ nas variáveis de $\mathrm{VO}_{2 \text { pico, }}$ FEVE e VDFVE em associação ao grupo controle;

5.2.3. Analisar do ER nas variáveis de $\mathrm{VO}_{2 \text { pico }}$, FEVE e VDFVE em associação com EA e EC;

5.2.4. Averiguar do $\mathrm{EC}$ nas variáveis de $\mathrm{VO}_{2 \text { pico, }}$ FEVE e VDFVE em comparação com EA e ER. 


\section{MÉTODOS}

\subsection{Estratégia de Pesquisa}

Foi realizada uma revisão sistemática e meta-análise em conformidade com as recomendações e critérios descritos nos itens de relatório preferido para revisões sistemáticas e meta-análises (PRISMA) e Cochrane Handbook ${ }^{(135)}$. O referido protocolo foi devidamente registrado no banco de dados PROSPERO (www.crd.york.ac.uk/prospero/) sob o número: CRD42014013857.

\subsection{Fontes de dados}

Potenciais estudos foram identificados por uma base de dados de avaliação sistemática. A revisão sistemática foi realizada nas seguintes bases de dados: MEDLINE (Ovíd) (1950 a Março de 2016); EMBASE (1974-2016), The Cochrane e CINAHL (19812016); Amedeo (1997-2016) e base de dados PEDro (1929-2016). A estratégia de busca envolveu o cruzamento de dados de palavras-chave selecionadas com base nos assuntos médicos (Mesh) - Biblioteca Nacional de Medicina dos Estados Unidos e termos livres para palavras-chave (intervenção + população), com filtros para limitar a pesquisa a ensaios clínicos (Fases I- IV), estudos clínicos, ensaios clínicos controlados, estudos multicentricos, ensaios clínicos pragmáticos, ensaios controlados randomizados e revisões sistemáticas. Não houve restrição de idioma. A pesquisa incluiu artigos publicados até março de 2016. As seguintes palavras-chave foram utilizadas para: i) intervenção: "Resistance exercise” [Mesh] OR "Muscle Contraction" [Mesh] OR "Muscle Strength"[Mesh] OR "Muscle Strenght Dynamometer"[Mesh] OR “Exercise”[Mesh] OR "Exercise Therapy"[Mesh] OR Exercise Tolerance"[Mesh] OR "Exercise Test"[Mesh] OR "Physical Education and Training" [Mesh] OR "Physical and Rehabilitation Medicine" [Mesh] OR "Physical Fitness " [Mesh] OR "Physical Exertion" [Mesh] OR "Physical Endurance" [Mesh]; ii) Desfechos: "Myocardium" [Mesh] OR "Myocardial Contraction" [Mesh] OR "Cardiomyopathies" [Mesh] OR "Ventricular Remodeling" [Mesh] OR "Atrial Remodeling" [Mesh]; e iii) População de estudo: "Heart Failure" [Mesh] OR "Cardiomegaly"[Mesh] OR "Myocytes, Cardiac"[Mesh]. 
Os estudos foram avaliados com base nas diretrizes da Cochrane ${ }^{(135)}$. Os autores avaliaram inicialmente os estudos pelo título e resumo (tipo de desenho do estudo, descrição da população e informações sobre as intervenções) para a elegibilidade. Após a seleção dos estudos potencialmente relevantes, as versões de texto completo foram analisadas no que diz respeito à qualidade metodológica por dois pesquisadores de forma independente.

\subsection{Tipos de Estudos e Participantes}

Os seguintes critérios foram adotados para a seleção dos estudos: Ensaios Clínicos Randomizados com ou sem uma estratégia de cross-over; intervenções envolvendo exercícios físicos baseados em The Cochrane Review Handbook ${ }^{(135)}$ e um grupo de comparação submetida a Exercício Resistido, Exercício Combinado (Exercício aeróbico + exercício resistido), o Exercício Aeróbico ou um grupo controle. A população foi constituída de indivíduos adultos com diagnóstico de Insuficiência Cardíaca com disfunção Sistólica (com base nos achados clínicos e índices objetivos, como a fração de ejeção <45\% e classe funcional I a IV) com idade de 45 a 65 anos (de meia-idade). Estudos com amostra de indivíduos exclusivamente de idosos (>60 anos) foram excluidos.

\subsection{Tipos de Intervenção e desfechos}

Consideramos Exercício Resistido isolado, o Exercício Aerobico isolado, ou uma combinação de ambas as intervenções realizadas no hospital, ambulatório ou configurações de intervenção em casa. O grupo de exercício resistido, isoladamente ou combinado, foi comparado a um grupo de exercício aeróbico ou grupo controle. O grupo de exercício aeróbico foi comparado apenas ao grupo controle. As intervenções necessárias para incluir o estudo obedeceram aos seguintes parâmetros: 1) Freqüência: 2-4 dias por semana; 2) Duração: mínimo de 8 até 26 semanas; 3) Intensidade: 50-90\% da frequência cardíaca máxima $\left(\mathrm{FC}_{\text {máx }}\right) ; 50-80 \%$ do $\mathrm{VO}_{2 \text { pico }}$ para o Exercício Aeróbico e $40-80 \%$ de uma repetição máxima (1-RM) para o Exercício Resistido.

Os desfechos clínicos avaliados envolviam, pelo menos, uma das seguintes variáveis: Consumo de Oxigênio de pico $\left(\mathrm{VO}_{2 \text { pico, }} \mathrm{ml} \bullet \mathrm{kg}^{-1} \cdot \mathrm{min}^{-1}\right)$, Fração de Ejeção do 
Ventriculo Esquerdo (FEVE, \%) e Volume Diastólico Final do Ventrículo Esquerdo (VDFVE, $\mathrm{mL}$ ).

\subsection{Extração dos Dados}

Todos os dados relevantes sobre os critérios de inclusão (tipo de estudo, a população, as intervenções (incluindo tipo de exercício, intensidade, frequência, duração e modalidade), comparação e resultados), risco de viés (randomização, cegamento e presença de um grupo de controle) e resultados foram extraídos a partir de todos os estudos selecionados. Um único pesquisador realizou o procedimento de extração e um segundo pesquisador a examinou. Quaisquer divergências foram resolvidas por consenso.

\subsection{Avaliação de Qualidade}

Um pesquisador avaliou a qualidade e risco de viés de forma independente, utilizando a escala PEDro ${ }^{(136)}$ desenvolvida com base na lista Delphi por Verhagen e colaboradores ${ }^{(137)}$. Um segundo pesquisador analisou novamente os dados. Esta escala inclui os seguintes itens a serem avaliados: critérios de elegibilidade, randomização, ocultação da alocação, semelhança nos dados iniciais, cegamento de assuntos, cegamento de terapeutas, cegamento de avaliadores, seguimento adequado, a análise de intenção de tratamento, a análise estatística entre os grupos e o uso de medidas.

\subsection{Análise dos dados}

As mudanças relativas $\left(\mathrm{VO}_{2 \text { pico }}\right)$ e absolutas (FEVE e VDFVE) foram relatadas como diferenças entre médias aritméticas antes e depois das intervenções. Os resultados de análises de intenção de tratamento foram inseridos sempre que disponível nos ECR's incluídos. Estimativas de efeito combinado foram obtidas por comparação da porcentagem dos quadrados mínimos da média de alteração para o final do estudo para cada grupo, e foram expressos como a diferença da média ponderada (WMD) entre os grupos. Os cálculos foram realizados utilizando um modelo de efeitos aleatórios. Os testes de diferenças de subgrupos com base em modelos de efeitos aleatórios podem ser considerados como preferíveis a aqueles com base em modelos de efeito fixo, devido ao elevado risco de resultados falsos 
positivos quando se comparam subgrupos em um modelo de efeito fixo (135). Quatro comparações foram feitas com cada grupo sendo comparado com um grupo sem intervenção (controle): Exercício Aeróbico, Exercício Resistido, Exercício Combinado (Aeróbico + Resistido) e controle. Um valor $\alpha=0,05$ foi considerado estatisticamente significativo. A análise do viés de publicação foi realizada usando gráfico de Funnel Plot para a magnitude do efeito de cada estudo em relação ao erro padrão. A Assimetria do Funnel Plot foi avaliada pelos testes de Egger ${ }^{(135)}$.

A heterogeneidade estatística do efeito do tratamento entre os estudos foi avaliada pelo teste $\mathrm{Q}$ de Cochrane com um valor de $P<0,1$ considerado estatisticamente significativo e a análise de sensibilidade foi avaliada pelo teste $\mathrm{I}^{2}$ em que valores superiores a $50 \%$ foram considerados como indicativos de elevada heterogeneidade ${ }^{(135)}$. A heterogeneidade entre estudos incluídos foi também explorada. Primeiro, foram executadas novamente as metaanálises removendo um estudo de cada vez para verificar se um determinado estudo poderia explicar a heterogeneidade. Em segundo lugar, foi realizada a análise de sensibilidade para avaliar subgrupos de estudos com maior probabilidade de produzir estimativas válidas da intervenção com base em informações clínicas relevantes pré-especificadas. Todas as análises foram realizadas utilizando Review Manager versão 5.0. 


\section{RESULTADOS}

\subsection{Seleção e Avaliação dos Estudos}

A busca inicial identificou 4.919 estudos a cerca de exercícios aeróbicos e exercícios de resistência (isoladamente ou em combinação com exercícios aeróbicos) envolvendo pacientes com ICFEr. Dois estudos duplicados foram removidos $(n=4917)$. Depois da análise de título e resumo, foram excluídos 4.827 estudos inelegíveis com base em critérios de inclusão (Figura 6). Trinta e um estudos não eram elegíveis após análise de texto completo: 15 estudos sobre ER isolado ou $\mathrm{EC}^{(92,113,138-150)}$ e 16 estudos sobre o exercício aeróbico ${ }^{(84,151-165)}$ foram excluídos por: a) ausência de grupo comparativo; b) os resultados analisados não foram mostrados; c) protocolo não está de acordo; d) média e desvio padrão de dados não mostrados; e) efeitos agudos do exercicio; e f) IC com FE preservada (Tabela 2).

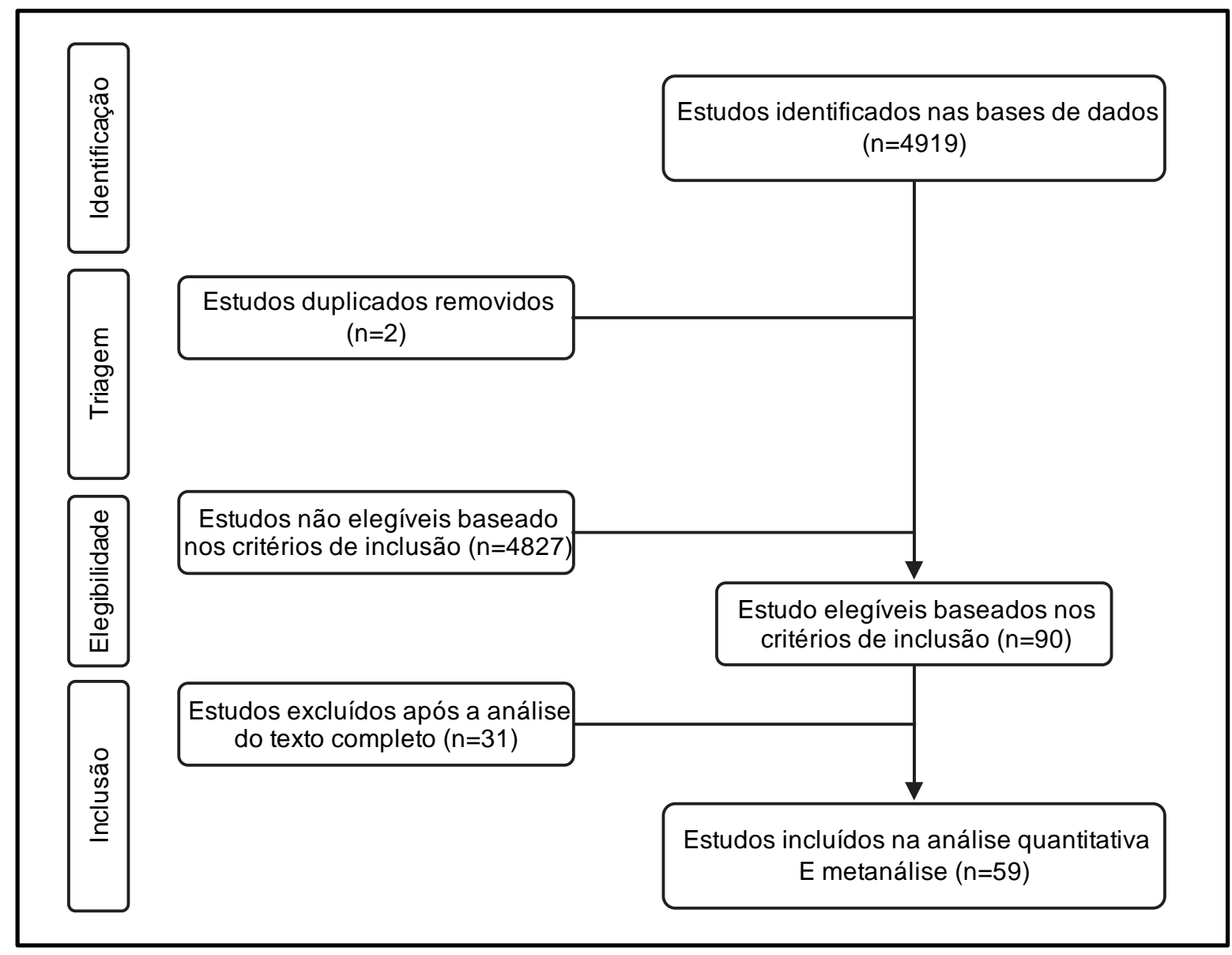

Figura 6. Fluxograma de análise e seleção dos Estudos. Fonte: Resultados do presente estudo 
Tabela 1. Razões para exclusão dos estudos

\begin{tabular}{ll}
\hline Estudo (ref), Ano & Razão para exclusão \\
\hline Maiorana e cols. (114), 2000 & \\
Larsen e cols. (152), 2001 & \\
Miche e cols. (148), 2008 & Ausência de Grupo Comparativo \\
Karapolat e cols. (153), 2009 & \\
Savage e cols. (149), 2011 & \\
Aslanger e cols. (139), 2015 & \\
\hline
\end{tabular}

Hambrecht e cols. (154), 1998

Myers e cols. (92), 2002

Jankowska e cols. (146), 2007

Gary e cols. (144), 2011

Gary e cols. (145), 2012

Keteyian e cols. (154), 2012

Não mostra os desfechos analisados

Cowie e cols. (156), 2012

Mentz e cols. (157), 2013

Ahmad e cols. (155), 2014

Owen e cols. (149), 2000

Coats e cols. (151), 1992

Tyni-Lenné e cols. (150), 1997

Besson e cols. (160), 2013

O Protocolo não está de acordo

Koufaki e cols. (161), 2014

Delagardelle e cols. (142), 2002

Kemps e cols. (147), 2010

Nishi e cols. (162), 2011

Média e DP não mostrados no estudo

Caminiti e cols. (140), 2011

Belardinelli e cols. (163), 2012

Taylor e cols. (164), 1999

Cheetham e cols. (141), 2002

Efeitos agudos do Exercício Resistido

Kitzman e cols. (166), 2010

Edelmann e cols. (143), 2011

Smart e cols. (167), 2012

Insuficiência Cardíaca sem disfunção Sistólica

Kitzman e cols. (165), 2013

Fonte: Resultados do presente estudo

\subsection{Estudos incluídos na revisão sistemática}

A data de publicação variou de 1992 a 2015, envolvendo um total de 5.046 pacientes, $3.939(78,1 \%)$ do sexo masculino com a média de idade em 58,2 \pm 7,99 anos. Os pacientes com IC estavam clinicamente estáveis, com classificação da classe funcional pela 
New York Heart Association entre I e IV. Os valores de FEVE variaram de 20-45\%. A média de frequência de realização tanto para ER isolado ou EC foi de 3,0 \pm 0,49 dias por semana, com uma duração média de 49,8 $\pm 16,7$ minutos por sessão e duração média de protocolo de 17,8 \pm 4,9 semanas. A frequência média de EA foi de $4 \pm 1,76$ vezes por semana, com uma duração média de 44,9 \pm 14,9 minutos por sessão e duração média de protocolo de 17,8 \pm 8,6 semanas. A intensidade do EA variou de $50-80 \%$ do $\mathrm{VO}_{2}, 40-90 \%$ da $\mathrm{FC}_{\text {máx }}$ ou $40-80 \%$ da FCR. A intensidade do ER variou de 30-90\% de 1-RM (Tabela 2). A Heterogeneidade entre os estudos foi baixa (P <50\%), com exceção de análise comparativa entre EC e grupo controle (I2 $=69 \%$ ), para o desfecho de $\mathrm{VO}_{2 \text { pico. }}$ O Exercício combinado foi comparado com: exercício

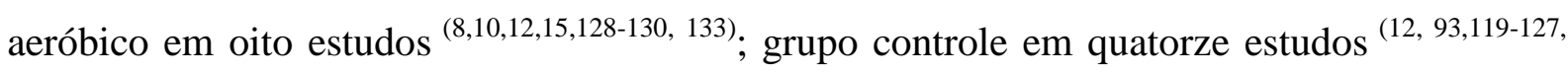
${ }^{131,134,169)}$; e ER isolado em um estudo ${ }^{(12)}$. Os ER isolado foi comparado com: EA em três estudos ${ }^{(12,117,118)}$; Grupo controle em oito estudos ${ }^{(12,16-18,112,115,118,170)}$. Trinta e dois estudos compararam o EA com um grupo controle ${ }^{(9,11,12,77,78,81,83-89,92-102,105,106,171-176)}$. A análise de qualidade dos estudos usando a escala PEDro demonstrou escores medianos, que variaram de 4 a 7 pontos, tanto para o ER isolado, quanto para o EC, bem como o EA. Os gráfcos de Funnel plot gerados para análise do viés de publicação são mostrados nas figuras 6 e 7 . O nível de concordância entre os revisores, que foi calculado utilizando o coeficiente Kappa, foi 0,95 (IC 95\%: 0,88-1,0). 
Tabela 2. Descrição dos Estudos envolvendo exercício resistido isolado e/ou combinado incluídos na revisão sistemática e metanálise. (continua)

\begin{tabular}{|c|c|c|c|c|c|c|c|c|c|c|c|}
\hline \multicolumn{2}{|l|}{ Estudo (ref), ano } & \multirow{4}{*}{$\begin{array}{c}\text { Pacientes } \\
\\
\text { IC CF I-III / } \\
\text { FEVE }<40 \%\end{array}$} & \multicolumn{2}{|c|}{$\begin{array}{c}\text { Amostra } \\
(\mathbf{n})\end{array}$} & \multirow{4}{*}{$\begin{array}{c}\begin{array}{c}\text { Idade } \\
\text { (Média } \pm \text { DP) }\end{array} \\
56 \pm 11 \\
54 \pm 10 \\
75 \pm 5\end{array}$} & \multirow{4}{*}{$\begin{array}{c}\text { Desfechos } \\
\text { FEVE }\end{array}$} & \multirow{4}{*}{$\begin{array}{c}\text { Descrição da Intervenção } \\
\begin{array}{c}\text { sessões no banco de KOCH - Grupos } \\
\text { musculares menores }\end{array}\end{array}$} & \multirow{4}{*}{$\begin{array}{c}\begin{array}{c}\text { Frequência } \\
\text { (d/sem) }\end{array} \\
3\end{array}$} & \multirow{4}{*}{$\begin{array}{c}\text { Duração da } \\
\text { Sessão (min) } \\
90\end{array}$} & \multirow{4}{*}{$\begin{array}{c}\begin{array}{c}\text { Duração do } \\
\text { programa (sem) }\end{array} \\
12\end{array}$} & \multirow{4}{*}{$\begin{array}{c}\text { PEDro } \\
\text { score } \\
5\end{array}$} \\
\hline \multirow{3}{*}{ Koch e cols. (16) } & \multirow{3}{*}{1992} & & ER & 12 & & & & & & & \\
\hline & & & $\mathrm{EC}$ & 13 & & & & & & & \\
\hline & & & GC & 7 & & & & & & & \\
\hline \multirow{2}{*}{ Tyni-Lenné e cols. (112) } & \multirow{2}{*}{2001} & \multirow{2}{*}{$\begin{array}{l}\text { IC CF II-III / } \\
\text { FEVE } \leq 40 \%\end{array}$} & ER & 16 & $63 \pm 9$ & \multirow{2}{*}{$\mathrm{VO}_{2 \text { pico }}$} & \multirow{2}{*}{$\begin{array}{l}\text { Borg < } 12 \text { (central) e } 13 \text { a } 16 \text { (muscular) } \\
\text { (Therabands de seis cores diferentes) }\end{array}$} & \multirow{2}{*}{3} & \multirow{2}{*}{60} & \multirow{2}{*}{8} & \multirow{2}{*}{5} \\
\hline & & & GC & 08 & $62 \pm 11$ & & & & & & \\
\hline \multirow{2}{*}{ McKelvie e cols. (120) } & \multirow{2}{*}{2002} & \multirow{2}{*}{$\begin{array}{l}\text { IC CF I-III / } \\
\text { FEVE }<40 \%\end{array}$} & EC & 90 & $64,8 \pm 1,1$ & \multirow{2}{*}{$\begin{array}{l}\mathrm{FEVE}+ \\
\text { VDF }\end{array}$} & \multirow{2}{*}{$\begin{array}{l}\text { EA: 60-70\% FCmáx (ciclo MMII + esteira + } \\
\text { ciclo MMSS) + ER: 40-60\% 1RM }\end{array}$} & \multirow{2}{*}{3} & \multirow{2}{*}{30} & \multirow{2}{*}{$\begin{array}{c}12 \text { (Superv) } \\
36 \text { (casa) }\end{array}$} & \multirow{2}{*}{7} \\
\hline & & & GC & 91 & $66,1 \pm 0,9$ & & & & & & \\
\hline \multirow{2}{*}{ Stolen e cols. (119) } & 2003 & IC CF I-III / & $\mathrm{EC}$ & 9 & $55 \pm 8$ & $\mathrm{VO}_{2 \text { pico }}+$ & EA: $50 \%-70 \% \mathrm{VO}_{2 \text { pico }}($ ciclo $)+\mathrm{ER}$ & 3 (EA) & 45 & 20 & 5 \\
\hline & 2000 & FEVE $<40 \%$ & GC & 7 & $55 \pm 8$ & FEVE & (tronco + MMSS e MMII) Borg + FC & $2(\mathrm{ER})$ & 45 & 20 & 5 \\
\hline Roveda e cols (121) & 2003 & IC CF II-III / & $\mathrm{EC}$ & 7 & $53 \pm 9$ & $\mathrm{VO}_{2 \text { pico }}+$ & EA: Até10\% abaixo PCR (ciclo) + ER: & 3 & 60 & 16 & 6 \\
\hline 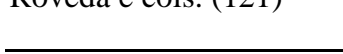 & 2005 & $\mathrm{FEVE} \leq 40 \%$ & GC & 9 & $46 \pm 5$ & FEVE & Local (sit-up + push-up + pull-up) & $\mathrm{J}$ & 00 & 10 & 0 \\
\hline Selig e cols (115) & 2004 & IC CF II-IV / & $\mathrm{EC}$ & 14 & $65 \pm 13$ & $\mathrm{VO}$ & Circuito treinamento com EA e ER (multi- & 3 & 12 & 12 & 5 \\
\hline & & FEVE $<40 \%$ & GC & 19 & $64 \pm 9$ & $\mathrm{U}_{2 \text { pico }}$ & estação e ciclo) - Intensidade moderada & & 12 & 12 & 3 \\
\hline Sobolice cols (123) & 2004 & IC CF II-III / & $\mathrm{EC}$ & 16 & $59,6 \pm 8,3$ & $\mathrm{VO}_{2 \text { pico }}+$ & EA: 70\% FCmáx (endurance) + ER 50\% & 2 (superv) & 60 (superv) & 26 & 5 \\
\hline Sabens e cors. (12J) & 2004 & FEVE $<40 \%$ & GC & 13 & $60 \pm 8$ & & (grandes grupos musculares) & 2 (casa) & 11 (casa) & 20 & $J$ \\
\hline Senden e cols (125) & 2005 & IC CF II-III / & $\mathrm{EC}$ & 25 & $59,8 \pm 9,3$ & & Casa: ER (grandes grupos musculares) + & 2 (superv) & & & 4 \\
\hline Senden e cols. (12J) & 2005 & FEVE $<35 \%$ & GC & 36 & $59,8 \pm 9,3$ & $\sqrt{2 \text { pico }}$ & desempenho no TR) + ER (70\% FCpico) & 2 (casa) & $>11$ & 20 & 4 \\
\hline Levinger e cols. (17) & 2005 & IC CF II-IV / & ER & 8 & $57,3 \pm 11$ & FEVE & ER: $40 \%-60 \%$ 1-RM (9 exercícios para os & 3 & 50 & 8 & 5 \\
\hline & & FEVE $<40 \%$ & GC & 7 & $56,7 \pm 10$ & $1 \mathrm{LV}$ & grandes grupos musculares) & & 50 & 0 & $J$ \\
\hline de Mello Franco e cols. & 2006 & IC CF II-III / & $\mathrm{EC}$ & 17 & $56 \pm 2,9$ & $\mathrm{VO}_{2 \text { pico }}+$ & Endurance (Ciclo - 20 a 40min) + ER local & 3 & 60 & 16 & 5 \\
\hline$(134)$ & & FEVE $<40 \%$ & GC & 12 & $52 \pm 2,2$ & FEVE & (10min) to $10 \%$ do PCR. & & 00 & 10 & J \\
\hline Jonsdolttir e cols (127) & 2006 & IC CF II-III / & $\mathrm{EC}$ & 21 & $68 \pm 6.6$ & $\begin{array}{l}\mathrm{VO}_{2 \text { pico }}+ \\
\text { FEVE + }\end{array}$ & EA: $50 \%$ pico (ciclo) + ER: $20 \%-40 \% 1-$ & 2 & 50 & 20 & 4 \\
\hline Jonsaortur e cols. (127) & 2000 & FEVE $<45 \%$ & GC & 22 & $69 \pm 5.3$ & VDF & RM (circuito - pesos livres e therabands) & 2 & J & 20 & $T$ \\
\hline
\end{tabular}


Tabela 2. Descrição dos Estudos envolvendo exercício resistido isolado e/ou combinado incluídos na revisão sistemática e metanálise. (continuação)

\begin{tabular}{|c|c|c|c|c|c|c|c|c|c|c|c|}
\hline \multicolumn{2}{|l|}{ Estudo (ref), ano } & \multirow{3}{*}{$\begin{array}{l}\text { Pacientes } \\
\text { IC CF II-IV / } \\
\text { FEVE }<40 \%\end{array}$} & \multicolumn{2}{|c|}{$\underset{(n)}{\operatorname{Amostra}}$} & \multirow{3}{*}{$\begin{array}{c}\begin{array}{c}\text { Idade } \\
\text { (Média } \pm \text { DP) }\end{array} \\
53,3 \pm 12,7 \\
54,6 \pm 12,5\end{array}$} & \multirow{3}{*}{$\frac{\text { Desfechos }}{\mathrm{VO}_{2 \text { pico }}}$} & \multirow{3}{*}{$\begin{array}{c}\text { Descrição da Intervenção } \\
\text { Caminhada (40-60\% FCmáx) + ER } \\
\text { grandes grupos musculares (80\% 1-RM) }\end{array}$} & \multirow{3}{*}{$\begin{array}{c}\begin{array}{c}\text { Frequência } \\
\text { (d/sem) }\end{array} \\
4\end{array}$} & \multirow{3}{*}{$\begin{array}{c}\begin{array}{c}\text { Duração da } \\
\text { Sessão (min) }\end{array} \\
60\end{array}$} & \multirow{3}{*}{$\begin{array}{c}\begin{array}{c}\text { Duração do } \\
\text { programa (sem) }\end{array} \\
12\end{array}$} & \multirow{3}{*}{$\begin{array}{c}\text { PEDro } \\
\text { score } \\
6\end{array}$} \\
\hline \multirow{2}{*}{ Dracup e cols. (126) } & \multirow{2}{*}{2007} & & $\mathrm{EC}$ & & & & & & & & \\
\hline & & & GC & 86 & & & & & & & \\
\hline \multirow{2}{*}{ Williams e cols. (170) } & \multirow{2}{*}{2007} & \multirow{2}{*}{$\begin{array}{l}\text { IC CF II-III / } \\
\text { FEVE <40\% }\end{array}$} & ER & 07 & $67 \pm 9$ & \multirow{2}{*}{$\mathrm{VO}_{2 \text { pico }}$} & \multirow{2}{*}{$\begin{array}{c}\text { Intensidade até } 5 \text { bpm abaixo FCmáx } \\
\text { (Sistema multi-estação + Ciclo MMSS e } \\
\text { MMII) }\end{array}$} & \multirow{2}{*}{3} & \multirow{2}{*}{ Não descrito } & \multirow{2}{*}{12} & \multirow{2}{*}{6} \\
\hline & & & GC & 06 & $64 \pm 4$ & & & & & & \\
\hline \multirow{4}{*}{ Feiereisen e cols. (12) } & \multirow{4}{*}{2007} & \multirow{4}{*}{$\begin{array}{l}\text { IC CF II-III / } \\
\text { FEVE <35\% }\end{array}$} & ER & 15 & $57,9 \pm 5,8$ & \multirow{4}{*}{$\begin{array}{l}\mathrm{VO}_{2 \text { pico }}+ \\
\mathrm{FEVE}+ \\
\mathrm{VDF}\end{array}$} & \multirow{4}{*}{$\begin{array}{c}\text { EA: } 60 \%-75 \% \mathrm{VO}_{2 \text { pico }}(\text { ciclo + esteira) } / \\
\text { ER: } 60 \%-70 \% 1 \mathrm{RM}(\text { tronco + MMSS + } \\
\text { MMII })\end{array}$} & \multirow{4}{*}{3} & \multirow{4}{*}{40} & \multirow{4}{*}{13} & \multirow{4}{*}{5} \\
\hline & & & $\mathrm{EC}$ & 15 & $60,6 \pm 5,6$ & & & & & & \\
\hline & & & EA & 15 & $59,4 \pm 6,5$ & & & & & & \\
\hline & & & GC & 15 & $55,5 \pm 7,5$ & & & & & & \\
\hline \multirow{2}{*}{ Beckers e cols. (10) } & & IC CF II-III / & $\mathrm{EC}$ & 28 & $58 \pm 11$ & & EC: $90 \%$ FCmax (circuito) + ER: $50 \%-60 \%$ & & & & \\
\hline & 2008 & FEVE $<40 \%$ & EA & 30 & $59 \pm 11$ & $\mathrm{O}_{2 \text { pico }}$ & 1RM (quarto maiores grupos musculares) & 3 & 60 & 24 & 5 \\
\hline Palevo e cols. (18) & 2008 & IC CF II-III / & ER & 10 & $60 \pm 12$ & FEVE + & $60 \%$ 1RM (pesos livres e/ou máquinas para & 3 & 30 & 8 & 6 \\
\hline Palevo e cols. (18) & 2008 & FEVE $<40 \%$ & GC & 06 & $65 \pm 13$ & VDF & grandes grupos musculares) & 3 & 30 & 8 & \\
\hline & & & $\mathrm{EC}$ & 10 & $59 \pm 11$ & & EC: $50 \%-70 \%$ FCR + Borg 11-14 (ciclo- & & & & \\
\hline Mandic e cols. (08) & 2009 & $\begin{array}{l}\text { IC CF I-III / } \\
\text { FEVE }<40 \%\end{array}$ & EA & 8 & $63 \pm 11$ & $\begin{array}{l}\mathrm{VO}_{2 \text { pico }}+ \\
\mathrm{FEVE}\end{array}$ & $15 \mathrm{~min}+$ esteira-15min) + ER: $50 \%-70 \%$ & 3 & 30 & 12 & 7 \\
\hline & & & GC & 13 & $62 \pm 13$ & & स & & & & \\
\hline Bouchlo e cols (128) & 2011 & IC CF I-III / & EA & 10 & $50.5 \pm 11$ & & EA: Intervalado a $50 \%$ pico (30s exercício & 3 & EA: 40 & & \\
\hline Boucnia e cors. (128) & 2011 & FEVE $<40 \%$ & $\mathrm{EC}$ & 10 & $56.7 \pm 7.2$ & $\mathrm{VO}_{2 \text { pico }}$ & $\begin{array}{l}\text { com bus repouso) / EC: EA + ER: } 4 \text { grupos } \\
\text { musculares 55\%-65\% 1-RM }\end{array}$ & 3 & EC: 60 & 12 & 5 \\
\hline Jakovlievic e cols. (117) & 2010 & IC CF I-II / & ER & 10 & $63 \pm 10$ & $\mathrm{VO} \mathrm{C}_{\mathrm{c}}$ & EA: $60 \%-80 \% \mathrm{VO}_{2 \text { pico }}+$ Borg (circuito) + & 5 & 30 & 12 & 5 \\
\hline & & FEVE $<40 \%$ & EA & 11 & $65 \pm 12$ & 2 pico & ER (circuito - grandes grupos musculares) & (4 em casa) & 30 & 12 & $J$ \\
\hline Santos e cols (131) & 2010 & IC FEVE & $\mathrm{EC}$ & 13 & $53,1 \pm 12,7$ & FEVE + & EA: $10 \%$ abaixo PCR (ciclo) / ER: 10 & 3 & 40 & 16 & 5 \\
\hline & & $<45 \%$ & $\mathrm{GC}$ & 10 & $59,4 \pm 12,2$ & VDF & minutos of ER local & & & & \\
\hline & & & ER & 12 & $58,8 \pm 3,5$ & & & & & & \\
\hline Maiorana e cols. (118) & 2011 & $\begin{array}{l}\text { IC CF I-III / } \\
\text { FEVE }<40 \%\end{array}$ & EA & 12 & $61,3 \pm 2,8$ & $\mathrm{VO}_{2 \text { pico }}$ & $\begin{array}{c}\text { EA: } 50 \%-70 \% \mathrm{VO}_{2 \text { pico }}(\text { ciclo + esteira) } / \\
\text { ER: } 50 \%-70 \% 1-\mathrm{RM}\end{array}$ & 3 & 46 & 12 & 5 \\
\hline & & & GC & 12 & $64,4 \pm 2,4$ & & & & & & \\
\hline
\end{tabular}


Tabela 2. Descrição dos Estudos envolvendo exercício resistido isolado e/ou combinado incluídos na revisão sistemática e metanálise. (continuação)

\begin{tabular}{|c|c|c|c|c|c|c|c|c|c|c|c|}
\hline \multicolumn{2}{|l|}{ Estudo (ref), ano } & \multirow{3}{*}{$\begin{array}{c}\text { Pacientes } \\
\text { IC CF I-III / } \\
\text { FEVE <45\% }\end{array}$} & \multicolumn{2}{|c|}{$\underset{(n)}{\operatorname{Amostra}}$} & \multirow{3}{*}{$\begin{array}{c}\begin{array}{c}\text { Idade } \\
(\text { Média } \pm \mathbf{D P})\end{array} \\
54 \pm 10 \\
52 \pm 11\end{array}$} & \multirow{3}{*}{$\frac{\text { Desfechos }}{\mathrm{VO}_{2 \text { pico }}}$} & \multirow{3}{*}{$\begin{array}{c}\text { Descrição da Intervenção } \\
\text { EA: } 50 \% \text { da carga no TR (ciclo } \\
\text { intervalado) + ER: } 55 \%-65 \% \text { 2RM } \\
\text { (grandes grupos musculares) }\end{array}$} & \multirow{3}{*}{$\begin{array}{c}\begin{array}{c}\text { Frequência } \\
\text { (d/sem) }\end{array} \\
3\end{array}$} & \multirow{3}{*}{$\begin{array}{c}\begin{array}{c}\text { Duração da } \\
\text { Sessão (min) }\end{array} \\
40\end{array}$} & \multirow{3}{*}{$\begin{array}{c}\begin{array}{c}\text { Duração do } \\
\text { programa (sem) }\end{array} \\
12\end{array}$} & \multirow{3}{*}{$\begin{array}{r}\text { PEDro } \\
\text { score } \\
4\end{array}$} \\
\hline \multirow{2}{*}{$\begin{array}{l}\text { Anagnoustaku e cols. } \\
\text { (129) }\end{array}$} & \multirow{2}{*}{2011} & & $\mathrm{EC}$ & 14 & & & & & & & \\
\hline & & & EA & 14 & & & & & & & \\
\hline \multirow{2}{*}{ Laoutaris e cols. (15) } & \multirow{2}{*}{2013} & \multirow{2}{*}{$\begin{array}{l}\text { IC CF II-III / } \\
\text { FEVE }<40 \%\end{array}$} & EC & 13 & $57.1 \pm 11$ & \multirow{2}{*}{$\begin{array}{l}\mathrm{VO}_{2 \text { pico }}+ \\
\text { FEVE }\end{array}$} & \multirow{2}{*}{$\begin{array}{c}\text { EC: } 70 \%-80 \% \text { FCmáx (ciclo) ER: } 50 \% 1- \\
\text { RM + TMR (60\% PImax) }\end{array}$} & \multirow{2}{*}{3} & \multirow{2}{*}{65} & \multirow{2}{*}{12} & \multirow{2}{*}{6} \\
\hline & & & EA & 14 & $58.6 \pm 8$ & & & & & & \\
\hline \multirow[b]{2}{*}{ Keast e cols. (133) } & \multirow[b]{2}{*}{2013} & \multirow{2}{*}{$\begin{array}{l}\text { IC CF II-III / } \\
\text { FEVE }<35 \%\end{array}$} & $\mathrm{EC}$ & 27 & $62.8 \pm 11$ & \multirow[b]{2}{*}{$\mathrm{VO}_{2 \text { pico }}$} & \multirow{2}{*}{$\begin{array}{c}\text { EC: pesos livres }+ \text { therabands }+ \\
\text { Caminhada / EA: Nordic Walking. 60\%- } \\
75 \% \text { FCR e Borg 3-5 }\end{array}$} & \multirow[b]{2}{*}{2} & \multirow[b]{2}{*}{75} & \multirow[b]{2}{*}{12} & \multirow[b]{2}{*}{6} \\
\hline & & & EA & 27 & $62.1 \pm 12$ & & & & & & \\
\hline \multirow{2}{*}{$\begin{array}{l}\text { Antunes-Correa e cols. } \\
\text { (122) }\end{array}$} & \multirow{2}{*}{2014} & \multirow{2}{*}{$\begin{array}{l}\text { IC CF II-III / } \\
\text { FEVE }<40 \%\end{array}$} & $\mathrm{EC}$ & 17 & $56 \pm 2$ & \multirow{2}{*}{$\begin{array}{l}\mathrm{VO}_{2 \text { pico }}+ \\
\mathrm{FEVE}\end{array}$} & EC: $60 \%-70 \% \mathrm{VO}_{2 \text { pico }}$ (ciclo) / ER: $10 \mathrm{~min}$ & 3 & 60 & 16 & 5 \\
\hline & & & GC & 17 & $54 \pm 2$ & & & & & & \\
\hline & & & $\mathrm{EC}$ & & $55 \pm 11$ & & EA: TI (Ciclo a $50 \%$ pico TR - 30s & & & & \\
\hline Georgantas e cols. (130) & 2014 & $\begin{array}{l}\text { IC } 1-111 / \mathrm{FEVE} \\
<45 \%\end{array}$ & & & & $\mathrm{VO}_{2 \text { pico }}$ & EC: TI + ER para grandes grupos & 3 & 12 & 40 & 5 \\
\hline & & & EA & 20 & $53 \pm 11$ & & musculares & & & & \\
\hline & & IC CF II-III / & $\mathrm{EC}$ & 15 & $54 \pm 3$ & & EC: $5 \%-15 \%$ acima do LV (30 min esteira) & & & & \\
\hline de Meirelles e cols. (124) & 2014 & FEVE $<35 \%$ & GC & 15 & $55 \pm 2$ & $\mathrm{VO}_{2 \text { pico }}$ & $\begin{array}{c}\text { / ER: } 8 \text { a } 10 \text { exercícios para maiores grupos } \\
\text { musculares }\end{array}$ & 3 & 90 & 24 & 6 \\
\hline Chouroboum (120) & & IC I-III / FEVE & $\mathrm{EC}$ & 33 & $63 \pm 9$ & & EC: TI - 80\%-100\% pico (30s exercício / & 3 & 15 & 12 & 6 \\
\hline Cnrysonoou e cols. (132) & 2015 & $<35 \%$ & GC & 39 & $53 \pm 11$ & $\mathrm{VU}_{2 \text { pico }}$ & $\begin{array}{l}\text { 30s repouso)/ ER: } 4 \text { exercicios - 30\%-90\% } \\
\text { 1-RM }\end{array}$ & 3 & 45 & 12 & 0 \\
\hline Groebse cols (160) & 2015 & IC CF II-III / & $\mathrm{EC}$ & 13 & $57 \pm 3$ & $\mathrm{VO}_{2 \text { pico }}+$ & EC: 08\%-10\% abaixo PCR (ciclo) / ER: 10 & 3 & 60 & 16 & 6 \\
\hline UIUents e cols. (109) & 2010 & FEVE $<40 \%$ & GC & 13 & $49 \pm 3$ & $\begin{array}{l}\text { FEVE + } \\
\text { VDF }\end{array}$ & min de ER local & 3 & 00 & 10 & 0 \\
\hline
\end{tabular}

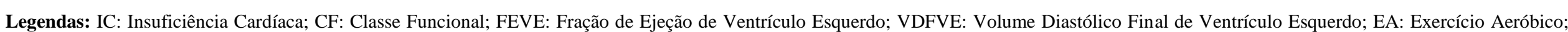

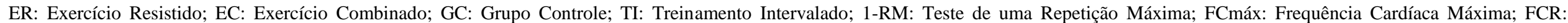

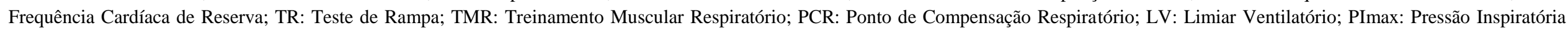
Máxima. Fonte: Resultados do presente estudo 
Tabela 3. Descrição dos Estudos envolvendo Exercício Aeróbico incluídos na Revisão Sistemática e Metanálise (continua).

\begin{tabular}{|c|c|c|c|c|c|c|c|c|c|c|c|}
\hline \multicolumn{2}{|l|}{ Estudo (ref), ano } & \multirow{3}{*}{$\begin{array}{c}\text { Pacientes } \\
\text { IC CF II-III }\end{array}$} & \multicolumn{2}{|c|}{$\underset{(n)}{\operatorname{Amostra}}$} & \multirow{3}{*}{$\begin{array}{c}\begin{array}{c}\text { Idade } \\
(\text { Média } \pm \text { DP })\end{array} \\
55 \pm 7 \\
54 \pm 6\end{array}$} & \multirow{3}{*}{$\frac{\text { Desfechos }}{\text { FEVE }}$} & \multirow{3}{*}{$\begin{array}{c}\text { Descrição da Intervenção } \\
60 \% \mathrm{VO}_{2 \text { pico }}(\text { ciclo })\end{array}$} & \multirow{3}{*}{$\begin{array}{c}\begin{array}{c}\text { Frequência } \\
\text { (d/sem) }\end{array} \\
3\end{array}$} & \multirow{3}{*}{$\begin{array}{c}\begin{array}{c}\text { Duração da } \\
\text { Sessão (min) }\end{array} \\
40\end{array}$} & \multirow{3}{*}{$\begin{array}{c}\begin{array}{c}\text { Duração do } \\
\text { programa (sem) }\end{array} \\
8\end{array}$} & \multirow{3}{*}{$\begin{array}{c}\text { PEDro } \\
\text { score }\end{array}$} \\
\hline Belardinelli e cols. (95) & 1995 & & & & & & & & & & \\
\hline Belardinelli e cols. (95) & 1995 & & GC & 13 & & & & & & & \\
\hline \multirow{2}{*}{ Belardinelli e cols. (96) } & \multirow{2}{*}{1996} & \multirow{2}{*}{ IC FEVE $<30 \%$} & & & $55 \pm 7$ & \multirow{2}{*}{$\begin{array}{c}\mathrm{VO}_{2 \text { pico }}+ \\
\text { FEVE }\end{array}$} & \multirow{2}{*}{$60 \% \mathrm{VO}_{2 \text { pico }}($ ciclo $)$} & \multirow{2}{*}{3} & \multirow{2}{*}{60} & \multirow{2}{*}{8} & \multirow{2}{*}{6} \\
\hline & & & GC & 21 & $54 \pm 6$ & & & & & & \\
\hline \multirow{2}{*}{ Kiilavuori e cols. (98) } & \multirow{2}{*}{1996} & \multirow{2}{*}{$\begin{array}{l}\text { IC CF II-III / } \\
\text { FEVE<30\% }\end{array}$} & EA & & $52 \pm 7$ & \multirow{2}{*}{$\begin{array}{c}\mathrm{VO}_{2 \text { pico }}+ \\
\text { FEVE }\end{array}$} & \multirow{2}{*}{$60 \%-70 \% \mathrm{VO}_{2 \text { pico }}($ ciclo $)$} & \multirow{2}{*}{3} & \multirow{2}{*}{30} & \multirow{2}{*}{30} & \multirow{2}{*}{5} \\
\hline & & & GC & 15 & $52 \pm 9$ & & & & & & \\
\hline \multirow{2}{*}{ Willenheimer e cols. (101) } & \multirow{2}{*}{1998} & \multirow{2}{*}{$\begin{array}{l}\text { IC CF I-III / } \\
\text { FEVE< }<40 \%\end{array}$} & & & $64 \pm 5$ & \multirow{2}{*}{$\mathrm{VO}_{2 \text { pico }}$} & $80 \% \mathrm{VO}$ & 3 & 15 & 16 & 5 \\
\hline & & & GC & 27 & $63 \pm 3$ & & $00 \% \mathrm{~V}_{2 \mathrm{n}}$ & 3 & $4 J$ & 10 & $\mathrm{~J}$ \\
\hline Sturm e cols (102) & 1090 & IC CF II-III / & EA & 13 & $55 \pm 9$ & $\mathrm{VO}$ & & 2 & 50 & 12 & 6 \\
\hline 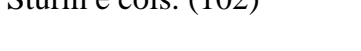 & 1999 & FEVE<25\% & GC & 13 & $53 \pm 9$ & $\mathrm{U}_{2 \text { pico }}$ & $50 \% \mathrm{VO}_{2 \text { pico }}(\mathrm{Clclo}+$ step $)$ & 3 & 50 & 12 & 6 \\
\hline Relardinellie cols (11) & 1090 & IC CF II-IV / & EA & 50 & $56 \pm 7$ & $\mathrm{VO}_{2 \text { pico }}+$ & $60 \%$ VO (ciclo) & Fase I: 3 & 60 & Fase I: 8 & 7 \\
\hline 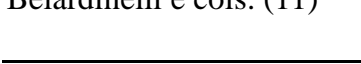 & 1999 & FEVE<30\% & GC & 49 & $53 \pm 9$ & $\begin{array}{l}\text { FEVE + } \\
\text { VDF }\end{array}$ & $00 \% \vee U_{2 \text { pico }}($ CIClO $)$ & Fase II: 2 & 60 & Fase II: 48 & 1 \\
\hline Ketevian e cols (84) & 1090 & IC CF II-III / & EA & 21 & $55 \pm 12$ & $\mathrm{~V} O \mathrm{r}$ & 50-80\% ECR (ciclo + esteira) & 3 & 30 & 24 & 4 \\
\hline 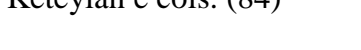 & 1797 & FEVE $<35 \%$ & GC & 22 & $57 \pm 12$ & $\mathrm{O}_{2 \text { pico }}$ & 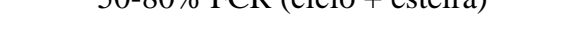 & J & 30 & 24 & 4 \\
\hline Wielenga e cols $(100)$ & 1090 & IC CF II-III / & EA & 35 & $62.4 \pm 1.5$ & $\mathrm{VO}$ & TI / EA pelo menos 20 min no FCA (ciclo, & 3 & 30 & $\mathrm{NR}$ & 5 \\
\hline 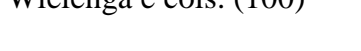 & 1793 & $\mathrm{FEVE}<30 \%$ & $\mathrm{GC}$ & 32 & $64.6 \pm 1.4$ & $\mathrm{O}_{2 \text { pico }}$ & caminhada e bola) & $\mathrm{J}$ & 30 & NIN & $J$ \\
\hline Wombrolo (00) & 2000 & IC CF I-III / & EA & 31 & $54 \pm 9$ & $\mathrm{VO}_{2 \text { pico }}+$ & & 7 & Hospital: & Hospital: 2 & 6 \\
\hline Hamorectit e cois. (80) & 2000 & FEVE $<40 \%$ & GC & 33 & $54 \pm 8$ & VDF & $/ 0 \% \mathrm{VU}_{2}$ pico $(\mathrm{CICIO})$ & 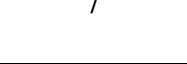 & 20 & Casa: 24 & 0 \\
\hline & & & EA & 12 & $52.8 \pm 12$ & $\mathrm{VO}_{2 \text { pico }}+$ & & & & & \\
\hline Myers e cols. (92) & 2002 & IC FEVE<30\% & & 12 & $58.2 \pm 6$ & $\begin{array}{l}\text { FEVE + } \\
\text { VDF }\end{array}$ & $60 \%-80 \% \mathrm{VO}_{2 \text { pico }}+\mathrm{BORG}(13-15)$ & 5 & 45 & 8 & 5 \\
\hline & & IC CF II-III / & EA & 45 & $60 \pm 7$ & $\mathrm{VO}_{2 \text { pico }}+$ & & & Superv: $30 /$ & & \\
\hline Giannuzzi e cols. (172) & 2003 & FEVE $<35 \%$ & & 45 & $61 \pm 7$ & $\begin{array}{l}\text { FEVE + } \\
\text { VDF }\end{array}$ & $60 \% \mathrm{VO}_{2 \text { pico }}(\mathrm{ciclo})$ & 3 to 5 & $\begin{array}{c}\text { Não superv: } \\
>30\end{array}$ & 24 & 5 \\
\hline
\end{tabular}


Tabela 3. Descrição dos Estudos envolvendo Exercício Aeróbico incluídos na Revisão Sistemática e Metanálise (continuação).

\begin{tabular}{|c|c|c|c|c|c|c|c|c|c|c|c|}
\hline \multicolumn{2}{|l|}{ Estudo (ref), ano } & \multirow{3}{*}{$\begin{array}{c}\text { Pacientes } \\
\text { IC CF II-IV / } \\
\text { FEVE }<35 \%\end{array}$} & \multicolumn{2}{|c|}{$\underset{(n)}{\operatorname{Amostra}}$} & \multirow{3}{*}{$\begin{array}{c}\begin{array}{c}\text { Idade } \\
(\text { Média } \pm D P)\end{array} \\
63.8 \pm 10.1 \\
61.3 \pm 11.1\end{array}$} & \multirow{3}{*}{$\frac{\text { Desfechos }}{\mathrm{VO}_{2 \text { pico }}}$} & \multirow{3}{*}{$\begin{array}{c}\text { Descrição da Intervenção } \\
\text { Caminhada (40-60\% FCmáx) }\end{array}$} & \multirow{3}{*}{$\begin{array}{c}\begin{array}{c}\text { Frequência } \\
\text { (d/sem) }\end{array} \\
5\end{array}$} & \multirow{3}{*}{$\begin{array}{c}\begin{array}{c}\text { Duração da } \\
\text { Sessão (min) }\end{array} \\
60\end{array}$} & \multirow{3}{*}{$\begin{array}{c}\begin{array}{c}\text { Duração do } \\
\text { programa (sem) }\end{array} \\
12\end{array}$} & \multirow{3}{*}{$\begin{array}{c}\text { PEDro } \\
\text { score }\end{array}$} \\
\hline \multirow{2}{*}{$\begin{array}{l}\text { Corvera-Tyndel e cols. } \\
\text { (97) }\end{array}$} & \multirow{2}{*}{2004} & & EA & & & & & & & & \\
\hline & & & GC & 37 & & & & & & & \\
\hline \multirow{2}{*}{ Van de berg e cols. (99) } & \multirow{2}{*}{2004} & \multirow{2}{*}{$\begin{array}{l}\text { IC CF II-III / } \\
\text { FEVE< }<40 \%\end{array}$} & EA & 18 & $58.6 \pm 12.1$ & \multirow{2}{*}{$\mathrm{VO}_{2 \text { pico }}$} & \multirow{2}{*}{$60 \%$ FCR (ciclo + Caminhada + jogos $)$} & \multirow{2}{*}{2} & \multirow{2}{*}{60} & \multirow{2}{*}{12} & \multirow{2}{*}{4} \\
\hline & & & GC & 16 & $58.6 \pm 10.6$ & & & & & & \\
\hline \multirow{2}{*}{ Koukouvou e cols. (94) } & \multirow{2}{*}{2004} & \multirow{2}{*}{$\begin{array}{l}\text { IC CF II-III / } \\
\text { FEVE< }<40 \%\end{array}$} & EA & & $52.3 \pm 9.2$ & \multirow{2}{*}{$\mathrm{VO}_{2 \text { pico }}$} & \multirow{2}{*}{$\begin{array}{l}\text { Circuito (ciclo + caminhada + step) 50- } \\
\quad 70 \% \mathrm{VO}_{2 \text { pico }}+\text { Borg 12-14 }\end{array}$} & \multirow{2}{*}{4} & \multirow{2}{*}{60} & \multirow{2}{*}{24} & \multirow{2}{*}{5} \\
\hline & & & GC & 10 & $52.8 \pm 10.6$ & & & & & & \\
\hline \multirow{3}{*}{ Klocek e cols. (164) } & \multirow{3}{*}{2005} & & EA1 & 14 & $54 \pm 7$ & & EA1: Carga Constante a 60\% FCmáx & & & & \\
\hline & & $\begin{array}{l}\text { IC CF II-III / } \\
\text { FEVE }<35 \%\end{array}$ & AT2 & 14 & $57 \pm 8$ & $\begin{array}{l}\mathrm{VO}_{2 \text { pico }}+ \\
\text { FEVE }\end{array}$ & $\begin{array}{l}(5 \mathrm{x} 4 \mathrm{~min} \text { e } 1 \mathrm{~min} \text { rep }) / \text { EA2: Carga } \\
\text { progressiva }(25 \mathrm{~W} \text { a cada } 5 \text { min nos } 2\end{array}$ & 3 & 25 & 24 & 5 \\
\hline & & & & 14 & $55 \pm 9$ & & $\begin{array}{c}\text { primeiros meses e } 10 \mathrm{~W} \text { a cada } 5 \mathrm{~min} \text { após } 2 \\
\text { e } 4 \text { meses) }\end{array}$ & & & & \\
\hline & & IC CF I-III / & EA & & $60 \pm 2$ & $\mathrm{VO}_{2 \text { pico }}+$ & & & & & \\
\hline Passino e cols. (86) & 2006 & FEVE $<45 \%$ & GC & 41 & $61 \pm 2$ & $\begin{array}{l}\text { FEVE + } \\
\text { VDF }\end{array}$ & $60 \% \mathrm{FC} \mathrm{EA} \mathrm{VO}_{2 \text { pico }}($ ciclo) & 3 & 30 & 36 & 6 \\
\hline & & & EA & 25 & $59.6 \pm 10.2$ & $\mathrm{VO}+\mathrm{O}_{2}+$ & & & & & \\
\hline Klecha e cols. (78) & 2007 & $\begin{array}{l}\text { IC CF II-III / } \\
\text { FEVE<35\% }\end{array}$ & GC & 25 & $61.2 \pm 9.5$ & FEVE + & $80 \%$ FC no $\mathrm{VO}_{2 \text { pico }}$ (ciclo) & 3 & 60 & 24 & 7 \\
\hline & & & GC & 29 & $69.9 \pm 6.3$ & & & & & & \\
\hline Muollor o le (106) & 2007 & IC CF I-III / & EA & 25 & $55 \pm 10$ & & 60-80\% FCmáx / Borg 12-14 (ciclo + & 5 & 30 & i & 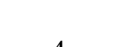 \\
\hline Mueller e cols. (106) & 2007 & FEVE $<40 \%$ & GC & 25 & $55 \pm 10$ & $\mathrm{VO}_{2 \text { pico }}$ & walking) & 5 & 30 & 4 & 4 \\
\hline & & IC CF II-III / & EA & 15 & $59.4 \pm 6.5$ & $\mathrm{VO}_{2 \text { pico }}+$ & & & & & \\
\hline Feiereisen e cols. (12) & 2007 & FEVE $<35 \%$ & GC & 15 & $55.5 \pm 7.5$ & $\begin{array}{l}\text { FEVE + } \\
\text { VDF }\end{array}$ & EA: $60 \%-75 \% \mathrm{VO}_{2 \text { pico }}($ ciclo + esteira) & 3 & 40 & 13 & 5 \\
\hline Gademan e cols (81) & 2008 & IC CF II-III / & EA & 20 & $60 \pm 9$ & $\mathrm{VO} \times \mathrm{r}$ & $50 \%$ do nico do TR $(\mathrm{Ciclo})$ & 3 & 75 & 10 & 6 \\
\hline Gademant e cols. (01) & 2000 & FEVE $<40 \%$ & GC & 14 & $63 \pm 10$ & $\mathrm{VU}_{2 \text { pico }}$ & $50 \%$ do pico do IR (Ciclo) & 3 & 15 & 10 & 0 \\
\hline & & IC CF II-III / & EA & 27 & $65 \pm 11$ & $\mathrm{VO}_{2 \text { pico }}+$ & & & & & \\
\hline Mrallatto e cois. (89) & 2009 & FEVE $<40 \%$ & GC & 27 & $67 \pm 9$ & $\begin{array}{l}\text { FEVE + } \\
\text { VDF }\end{array}$ & $60 \% \mathrm{VO}_{2 \text { pico }}$ (ciclo ou esteira & 3 & 60 & 12 & 4 \\
\hline
\end{tabular}


Tabela 3. Descrição dos Estudos envolvendo Exercício Aeróbico incluídos na Revisão Sistemática e Metanálise (continuação).

\begin{tabular}{|c|c|c|c|c|c|c|c|c|c|c|c|}
\hline \multicolumn{2}{|l|}{ Estudo (ref), ano } & \multirow{3}{*}{$\begin{array}{c}\text { Pacientes } \\
\text { IC CF I-III / } \\
\text { FEVE }<40 \%\end{array}$} & \multicolumn{2}{|c|}{$\begin{array}{c}\text { Amostra } \\
(\mathbf{n})\end{array}$} & \multirow{3}{*}{$\begin{array}{c}\begin{array}{c}\text { Idade } \\
(\text { Média } \pm \text { DP) }\end{array} \\
63 \pm 11 \\
62 \pm 13\end{array}$} & \multirow{3}{*}{$\begin{array}{c}\text { Desfechos } \\
\mathrm{VO}_{2 \text { pico }}+ \\
\text { FEVE }\end{array}$} & \multirow{3}{*}{$\begin{array}{c}\text { Descrição da Intervenção } \\
\text { EA: 50-70\% FCR e BORG 11-14 (Ciclo- } \\
\text { 15min e Esteira-15min) }\end{array}$} & \multirow{3}{*}{$\begin{array}{c}\begin{array}{c}\text { Frequência } \\
\text { (d/sem) }\end{array} \\
3\end{array}$} & \multirow{3}{*}{$\begin{array}{c}\begin{array}{c}\text { Duração da } \\
\text { Sessão (min) }\end{array} \\
30\end{array}$} & \multirow{3}{*}{$\begin{array}{c}\begin{array}{c}\text { Duração do } \\
\text { programa (sem) }\end{array} \\
12\end{array}$} & \multirow{3}{*}{$\begin{array}{r}\text { PEDro } \\
\text { score }\end{array}$} \\
\hline \multirow{2}{*}{ Mandic e cols. (08) } & \multirow{2}{*}{2009} & & EA & 8 & & & & & & & \\
\hline & & & $\mathrm{GC}$ & 13 & & & & & & & \\
\hline \multirow{2}{*}{$\begin{array}{l}\text { Craenenbroeck e cols. } \\
\text { (171) }\end{array}$} & \multirow{2}{*}{2010} & \multirow{2}{*}{$\begin{array}{l}\text { IC CF I-II / } \\
\text { FEVE }<35 \% \\
\end{array}$} & EA & 21 & $61.3 \pm 2.2$ & \multirow{2}{*}{ FEVE } & \multirow{2}{*}{$60 \%$ FC no PCR } & \multirow[t]{2}{*}{3} & \multirow{2}{*}{60} & \multirow{2}{*}{24} & \multirow{2}{*}{5} \\
\hline & & & $\mathrm{GC}$ & 17 & $63.4 \pm 3$ & & & & & & \\
\hline \multirow{2}{*}{ O'Connor e cols. (83) } & \multirow{2}{*}{2009} & \multirow{2}{*}{$\begin{array}{l}\text { IC CF II-IV / } \\
\text { FEVE }<30 \%\end{array}$} & EA & 1159 & $59,3 \pm 9$ & \multirow{2}{*}{$\mathrm{VO}_{2 \text { pico }}$} & \multirow{2}{*}{$\begin{array}{l}\text { 60-70\% FCR (Caminhada, esteira ou } \\
\text { Ciclo) }\end{array}$} & \multirow{2}{*}{3} & \multirow{2}{*}{35} & \multirow{2}{*}{12} & \multirow{2}{*}{7} \\
\hline & & & $\mathrm{GC}$ & 1172 & $59,2 \pm 8$ & & & & & & \\
\hline \multirow{2}{*}{ Erbs e cols. (87) } & \multirow{2}{*}{2010} & IC CF IIIb / & EA & 18 & $60 \pm 11$ & $\mathrm{VO}_{2 \text { pico }}+$ & & Hosp: 3 & Hosp: 20 & Hosp: 3 & \\
\hline & & FEVE $<30 \%$ & $\mathrm{GC}$ & 19 & $62 \pm 12$ & $\begin{array}{l}\text { FEVE }+ \\
\text { VDF }\end{array}$ & Hosp.: $50 \% \mathrm{VO}_{2 \text { pico }}$; Casa: $60 \% \mathrm{VO}_{2 \text { pico }}$ & Home: 12 & Home: 30 & Home: 12 & 6 \\
\hline Lenk e cols (79) & 2011 & IC CF III / & EA & 12 & $61 \pm 11$ & $\mathrm{VO}_{2}$ & & Hosp: 3 & Hosp: 20 & 12 & \\
\hline Lenk e cols. (19) & 2011 & FEVE $<30 \%$ & $\mathrm{GC}$ & 12 & $60 \pm 10.7$ & $\mathrm{U}_{2 \text { pico }}$ & Hosp.: $50 \% \vee_{2 \text { pico; }}$; Casa: $60 \% \mathrm{VU}_{2 \text { pico }}$ & Home: 12 & Home: 30 & 12 & 3 \\
\hline Alyes e cols (09) & 2012 & IC CF I-IV / & EA & 34 & $62 \pm 9.9$ & FEVE & $5 \times 3 \min : 70 \%-75 \%+1 \min : 45 \%-55 \%$ & 3 & 35 & 24 & 6 \\
\hline (3) & 2012 & FEVE $<45 \%$ & $\mathrm{GC}$ & 33 & $62 \pm 9.9$ & $1 \mathrm{LV}$ & FCmáx TI (esteira ou ciclo) & J & $J$ & 24 & 0 \\
\hline Myers e cols. (105) & 2012 & IC FEVE $<35 \%$ & EA & 24 & $55 \pm 9$ & & $60 \%-80 \%$ FCR (Caminhada + ciclo) & 7 & Caminhada: & 8 & 6 \\
\hline (1) & 2012 & 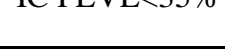 & GC & 26 & $57 \pm 7$ & $\mathrm{VO}_{2 \text { pico }}$ & - & 1 & 60 Ciclo: 45 & 0 & 0 \\
\hline Sandri e cols. (85) & 2012 & IC CF II-III / & EA & 15 & $50 \pm 5$ & $\mathrm{VO}_{2 \text { pico }}+$ & $70 \% \mathrm{VO}_{2}$ & 4 & 20 & 4 & 6 \\
\hline 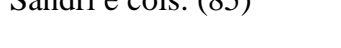 & 2012 & FEVE $<30 \%$ & GC & 15 & $49 \pm 5$ & & $10 \% V_{2 \text { pico }}$ (CTC10) & & 20 & 4 & 0 \\
\hline & & IC CF II-III / & EA & 18 & $67.8 \pm 5.9$ & & & & & & \\
\hline Guazzi e cols. (173) & 2012 & FEVE $<45 \%$ & GC & 8 & $67.8 \pm 5.9$ & $\mathrm{VO}_{2 \text { pico }}$ & $60 \%-80 \%$ FCR (ciclo) & 4 & 40 & 24 & 5 \\
\hline Huang e cols. (77) & 2014 & IC FEVE $<35 \%$ & EA & 33 & $60 \pm 3$ & & Fase I: Exercício no LV; Fase II: Intervalos & 3 & 50 & Fase I: 4 Fase II: & 5 \\
\hline nuange cois. (/7) & 2014 & IC FEVE $>33 \%$ & $\mathrm{GC}$ & 33 & $56 \pm 4$ & & de 3min: 40\%-80\% $\mathrm{VO}_{2}$ reserva (ciclo) & 3 & 30 & 8 & J \\
\hline Chrysohoou e cols. (93) & 2014 & IC CF II-IV / & EA & 33 & $63 \pm 9$ & & $80 \%-100 \% \mathrm{~W}$ de pico com 30 s repou & 3 & 45 & 12 & 5 \\
\hline & & FEVE $<50 \%$ & GC & 39 & $56 \pm 11$ & & 然 & & & & \\
\hline
\end{tabular}

Legendas: IC: Insuficiência Cardíaca; CF: Classe Funcional; FEVE: Fração de Ejeção de Ventrículo Esquerdo; VDF: Volume Diastólico Final; EA: Exercício Aeróbico; GC: Grupo Controle; FCmáx: Frequência Cardíaca Máxima; FCR: Frequência Cardíaca de Reserva; PCR: Ponto de Compensação Respiratório; LV: Limiar Ventilatório; FCA: Frequência Cardíaca Alvo; PCR: Ponto de Compensação Respiratória; W: Trabalho. Fonte: Resultados do presente estudo 


\subsection{Consumo de oxigênio de pico $\left(\mathrm{VO}_{2 \text { pico }}\right)$}

$\mathrm{O}$ exercício foi associado com uma significativa melhora do $\mathrm{VO}_{2 \text { pico }}$ quando todos os dados de todos os estudos foram pareados (46 estudos, $n=4.296$ pacientes, Diferença Média Ponderada $[\mathrm{WMD}]=2.70 \mathrm{ml} \bullet \mathrm{kg}^{-1} \bullet \mathrm{min}^{-1}, 95 \%$ CI: 2.11 a $3.28 \mathrm{ml} \bullet \mathrm{kg}^{-1} \bullet \mathrm{min}^{-1}, \mathrm{I}^{2}=$ $65 \%$ ) (Figura 8a). Além disso, o ER isolado foi associado com maior ganho de $\mathrm{VO}_{2 \text { pico }}(5$ estudos, $\mathrm{n}=124$ pacientes, WMD = $3.57 \mathrm{ml} \bullet \mathrm{kg}^{-1} \bullet \mathrm{min}^{-1}, 95 \%$ CI: 2.45 a $4.68 \mathrm{ml} \bullet \mathrm{kg}^{-1} \bullet \mathrm{min}^{-1}$, $\left.\mathrm{I}^{2}=0 \%\right)$ em relação ao EA (28 estudos, $\mathrm{n}=3.584$ pacientes, WMD $=2.63 \mathrm{ml} \bullet \mathrm{kg}^{-1} \bullet \mathrm{min}^{-1}$, 95\% CI: 1.96 a $\left.3.29 \mathrm{ml} \bullet \mathrm{kg}^{-1} \bullet \mathrm{min}^{-1}, \mathrm{I}^{2}=58 \%\right)$ e EC (13 estudos, $\mathrm{n}=588$ pacientes, WMD = $2.48 \mathrm{ml} \bullet \mathrm{kg}^{-1} \bullet \mathrm{min}^{-1}, 95 \%$ CI: 0.88 a $\left.4.09 \mathrm{ml} \bullet \mathrm{kg}^{-1} \bullet \mathrm{min}^{-1}, \mathrm{I}^{2}=69 \%\right)$. Os resultados da análise para comparações entre ER e EC, ambos com EA foram inconclusivos (ER: 03 estudos, $\mathrm{n}=$ 75 pacientes, WMD $=0.12 \mathrm{ml} \bullet \mathrm{kg}^{-1} \bullet \mathrm{min}^{-1}, 95 \% \mathrm{CI}:-1.22$ a $1.45 \mathrm{ml} \bullet \mathrm{kg}^{-1} \bullet \mathrm{min}^{-1}, \mathrm{I}^{2}=0 \% / \mathrm{EC}$ : 08 estudos, $\mathrm{n}=283$ pacientes, WMD $=0.69 \mathrm{ml} \bullet \mathrm{kg}^{-1} \bullet \mathrm{min}^{-1}, 95 \% \mathrm{CI}:-0.87$ a $2.25 \mathrm{ml} \bullet \mathrm{kg}^{-}$ ${ }^{1} \cdot \min ^{-1}, \mathrm{I}^{2}=0 \%$ ) (Figura 8b). Apenas um estudo comparando EC e ER isolado teve também resultado inconclusivo $\left(\mathrm{n}=30, \mathrm{WMD}=-0.60 \mathrm{ml} \bullet \mathrm{kg}^{-1} \bullet \mathrm{min}^{-1}, 95 \% \mathrm{CI}:-3.82\right.$ a $2.62 \mathrm{ml} \bullet \mathrm{kg}^{-}$ $\left.{ }^{1} \bullet \min ^{-1}\right)$.

\subsection{Fração de Ejeção de Ventrículo Esquerdo}

A análise dos Estudos comparando Exercício com grupo controle demonstraram efeitos favoráveis do exercício para o desfecho FEVE (32 estudos, $\mathrm{n}=1.373$ pacientes, WMD $=2.33 \%$, 95\% CI: 1.20 a $3.47 \%, \mathrm{I}^{2}=26 \%$ ) (Figura 9a). Entretanto, ER isolado e EC não demonstraram benefícios na melhora desta variável (ER: 04 estudos, $\mathrm{n}=86$ pacientes, WMD $=1.91 \%, 95 \%$ CI: -3.71 a $7.53 \%, \mathrm{I}^{2}=23 \% / \mathrm{EC}: 11$ estudos, $\mathrm{n}=468$ pacientes, WMD $=$ $0.02 \%, 95 \%$ CI: -1.47 a $1.52 \%, \mathrm{I}^{2}=0 \%$ ), enquanto a análise do EA mostrou melhora neste desfecho (17 estudos, $\mathrm{n}=819$ pacientes, $\mathrm{WMD}=3.15 \%, 95 \%$ CI: 1.87 a $4.44 \%, \mathrm{I}^{2}=17 \%$ ). Adicionalmente, os estudos testando EC com EA tiveram resultados inconclusivos (03 estudos, $\mathrm{n}=78$ pacientes, $\mathrm{WMD}=0.06 \%, 95 \% \mathrm{CI}:-4.14$ a $4.27 \%, \mathrm{I}^{2}=0 \%$ ) (Figura 9b) Houve apenas um estudo nas comparações entre ER com EA e EC, sendo também inconclusivos os seus resultados $(n=20, \mathrm{WMD}=-3.00,95 \%$ CI: -9.92 a $3.92 \%$ e $n=30$ pacientes, $\mathrm{WMD}=-3.00,95 \% \mathrm{CI}:-4.65$ a $10.65 \%$, respectivamente) 


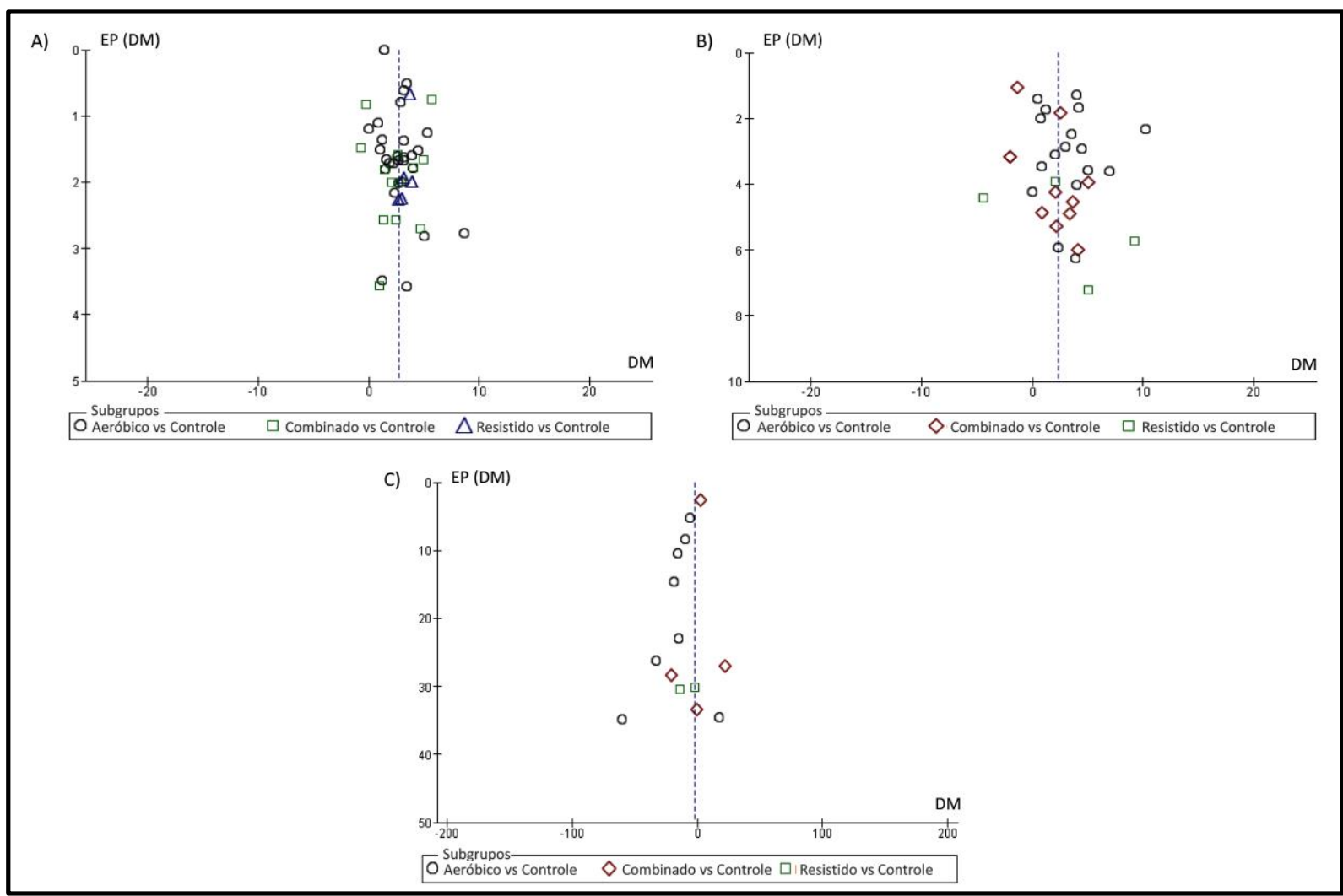

Figura 7. Análise de viés através de Funnel Plot para as análises de subgrupo. A) $\mathrm{VO}_{2 \text { pico }}$; $\mathrm{B}$ FEVE; e C) VDFVE. Legendas: EP: Erro padrão; DM: Diferença da Média. Fonte: Resultados do presente estudo

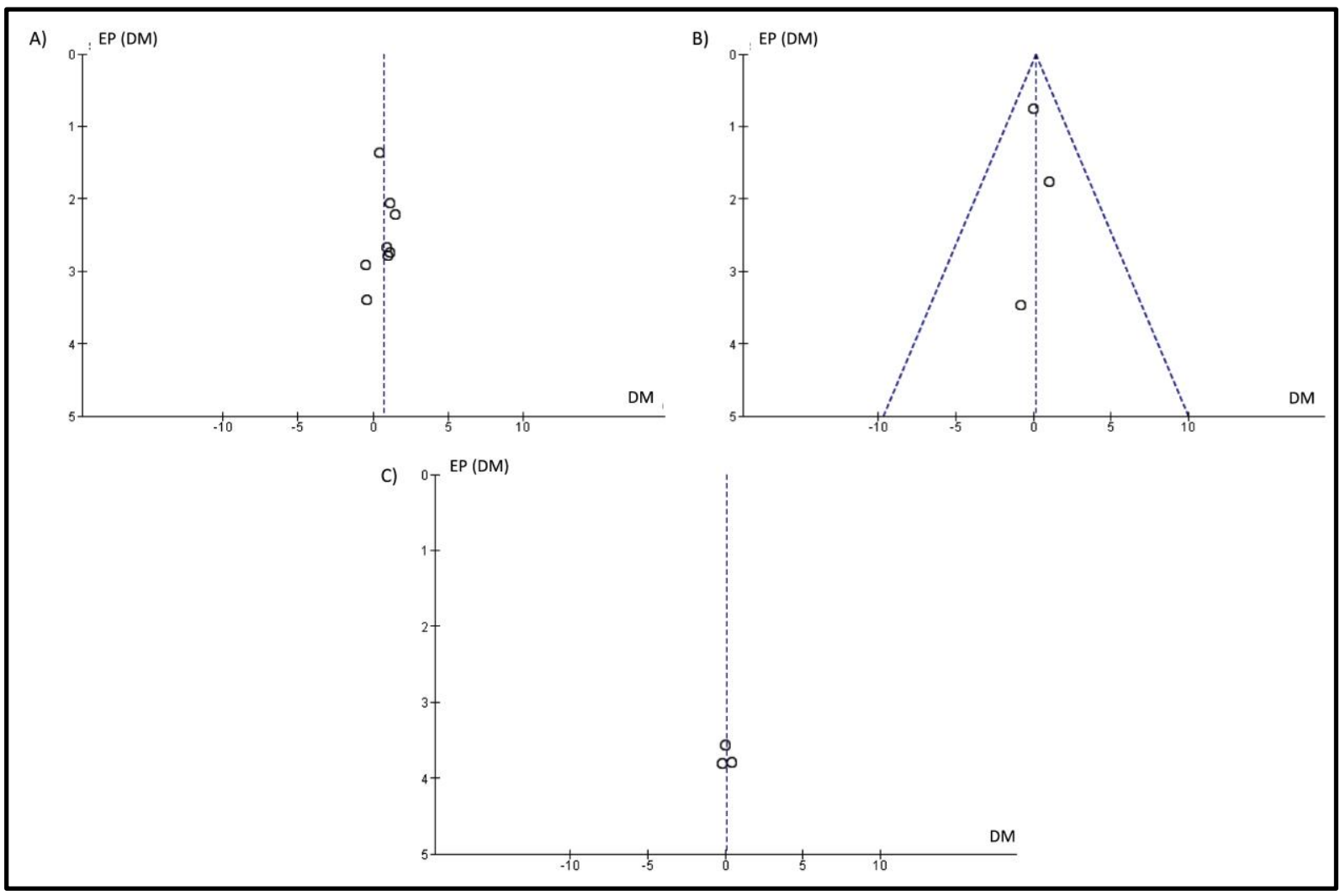

Figura 8. Análise de viés através de Funnel Plot para as comparações entre intervenções. A) EC vs EA para $\mathrm{VO}_{2}$ pico; $\left.\mathrm{B}\right) \mathrm{ER}$ versus EA para $\mathrm{VO}_{2}$ pico; e C) EC versus EA para FEVE. Fonte: Resultados do presente estudo 


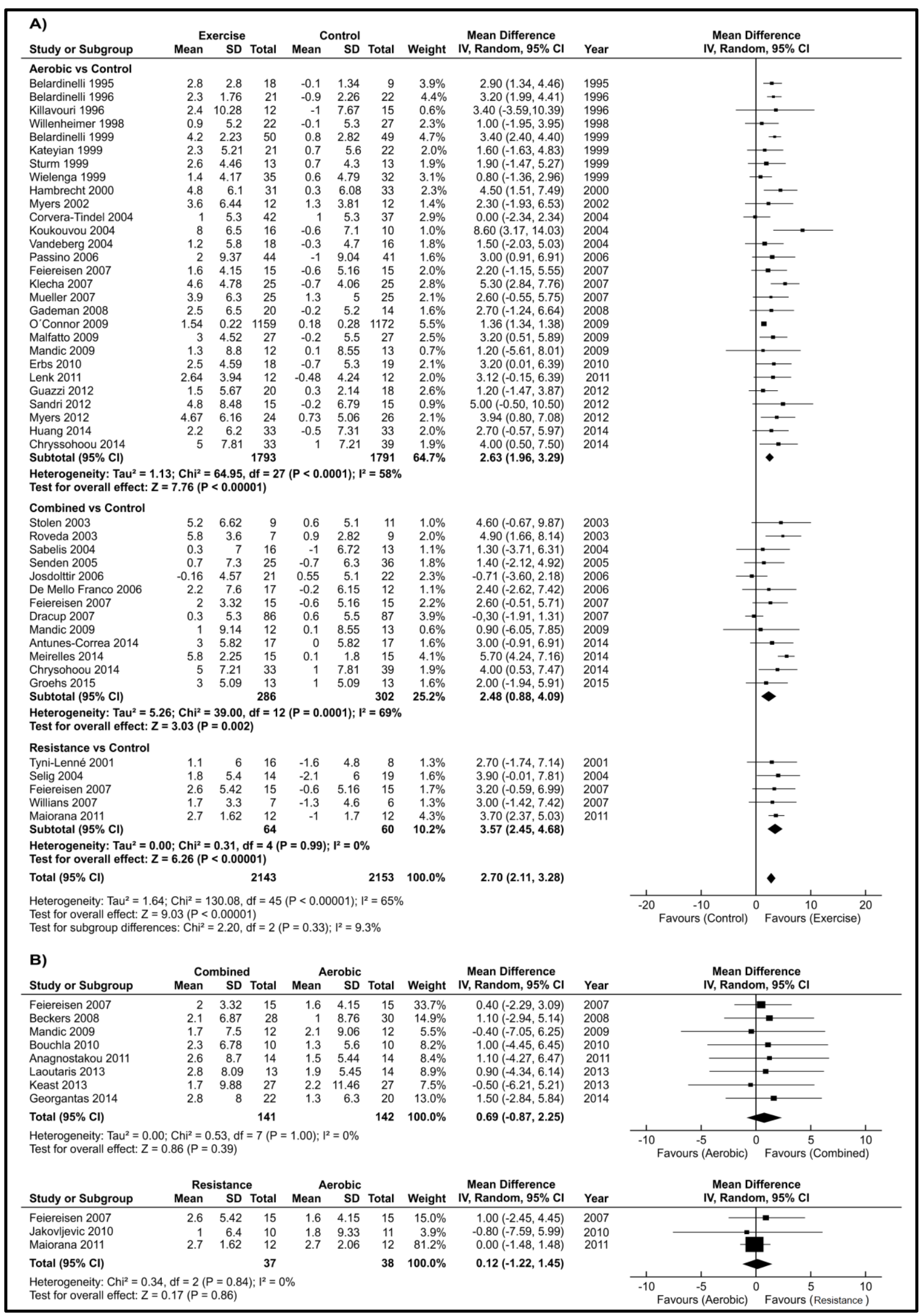

Figura 9. Resultados para o desfecho de $\mathrm{VO}_{2 \text { pico. }}$ A) comparação entre exercício aeróbico, combinado e resistido isolado com grupo controle; e B) Comparações entre exercício combinado e resistido isolado com exercício aeróbico. Fonte: Resultados do presente estudo 


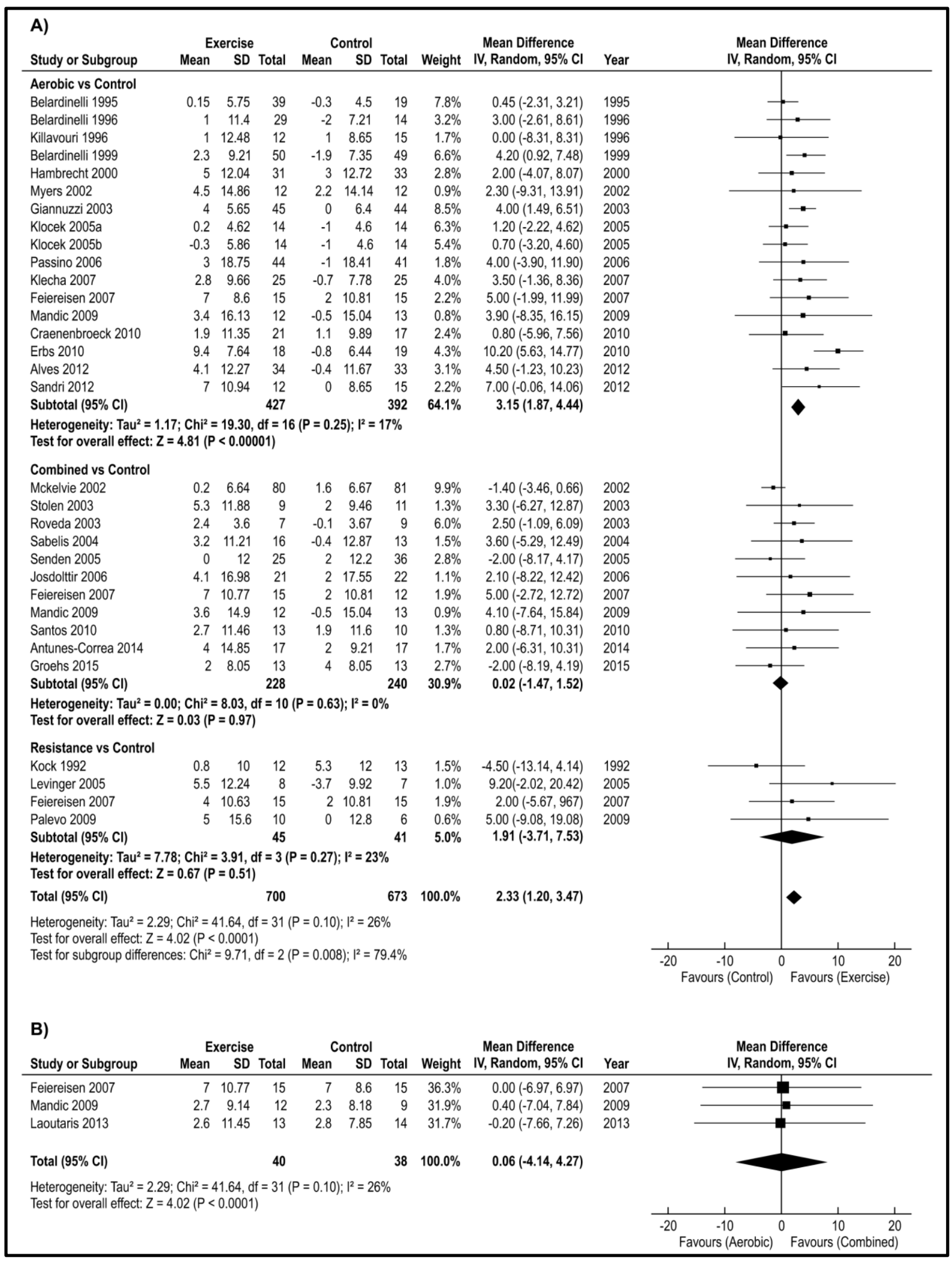

Figura 10. Resultados para o desfecho de Fração de Ejeção. A) comparação entre exercício aeróbico, combinado e resistido isolado com grupo controle; e B) Comparações entre exercício combinado e exercício aeróbico. Fonte: Resultados do presente estudo 


\subsection{Volume Diastólico Final de Ventrículo Esquerdo}

A despeito do fato de que o EA levou a uma melhora no VDFVE (08 estudos, $\mathrm{n}=$ 478 pacientes, $\mathrm{WMD}=-10.21 \mathrm{~mL} 95 \% \mathrm{CI}:-17.64$ a $2.77 \mathrm{~mL}$ ), os efeitos do EC e ER isolado foram inconclusivos (EC: 04 estudos, $\mathrm{n}=239$ pacientes, $\mathrm{WMD}=1,98 \mathrm{~mL} 95 \% \mathrm{CI}:-3.14$ a 7.09 mL / ER: 02 estudos, $\mathrm{n}=46$ pacientes, WMD = -7.93 mL 95\% CI: -49.82 a $33.97 \mathrm{~mL})$. De uma maneira geral, o exercício não foi associado com uma melhora significativa no VDFVE quando os dados de todos os estudos foram examinados (14 estudos, $\mathrm{n}=763$ pacientes, $\mathrm{WMD}=-2.42$ mL 95\% CI: -6.88 a $2.04 \mathrm{~mL}$ ) (Figura 10). Apenas um estudo avaliou os efeitos no LVEDV, porém os dados foram inconclusivos $(\mathrm{n}=30, \mathrm{WMD}=-6.0 \mathrm{~mL} 95 \% \mathrm{CI}:-51.74$ a $39.74 \mathrm{~mL})$. Um estudo comparando EC com ER isolado também obteve resultado inconclusivo $(\mathrm{n}=30$, WMD $=-7.0 \mathrm{~mL} .95 \%$ CI: -67.28 a $53.28 \mathrm{~mL}$ ) assim como na comparação entre ER isolado versus EA $(\mathrm{n}=30, \mathrm{WMD}=1.0 \mathrm{~mL}, 95 \%$ CI: -49.92 a $51.92 \mathrm{~mL})$.

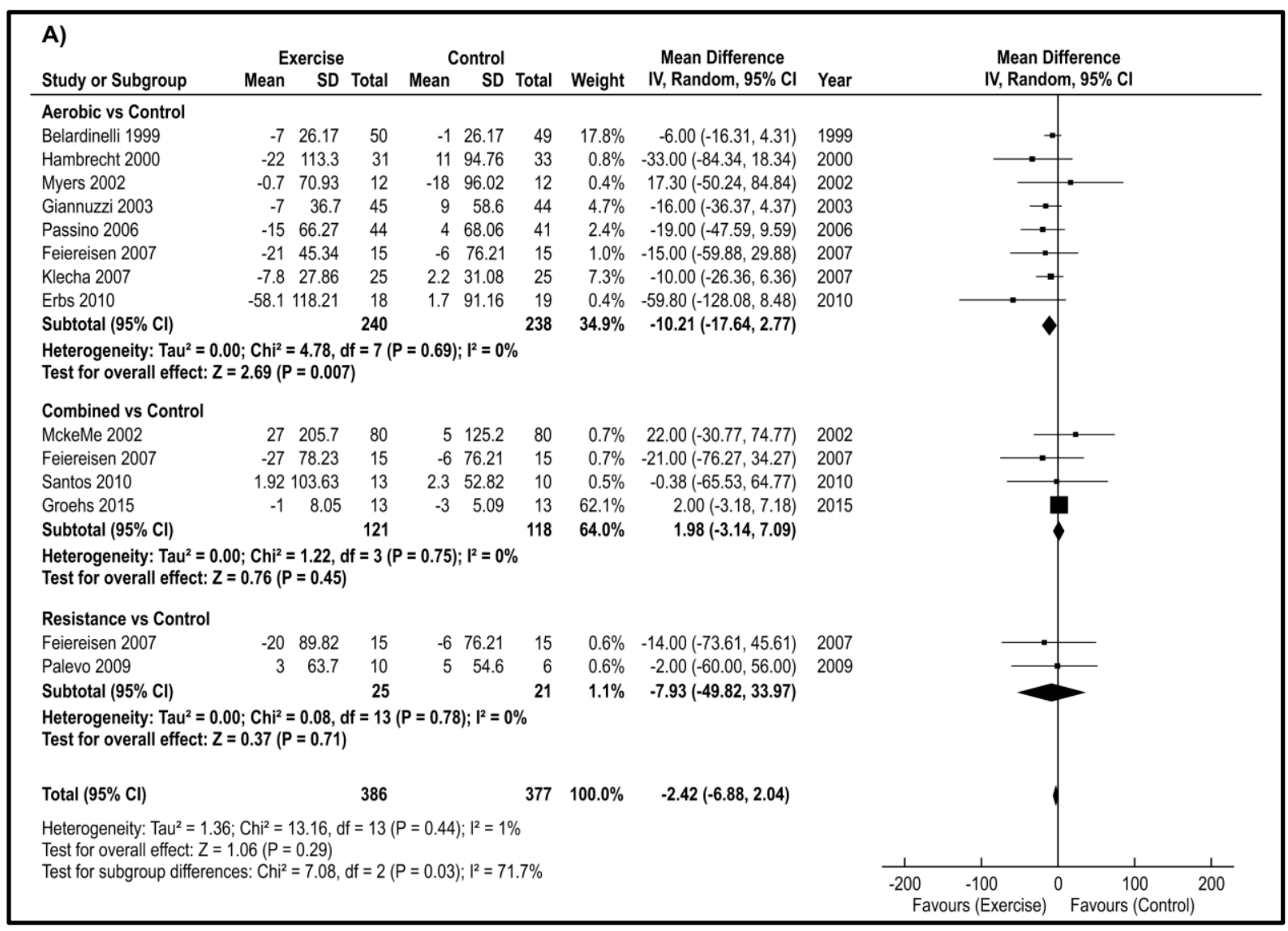

Figura 11. Resultados para o desfecho de Volume Diastólico Final. Comparação entre exercício aeróbico, combinado e resistido isolado com grupo controle. Fonte: Resultados do presente estudo 


\section{DISCUSSÃO}

A presente meta-análise se apoia em evidências atuais e consistentes de que o treinamento de ER em pacientes com ICFEr administrados isoladamente ou em combinação com exercícios aeróbicos, oferece grandes benefícios na capacidade cardiopulmonar sem causar efeitos deletérios sobre a função cardíaca. No entanto, mesmo com a inclusão de estudos mais recentes, o ER isolado ou na forma de EC não tiveram influências sobre as variáveis de Remodelamento Ventricular. Estes resultados adicionam informações relevantes para meta-análise publicada anteriormente ${ }^{(4,7,13)}$.

Adicionalmente, esta metanálise também incluiu uma análise de estudos mais recentes que avaliaram os efeitos do treinamento físico aeróbico sobre os três desfechos de interesse clínico $\left(\mathrm{VO}_{2 \text { pico, }}\right.$ FEVE e VDFVE), para comparar com os obtidos com ER. De acordo com a nossa análise, os efeitos favoráveis do EA nestas variáveis se mantêm, corroborando, portanto com os resultados fornecidos por meta-análises prévias para os desfechos de Remodelamento Ventricular ${ }^{(14)}$ e $\mathrm{VO}_{2 \text { pico }}{ }^{(7)}$. Adicionalmente, os resultados obtidos em nosso estudo no desfecho de $\mathrm{VO}_{2}$ pico são similares aos obtidos em uma metaanálise recente publicada por Dieberg e colaboradores com indivíduos diagnosticados com IC com fração de ejeção preservada. Outrossim, outros autores corroboram estes resultados, relatando efeitos similares no $\mathrm{VO}_{2 \text { pico }}$ entre pacientes com IC com fração de ejeção preservada e reduzida ${ }^{(178)}$.

\subsection{Efeitos do Exercício Resistido Isolado}

O aumento da força e massa muscular resultante do exercício de resistência pode

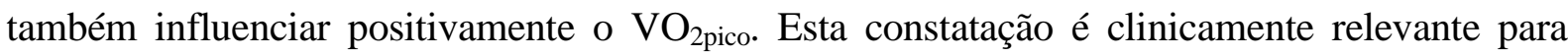
doentes com IC, nos quais a perda de força e massa muscular emerge como um preditor independente de mortalidade ${ }^{(179)}$. Portanto, além da disfunção cardíaca, outro mecanismo de intolerância ao exercício em doentes com IC está relacionado com anormalidades dos músculos esqueléticos ${ }^{(178)}$. No presente estudo, o ER revelou resultados comparáveis ao EA sobre a capacidade cardiopulmonar. Adicionalmente, o $\mathrm{VO}_{2 \text { pico }}$ aumentou significativamente com o ER isolado na comparação com o grupo controle. Em um estudo recente, Feiereisen e colaboradores demonstraram que o ER aumentou significativamente a força muscular periférica em comparação com o exercício aeróbico e um grupo de controle. Além disso, a redução da 
massa muscular no grupo de controle levou a uma redução significativa no $\mathrm{VO}_{2 \text { pico }}{ }^{(12)}$. Ademais, a diminuição da atividade neuro-hormonal como por exemplo a atenuação da atividade do SNS e redução dos níveis de catecolaminas, induzida pelo ER, pode contribuir directamente para melhorar a capacidade de exercício em pacientes com IC ${ }^{(112,122)}$. Estes resultados indicam a importância em aumentar a força e massa muscular como um componente relevante para melhorar o desempenho ao exercício em pacientes com IC.

O presente estudo demonstra que o ER isolado resultou em efeitos neutros sobre a FEVE e na VDFVE. No entanto, estes resultados não anulam os efeitos desta modalidade de exercício na hemodinâmica central desses pacientes. Primeiro, porque a segurança é uma preocupação durante este tipo de intervenção e nenhum efeito deletério no RC foi observado nestes estudos ${ }^{(12,16,113)}$. Em segundo lugar, há um papel importante do ER sobre o mecanismo de RC no que diz respeito às modificações periféricas, como o aumento da capilarização e capacidade oxidativa ${ }^{(180)}$ diminuição da RVP, inibição da deterioração da função hemodinâmica e atenuação da pós-carga de $\mathrm{VE}^{(8,17,112,115,118)}$. Adicionalmente, a não significâcia na análise comparativa dos resultados para o desfecho FEVE em alguns estudos isolados, pode ter sido causada pelo uso de drogas antiremodelamento no grupo controle, o que parece ser um fator confundidor, já que esta terapêutica pode ter contribuido para a atenuação da queda nos valores destas variáveis neste grupo ${ }^{(12,16,115)}$.

Esta revisão sistemática fornece informações relevantes por duas razões. Em primeiro lugar, este estudo acrescenta evidências com a adição de estudos mais recentes de $\mathrm{VO}_{2 \text { pico}}$, FEVE e VDFVE comparando modalidade de ER contra o grupo controle em pacientes com ICFEr. Em segundo lugar, esta é a primeira meta-análise a demonstrar melhora significativa no $\mathrm{VO}_{2 \text { pico }}$ com ER isolado, fato este não demonstrados nas metaanálises prévias ${ }^{(4,13)}$.

\subsection{Efeitos do exercício combinado ao exercício aeróbico}

O Exercício Combinado e EA atingiram um efeito semelhante em relação ao $\mathrm{VO}_{2 \text { pico }}$ e FEVE. Apenas um estudo demonstrou efeito análogo para estas duas intervenções sobre VDFVE ${ }^{(156)}$. Esta modalidade de exercício não demonstrou efeitos adicionais sobre a FEVE e VDFVE em comparação com o grupo controle ou o ER isolado. Em meta-análise anterior de Haykowsky e colaboradores ${ }^{(4)}$ os autores relatam que os efeitos positivos do 
exercício aeróbico sobre estas variáveis não podem ser sustentados com a adição de ER ao EA, justificando este efeito por meio de uma piora do desempenho ventricular causado por uma sobrecarga pressórica excessiva e estresse na parede ventricular mediada pelo ER. No entanto, vários estudos recentes têm demonstrado uma mudança neste paradigma. Eles sugerem que a adição de ER ao EA não desfavoreçe a função cardiovascular em pacientes com ICFEr em qualquer uma das variáveis de RC, tais como pré-carga, pós-carga e FEVE. Além disso, os referidos estudos têm mostrado melhor resposta endotelial ao exercício e resistência vascular após o exercício ${ }^{(8,10,12,15,119-121,123,127,142)}$.

Esta é a primeira meta-análise a demonstrar o efeito favorável do EC na

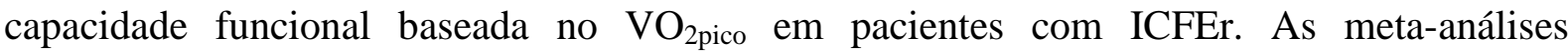
anteriores falharam em demonstrar este efeito ${ }^{(4,13)}$. Tal como demonstrado no presente estudo, a modalidade de EC é capaz de modificar o desempenho do exercício em tais pacientes, aumentando o $\mathrm{VO}_{2 \text { pico }}$ por uma média de $2,48 \mathrm{ml} \bullet \mathrm{kg}-1 \cdot \mathrm{min}-1$. De acordo com os scores de sobrevida atual de pacientes com ICFEr em níveis de $\mathrm{VO}_{2 \text { pico }}(<8 \mathrm{ml} \bullet \mathrm{kg}-1 \bullet \mathrm{min}-1$, 8 a $10 \mathrm{ml} \cdot \mathrm{kg}-1 \cdot \min -1 \mathrm{e}>10 \mathrm{ml} \cdot \mathrm{kg}-1 \cdot \min -1)^{(181)}$, essa magnitude do incremento pode eventualmente ajudar a melhorar o prognóstico desses pacientes, especialmente em participantes em lista de espera para transplante cardíaco. Assim, a inclusão de EC em programas de RCV está diretamente relacionada com melhorias na capacidade cardiorrespiratória em pacientes com ICFEr. Notavelmente, analisando comparativamente esta modalidade com o EA, os efeitos sobre esta variável foram semelhantes.

O principal objetivo de incluir exercícios de resistência em programas de reabilitação em pacientes com IC é certamente a reversão ou atenuação da disfunção vascular periférica e muscular esquelética secundária à síndrome. Além disso, outro efeito esperado com a estratégia de EC descrito na literatura é um aumento na resistência sub-máxima em comparação com o $\mathrm{EA}^{(10,12)}$. Esta última tem apenas ligeiros efeitos sobre essas disfunções ${ }^{(141)}$.

Os resultados da presente meta-análise sobre EC estão de acordo com estudos anteriores, mostrando a eficácia desta modalidade de exercício em ambos a melhoria ou a prevenção de uma piora no $\mathrm{VO}_{2 \text { pico }}$ em pacientes com ICFEr. Adicionalmente, estes resultados estão diretamente relacionados com a aderência dos pacientes ao programa de reabilitação ${ }^{(8)}$. 


\subsection{Limitações do estudo}

Observamos uma grande heterogeneidade nas metanálises, especialmente no EA $\left(\mathrm{I}^{2}=58 \%\right)$ com a inclusão do estudo HF-ACTION. De modo semelhante, observamos também uma heterogeneidade moderada no EC na comparação com o GC ( $\left.\mathrm{I}^{2}=69 \%\right)$. Isto se deveu, principalmente, a presença de dois estudos com resultados desfavoráveis ao grupo de intervenção. Para resolver isso, realizamos análises de subgrupos. Adicionalmente, foram excluídos os ensaios clínicos $(n=2)$ com amostras de pacientes excusivamente idosos. Isso resultou em uma melhor homogeneidade entre os estudos incluídos $\left(\mathrm{I}^{2}<50 \%\right)$ em todas as análises propostas. A qualidade geral dos estudos foi mediana (pontuação média = 5,62 em uma escala de 0 a 10), refletindo uma possibilidade de risco de viés em alguns estudos. Isso pode ter contribuído para a heterogeneidade em algumas das nossas análises. Finalmente, a qualidade dos estudos incluídos nesta meta-análise foi realizada utilizando a escala PEDro. Esta escala foi testada e confirmada em estudos anteriores, demonstrando a sua capacidade de avaliar a qualidade dos ensaios clínicos ${ }^{(182,183)}$. 


\section{CONCLUSÃO}

A descoberta mais convincente em relação aos nossos dados é de que o Exercício Resistido, isolado ou em combinação com EA é uma modalidade de tratamento eficaz para pacientes com ICFEr, com impacto positivo importante no $\mathrm{VO}_{2 \text { pico. }}$ O presente estudo mostra que o ER apresenta-se como uma opção eficaz em minimizar os efeitos no mecanismo de RC, além de uma excelente relação risco-benefício deste tipo de exercício, já que a ausência de efeitos adversos dessa modalidade é claramente sobrepujada pelos seus benefícios nestes pacientes. 


\section{REFERÊNCIAS BIBLIOGRÁFICAS}

1. Coats AJS. The "Muscle Hypothesis" of Chronic Heart Failure. J Mol Cell Cardiol. $1996 ; 28: 7$.

2. Ferraz AS BE, Meneghelo RS, Umeda II, Salvarani N, Guimarães GV, Piegas LS. High sensitive C-reactive protein is reduced by exercise training in chronic heart failure patients. A prospective randomized controlled study. Circulation. 2004;17(suppl):793-4.

3. Clavell AL BJ. Cardiovascular reflex and humoral control od the circulation. In: JG M, editor. Mayo Clinic Cardiology Review. 2nd ed. Philadelphia2000. p. 21-6.

4. Haykowsky MJ, Liang Y, Pechter D, Jones LW, McAlister FA, Clark AM. A metaanalysis of the effect of exercise training on left ventricular remodeling in heart failure patients: the benefit depends on the type of training performed. J Am Coll Cardiol. 2007 Jun 19;49(24):2329-36.

5. Krankel N, Adams V, Gielen S, Linke A, Erbs S, Schuler G, et al. Differential gene expression in skeletal muscle after induction of heart failure: impact of cytokines on protein phosphatase 2A expression. Mol Genet Metab. 2003 Sep-Oct;80(1-2):262-71.

6. Bui AL, Horwich TB, Fonarow GC. Epidemiology and risk profile of heart failure. Nat Rev Cardiol. 2011 Jan;8(1):30-41.

7. van der Meer S, Zwerink M, van Brussel M, van der Valk P, Wajon E, van der Palen J. Effect of outpatient exercise training programmes in patients with chronic heart failure: a systematic review. European Journal of Preventive Cardiology. 2011;19(4):795-803.

8. Mandic S, Tymchak W, Kim D, Daub B, Quinney HA, Taylor D, et al. Effects of aerobic or aerobic and resistance training on cardiorespiratory and skeletal muscle function in heart failure: a randomized controlled pilot trial. Clinical Rehabilitation. 2009;23(3):207-16.

9. Alves AJ, Ribeiro F, Goldhammer E, Rivlin Y, Rosenschein U, Viana JL, et al. Exercise training improves diastolic function in heart failure patients. Med Sci Sports Exerc. 2012 May;44(5):776-85.

10. Beckers PJ, Denollet J, Possemiers NM, Wuyts FL, Vrints CJ, Conraads VM. Combined endurance-resistance training vs. endurance training in patients with chronic 
heart failure: a prospective randomized study. European Heart Journal. 2008;29(15):1858-66.

11. Belardinelli R, Georgiou D, Cianci G, Purcaro A. Randomized, Controlled Trial of Long-Term Moderate Exercise Training in Chronic Heart Failure : Effects on Functional Capacity, Quality of Life, and Clinical Outcome. Circulation. 1999;99(9):1173-82.

12. Feiereisen P, Delagardelle C, Vaillant M, Lasar Y, Beissel J. Is Strength Training the More Efficient Training Modality in Chronic Heart Failure? Medicine \& Science in Sports \& Exercise. 2007;39(11):1910-7.

13. Hwang C-L, Chien C-L, Wu Y-T. Resistance training increases 6-minute walk distance in people with chronic heart failure: a systematic review. Journal of Physiotherapy. 2010;56(2):87-96.

14. Chen YM, Li ZB, Zhu M, Cao YM. Effects of exercise training on left ventricular remodelling in heart failure patients: an updated meta-analysis of randomised controlled trials. Int J Clin Pract. 2012 Aug;66(8):782-91.

15. Laoutaris ID, Adamopoulos S, Manginas A, Panagiotakos DB, Kallistratos MS, Doulaptsis C, et al. Benefits of combined aerobic/resistance/inspiratory training in patients with chronic heart failure. A complete exercise model? A prospective randomised study. International Journal of Cardiology. 2013;167(5):1967-72.

16. Koch M, Douard H, Broustet JP. The benefit of graded physical exercise in chronic heart failure. Chest. 1992 May;101(5 Suppl):231S-5S.

17. Levinger I, Bronks R, Cody DV, Linton I, Davie A. The effect of resistance training on left ventricular function and structure of patients with chronic heart failure. International Journal of Cardiology. 2005;105(2):159-63.

18. Palevo G, Keteyian SJ, Kang M, Caputo JL. Resistance Exercise Training Improves Heart Function and Physical Fitness in Stable Patients With Heart Failure. Journal of Cardiopulmonary Rehabilitation and Prevention. 2009;29(5):294-8. 
19. Roger VL, Go AS, Lloyd-Jones DM, Benjamin EJ, Berry JD, Borden WB, et al. Heart Disease and Stroke Statistics--2012 Update: A Report From the American Heart Association. Circulation. 2011;125(1):e2-e220.

20. Organization WH. Cardiovascular Diseases. [cited 2016 04/15]; Available from: http://www.who.int/cardiovascular_diseases/en/.

21. Brasil P. Doenças cardiovasculares causam quase 30\% das mortes no País. [cited 2016 04/20]; Available from: http://www.brasil.gov.br/saude/2011/09/doencascardiovasculares-causam-quase-30-das-mortes-no-pais.

22. Roth GA, Forouzanfar MH, Moran AE, Barber R, Nguyen G, Feigin VL, et al. Demographic and Epidemiologic Drivers of Global Cardiovascular Mortality. New England Journal of Medicine. 2015;372(14):1333-41.

23. Ziaeian B, Fonarow GC. Epidemiology and aetiology of heart failure. Nature Reviews Cardiology. 2016;13(6):368-78.

24. Nogueira PR, Rassi S, Correa Kde S. Epidemiological, clinical e therapeutic profile of heart failure in a tertiary hospital. Arq Bras Cardiol. 2010 Sep;95(3):392-8.

25. Albuquerque DCd, Souza Neto JDd, Bacal F, Rohde LEP, Bernardez-Pereira S, Berwanger O, et al. I Brazilian Registry of Heart Failure - Clinical Aspects, Care Quality and Hospitalization Outcomes. Arquivos Brasileiros de Cardiologia. 2015.

26. Gerber Y, Weston SA, Redfield MM, Chamberlain AM, Manemann SM, Jiang R, et al. A Contemporary Appraisal of the Heart Failure Epidemic in Olmsted County, Minnesota, 2000 to 2010. JAMA Internal Medicine. 2015;175(6):996.

27. Zarrinkoub R, Wettermark B, Wändell P, Mejhert M, Szulkin R, Ljunggren G, et al. The epidemiology of heart failure, based on data for 2.1 million inhabitants in Sweden. European Journal of Heart Failure. 2013;15(9):995-1002.

28. Levy D, Kenchaiah S, Larson MG, Benjamin EJ, Kupka MJ, Ho KK, et al. Long-term trends in the incidence of and survival with heart failure. N Engl J Med. 2002 Oct 31;347(18):1397-402.

29. Bytyçi I, Bajraktari G. Mortality in heart failure patients. Anadolu Kardiyoloji Dergisi/The Anatolian Journal of Cardiology. 2015;15(1):63-8. 
30. Datasus MdS. Mortalidade - 1996 a 2012, pela CID-10 - Brasil [Internet]. Brasília (DF). 2008 [cited 2016 04/20]; Available from:

http://tabnet.datasus.gov.br/cgi/deftohtm.exe?sim/cnv/obt10uf.def.

31. Yancy CW, Jessup M, Bozkurt B, Butler J, Casey DE, Jr., Drazner MH, et al. 2013 ACCF/AHA guideline for the management of heart failure: a report of the American College of Cardiology Foundation/American Heart Association Task Force on practice guidelines. Circulation. 2013 Oct 15;128(16):e240-327.

32. McMurray JJV, Adamopoulos S, Anker SD, Auricchio A, Bohm M, Dickstein K, et al. ESC Guidelines for the diagnosis and treatment of acute and chronic heart failure 2012: The Task Force for the Diagnosis and Treatment of Acute and Chronic Heart Failure 2012 of the European Society of Cardiology. Developed in collaboration with the Heart Failure Association (HFA) of the ESC. European Heart Journal. 2012;33(14):1787-847.

33. Bocchi EA, Braga FG, Ferreira SM, Rohde LE, Oliveira WA, Almeida DR, et al. [III Brazilian Guidelines on Chronic Heart Failure]. Arq Bras Cardiol. 2009;93(1 Suppl 1):3-70.

34. Callow AD. Cardiovascular disease 2005 - the global picture. Vascular Pharmacology. 2006;45(5):302-7.

35. Rigolli M, Whalley GA. Heart failure with preserved ejection fraction. J Geriatr Cardiol. 2013 Dec;10(4):369-76.

36. Gedela M, Khan M, Jonsson O. Heart Failure. S D Med. 2015 Sep;68(9):403-5, 7-9.

37. Bocchi EA, Marcondes-Braga FG, Bacal F, Ferraz AS, Albuquerque D, Rodrigues Dde A, et al. [Updating of the Brazilian guideline for chronic heart failure - 2012]. Arq Bras Cardiol. 2012 Jan;98(1 Suppl 1):1-33.

38. Brouwers FP, de Boer RA, van der Harst P, Voors AA, Gansevoort RT, Bakker SJ, et al. Incidence and epidemiology of new onset heart failure with preserved vs. reduced ejection fraction in a community-based cohort: 11-year follow-up of PREVEND.

European Heart Journal. 2013;34(19):1424-31. 
39. Pina IL. Exercise and Heart Failure: A Statement From the American Heart Association Committee on Exercise, Rehabilitation, and Prevention. Circulation. 2003;107(8):121025.

40. Phillips SA, Vuckovic K, Cahalin LP, Baynard T. Defining the system: contributors to exercise limitations in heart failure. Heart Fail Clin. 2015 Jan;11(1):1-16.

41. Kitzman DW, Higginbotham MB, Cobb FR, Sheikh KH, Sullivan MJ. Exercise intolerance in patients with heart failure and preserved left ventricular systolic function: failure of the Frank-Starling mechanism. J Am Coll Cardiol. 1991 Apr;17(5):1065-72.

42. Borlaug BA, Olson TP, Lam CS, Flood KS, Lerman A, Johnson BD, et al. Global cardiovascular reserve dysfunction in heart failure with preserved ejection fraction. $\mathbf{J}$ Am Coll Cardiol. 2010 Sep 7;56(11):845-54.

43. Haykowsky MJ, Brubaker PH, John JM, Stewart KP, Morgan TM, Kitzman DW. Determinants of exercise intolerance in elderly heart failure patients with preserved ejection fraction. J Am Coll Cardiol. 2011 Jul 12;58(3):265-74.

44. Abudiab MM, Redfield MM, Melenovsky V, Olson TP, Kass DA, Johnson BD, et al. Cardiac output response to exercise in relation to metabolic demand in heart failure with preserved ejection fraction. European Journal of Heart Failure. 2013;15(7):776-85.

45. Shibata S, Hastings JL, Prasad A, Fu Q, Bhella PS, Pacini E, et al. Congestive heart failure with preserved ejection fraction is associated with severely impaired dynamic Starling mechanism. J Appl Physiol (1985). 2011 Apr;110(4):964-71.

46. Borlaug BA, Nishimura RA, Sorajja P, Lam CSP, Redfield MM. Exercise Hemodynamics Enhance Diagnosis of Early Heart Failure With Preserved Ejection Fraction. Circulation: Heart Failure. 2010;3(5):588-95.

47. Hammoudi N, Achkar M, Laveau F, Boubrit L, Djebbar M, Allali Y, et al. Left atrial volume predicts abnormal exercise left ventricular filling pressure. European Journal of Heart Failure. 2014;16(10):1089-95.

48. Witte KKA. Chronic heart failure, chronotropic incompetence, and the effects of blockade. Heart. 2005;92(4):481-6. 
49. Keller-Ross ML, Johnson BD, Joyner MJ, Olson TP. Influence of the metaboreflex on arterial blood pressure in heart failure patients. American Heart Journal. 2014;167(4):521-8.

50. Notarius CF, Millar PJ, Floras JS. Muscle sympathetic activity in resting and exercising humans with and without heart failure1. Applied Physiology, Nutrition, and Metabolism. 2015;40(11):1107-15.

51. Notarius CF, Ando S, Rongen GA, Floras JS. Resting muscle sympathetic nerve activity and peak oxygen uptake in heart failure and normal subjects. Eur Heart J. 1999 Jun;20(12):880-7.

52. Notarius CF, Atchison DJ, Floras JS. Impact of heart failure and exercise capacity on sympathetic response to handgrip exercise. Am J Physiol Heart Circ Physiol. 2001 Mar;280(3):H969-76.

53. Notarius CF, Azevedo ER, Parker JD, Floras JS. Peak oxygen uptake is not determined by cardiac noradrenaline spillover in heart failure. Eur Heart J. 2002 May;23(10):800-5.

54. Floras JS. Sympathetic Nervous System Activation in Human Heart Failure. Journal of the American College of Cardiology. 2009;54(5):375-85.

55. Kishi T. Heart failure as an autonomic nervous system dysfunction. Journal of Cardiology. 2012;59(2):117-22.

56. Azevedo PS, Polegato BF, Minicucci MF, Paiva SAR, Zornoff LAM. Cardiac Remodeling: Concepts, Clinical Impact, Pathophysiological Mechanisms and Pharmacologic Treatment. Arquivos Brasileiros de Cardiologia. 2016.

57. Ponikowski P, Chua TP, Anker SD, Francis DP, Doehner W, Banasiak W, et al. Peripheral Chemoreceptor Hypersensitivity: An Ominous Sign in Patients With Chronic Heart Failure. Circulation. 2001;104(5):544-9.

58. Di Vanna A, Braga AM, Laterza MC, Ueno LM, Rondon MU, Barretto AC, et al. Blunted muscle vasodilatation during chemoreceptor stimulation in patients with heart failure. Am J Physiol Heart Circ Physiol. 2007 Jul;293(1):H846-52.

59. Georgiadou P, Adamopoulos S. Skeletal Muscle Abnormalities in Chronic Heart Failure. Current Heart Failure Reports. 2012;9(2):128-32. 
60. Ray CA. Muscle sympathetic nerve responses to prolonged one-legged exercise. J Appl Physiol (1985). 1993 Apr;74(4):1719-22.

61. Ray CA, Mark AL. Augmentation of muscle sympathetic nerve activity during fatiguing isometric leg exercise. J Appl Physiol (1985). 1993 Jul;75(1):228-32.

62. Mark AL, Victor RG, Nerhed C, Wallin BG. Microneurographic studies of the mechanisms of sympathetic nerve responses to static exercise in humans. Circ Res. 1985 Sep;57(3):461-9.

63. Belli J, Bacal, F, Bocchi, E.A, Guimarães, G.V. Ergoreflex Activity in Heart Failure. Arq Bras Cardiol. [Review]. 2011;97(2):8.

64. Poole DC, Hirai DM, Copp SW, Musch TI. Muscle oxygen transport and utilization in heart failure: implications for exercise (in)tolerance. Am J Physiol Heart Circ Physiol. 2012 Mar 1;302(5):H1050-63.

65. Ukkonen H, Burwash IG, Dafoe W, de Kemp RA, Haddad H, Yoshinaga K, et al. Is ventilatory efficiency (VE/VCO2slope) associated with right ventricular oxidative metabolism in patients with congestive heart failure? European Journal of Heart Failure. 2008;10(11):1117-22.

66. Brassard P, Gustafsson F. Exercise Intolerance in Heart Failure: Did We Forget the Brain? Canadian Journal of Cardiology. 2016;32(4):475-84.

67. Hill JA, Olson EN. Cardiac plasticity. N Engl J Med. 2008 Mar 27;358(13):1370-80.

68. Norton GR, Woodiwiss AJ, Gaasch WH, Mela T, Chung ES, Aurigemma GP, et al. Heart failure in pressure overload hypertrophy. The relative roles of ventricular remodeling and myocardial dysfunction. J Am Coll Cardiol. 2002 Feb 20;39(4):664-71.

69. Cohn JN, Ferrari R, Sharpe N. Cardiac remodeling--concepts and clinical implications: a consensus paper from an international forum on cardiac remodeling. Behalf of an International Forum on Cardiac Remodeling. J Am Coll Cardiol. 2000 Mar 1;35(3):56982.

70. Anand IS, Florea VG, Solomon SD, Konstam MA, Udelson JE. Noninvasive assessment of left ventricular remodeling: Concepts, techniques, and implications for clinical trials. Journal of Cardiac Failure. 2002;8(6):S452-S64. 
71. Bosimini E, Giannuzzi P, Temporelli PL, Gentile F, Lucci D, Maggioni AP, et al. Electrocardiographic evolutionary changes and left ventricular remodeling after acute myocardial infarction: results of the GISSI-3 Echo substudy. J Am Coll Cardiol. 2000 Jan;35(1):127-35.

72. Udelson JE, Konstam MA. Relation between left ventricular remodeling and clinical outcomes in heart failure patients with left ventricular systolic dysfunction. Journal of Cardiac Failure. 2002;8(6):S465-S71.

73. King KM, Humen DP, Teo KK. Cardiac rehabilitation: the forgotten intervention. Can J Cardiol. 1999 Sep;15(9):979-85.

74. Oldridge NB, Ragowski, B., Gotlieb, M. Use of outpatient cardiac rehabilitation services: factors associated with attendance. J cardiopulm Rehabil. 1992;12:7.

75. Gielen S, Laughlin MH, O'Conner C, Duncker DJ. Exercise Training in Patients with Heart Disease: Review of Beneficial Effects and Clinical Recommendations. Progress in Cardiovascular Diseases. 2015;57(4):347-55.

76. Williams MA, Haskell WL, Ades PA, Amsterdam EA, Bittner V, Franklin BA, et al. Resistance exercise in individuals with and without cardiovascular disease: 2007 update: a scientific statement from the American Heart Association Council on Clinical Cardiology and Council on Nutrition, Physical Activity, and Metabolism. Circulation. 2007 Jul 31;116(5):572-84.

77. Huang SC, Wong MK, Lin PJ, Tsai FC, Fu TC, Wen MS, et al. Modified high-intensity interval training increases peak cardiac power output in patients with heart failure. Eur $\mathrm{J}$ Appl Physiol. 2014 Sep;114(9):1853-62.

78. Klecha A, Kawecka-Jaszcz K, Bacior B, Kubinyi A, Pasowicz M, Klimeczek P, et al. Physical training in patients with chronic heart failure of ischemic origin: effect on exercise capacity and left ventricular remodeling. Eur J Cardiovasc Prev Rehabil. 2007 Feb;14(1):85-91.

79. Lenk K, Erbs S, Hollriegel R, Beck E, Linke A, Gielen S, et al. Exercise training leads to a reduction of elevated myostatin levels in patients with chronic heart failure. European Journal of Preventive Cardiology. 2011;19(3):404-11. 
80. Negrao CE, Middlekauff HR, Gomes-Santos IL, Antunes-Correa LM. Effects of exercise training on neurovascular control and skeletal myopathy in systolic heart failure. Am J Physiol Heart Circ Physiol. 2015 Apr 15;308(8):H792-802.

81. Gademan MG, Swenne CA, Verwey HF, van de Vooren H, Haest JC, van Exel HJ, et al. Exercise training increases oxygen uptake efficiency slope in chronic heart failure. Eur J Cardiovasc Prev Rehabil. 2008 Apr;15(2):140-4.

82. Piepoli MF, Davos C, Francis DP, Coats AJ. Exercise training meta-analysis of trials in patients with chronic heart failure (ExTraMATCH). Bmj. 2004 Jan 24;328(7433):189.

83. O'Connor CM, Whellan DJ, Lee KL, Keteyian SJ, Cooper LS, Ellis SJ, et al. Efficacy and safety of exercise training in patients with chronic heart failure: HF-ACTION randomized controlled trial. JAMA. 2009 Apr 8;301(14):1439-50.

84. Keteyian SJ, Leifer ES, Houston-Miller N, Kraus WE, Brawner CA, O'Connor CM, et al. Relation between volume of exercise and clinical outcomes in patients with heart failure. J Am Coll Cardiol. 2012 Nov 6;60(19):1899-905.

85. Sandri M, Kozarez I, Adams V, Mangner N, Hollriegel R, Erbs S, et al. Age-related effects of exercise training on diastolic function in heart failure with reduced ejection fraction: The Leipzig Exercise Intervention in Chronic Heart Failure and Aging (LEICA) Diastolic Dysfunction Study. European Heart Journal. 2012;33(14):1758-68.

86. Passino C, Severino S, Poletti R, Piepoli MF, Mammini C, Clerico A, et al. Aerobic Training Decreases B-Type Natriuretic Peptide Expression and Adrenergic Activation in Patients With Heart Failure. Journal of the American College of Cardiology. 2006;47(9):1835-9.

87. Erbs S, Hollriegel R, Linke A, Beck EB, Adams V, Gielen S, et al. Exercise Training in Patients With Advanced Chronic Heart Failure (NYHA IIIb) Promotes Restoration of Peripheral Vasomotor Function, Induction of Endogenous Regeneration, and Improvement of Left Ventricular Function. Circulation: Heart Failure. 2010;3(4):48694.

88. Hambrecht R, Gielen S, Linke A, Fiehn E, Yu J, Walther C, et al. Effects of exercise training on left ventricular function and peripheral resistance in patients with chronic heart failure: A randomized trial. JAMA. 2000 Jun 21;283(23):3095-101. 
89. Malfatto G, Branzi G, Osculati G, Valli P, Cuoccio P, Ciambellotti F, et al. Improvement in Left Ventricular Diastolic Stiffness Induced by Physical Training in Patients With Dilated Cardiomyopathy. Journal of Cardiac Failure. 2009;15(4):327-33.

90. Vromen T, Kraal JJ, Kuiper J, Spee RF, Peek N, Kemps HM. The influence of training characteristics on the effect of aerobic exercise training in patients with chronic heart failure: A meta-regression analysis. International Journal of Cardiology. 2016;208:1207.

91. Ismail H, McFarlane JR, Dieberg G, Smart NA. Exercise training program characteristics and magnitude of change in functional capacity of heart failure patients. Int J Cardiol. 2014 Jan 15;171(1):62-5.

92. Myers J, Prakash M, Froelicher V, Do D, Partington S, Atwood JE. Exercise capacity and mortality among men referred for exercise testing. N Engl J Med. 2002 Mar $14 ; 346(11): 793-801$.

93. Chrysohoou C, Tsitsinakis G, Vogiatzis I, Cherouveim E, Antoniou C, Tsiantilas A, et al. High intensity, interval exercise improves quality of life of patients with chronic heart failure: a randomized controlled trial. Qjm. 2014 Jan;107(1):25-32.

94. Koukouvou G, Kouidi E, Iacovides A, Konstantinidou E, Kaprinis G, Deligiannis A. Quality of life, psychological and physiological changes following exercise training in patients with chronic heart failure. Journal of Rehabilitation Medicine. 2004;36(1):3641.

95. Belardinelli R, Georgiou D, Scocco V, Barstow TJ, Purcaro A. Low intensity exercise training in patients with chronic heart failure. J Am Coll Cardiol. 1995 Oct;26(4):97582.

96. Belardinelli R, Georgiou D, Cianci G, Purcaro A. Effects of exercise training on left ventricular filling at rest and during exercise in patients with ischemic cardiomyopathy and severe left ventricular systolic dysfunction. Am Heart J. 1996 Jul;132(1 Pt 1):61-70.

97. Corvera-Tindel T, Doering LV, Woo MA, Khan S, Dracup K. Effects of a home walking exercise program on functional status and symptoms in heart failure. American Heart Journal. 2004;147(2):339-46. 
98. Kiilavuori K, Sovijarvi A, Naveri H, Ikonen T, Leinonen H. Effect of physical training on exercise capacity and gas exchange in patients with chronic heart failure. Chest. 1996 Oct;110(4):985-91.

99. van den Berg-Emons R, Balk A, Bussmann H, Stam H. Does aerobic training lead to a more active lifestyle and improved quality of life in patients with chronic heart failure? European Journal of Heart Failure. 2004;6(1):95-100.

100. Wielenga RP, Huisveld IA, Bol E, Dunselman PH, Erdman RA, Baselier MR, et al. Safety and effects of physical training in chronic heart failure. Results of the Chronic Heart Failure and Graded Exercise study (CHANGE). Eur Heart J. 1999 Jun;20(12):872-9.

101. Willenheimer R, Erhardt L, Cline C, Rydberg E, Israelsson B. Exercise training in heart failure improves quality of life and exercise capacity. Eur Heart J. 1998 May;19(5):77481.

102. Sturm B, Quittan M, Wiesinger GF, Stanek B, Frey B, Pacher R. Moderate-intensity exercise training with elements of step aerobics in patients with severe chronic heart failure. Arch Phys Med Rehabil. 1999 Jul;80(7):746-50.

103. Davies LC, Wensel R, Georgiadou P, Cicoira M, Coats AJ, Piepoli MF, et al. Enhanced prognostic value from cardiopulmonary exercise testing in chronic heart failure by nonlinear analysis: oxygen uptake efficiency slope. Eur Heart J. 2006 Mar;27(6):684-90.

104. Van Laethem C, Van De Veire N, De Backer G, Bihija S, Seghers T, Cambier D, et al. Response of the oxygen uptake efficiency slope to exercise training in patients with chronic heart failure. Eur J Heart Fail. 2007 Jun-Jul;9(6-7):625-9.

105. Myers J, Gademan M, Brunner K, Kottman W, Boesch C, Dubach P. Effects of HighIntensity Training on Indices of Ventilatory Efficiency in Chronic Heart Failure. Journal of Cardiopulmonary Rehabilitation and Prevention. 2012;32(1):9-16.

106. Mueller L, Myers J, Kottman W, Oswald U, Boesch C, Arbrol N, et al. Exercise capacity, physical activity patterns and outcomes six years after cardiac rehabilitation in patients with heart failure. Clin Rehabil. 2007 Oct;21(10):923-31. 
107. Braith RW, Beck DT. Resistance exercise: training adaptations and developing a safe exercise prescription. Heart Failure Reviews. 2007;13(1):69-79.

108. Featherstone JF, Holly RG, Amsterdam EA. Physiologic responses to weight lifting in coronary artery disease. Am J Cardiol. 1993 Feb 1;71(4):287-92.

109. Gordon NF, Kohl HW, 3rd, Pollock ML, Vaandrager H, Gibbons LW, Blair SN. Cardiovascular safety of maximal strength testing in healthy adults. Am J Cardiol. 1995 Oct 15;76(11):851-3.

110. Volaklis KA, Tokmakidis SP. Resistance exercise training in patients with heart failure. Sports Med. 2005;35(12):1085-103.

111. Meyer K, Hajric R, Westbrook S, Haag-Wildi S, Holtkamp R, Leyk D, et al. Hemodynamic responses during leg press exercise in patients with chronic congestive heart failure. Am J Cardiol. 1999 Jun 1;83(11):1537-43.

112. Tyni-Lenne R, Dencker K, Gordon A, Jansson E, Sylven C. Comprehensive local muscle training increases aerobic working capacity and quality of life and decreases neurohormonal activation in patients with chronic heart failure. Eur J Heart Fail. 2001 Jan;3(1):47-52.

113. Maiorana A, O'Driscoll G, Cheetham C, Collis J, Goodman C, Rankin S, et al. Combined aerobic and resistance exercise training improves functional capacity and strength in CHF. J Appl Physiol (1985). 2000 May;88(5):1565-70.

114. Hare DL, Ryan TM, Selig SE, Pellizzer AM, Wrigley TV, Krum H. Resistance exercise training increases muscle strength, endurance, and blood flow in patients with chronic heart failure. Am J Cardiol. 1999 Jun 15;83(12):1674-7, A7.

115. Selig S, Carey M, Menzies D, Patterson J, Geerling R, Williams A, et al. Moderateintensity resistance exercise training in patients with chronic heart failure improves strength, endurance, heart rate variability, and forearm blood flow*1. Journal of Cardiac Failure. 2004;10(1):21-30.

116. Jondeau G, Katz SD, Zohman L, Goldberger M, McCarthy M, Bourdarias JP, et al. Active skeletal muscle mass and cardiopulmonary reserve. Failure to attain peak aerobic 
capacity during maximal bicycle exercise in patients with severe congestive heart failure. Circulation. 1992 Nov;86(5):1351-6.

117. Jakovljevic DG, Donovan G, Nunan D, McDonagh S, Trenell MI, Grocott-Mason R, et al. The effect of aerobic versus resistance exercise training on peak cardiac power output and physical functional capacity in patients with chronic heart failure. Int $\mathbf{J}$ Cardiol. 2010 Dec 3;145(3):526-8.

118. Maiorana AJ, Naylor LH, Exterkate A, Swart A, Thijssen DH, Lam K, et al. The impact of exercise training on conduit artery wall thickness and remodeling in chronic heart failure patients. Hypertension. 2011 Jan;57(1):56-62.

119. Stolen KQ, Kemppainen J, Ukkonen H, Kalliokoski KK, Luotolahti M, Lehikoinen P, et al. Exercise training improves biventricular oxidative metabolism and left ventricular efficiency in patients with dilated cardiomyopathy. J Am Coll Cardiol. 2003 Feb 5;41(3):460-7.

120. McKelvie RS, Teo KK, Roberts R, McCartney N, Humen D, Montague T, et al. Effects of exercise training in patients with heart failure: The Exercise Rehabilitation Trial (EXERT). American Heart Journal. 2002;144(1):23-30.

121. Roveda F, Middlekauff HR, Rondon MU, Reis SF, Souza M, Nastari L, et al. The effects of exercise training on sympathetic neural activation in advanced heart failure: a randomized controlled trial. J Am Coll Cardiol. 2003 Sep 3;42(5):854-60.

122. Antunes-Correa LM, Nobre TS, Groehs RV, Alves MJ, Fernandes T, Couto GK, et al. Molecular basis for the improvement in muscle metaboreflex and mechanoreflex control in exercise-trained humans with chronic heart failure. Am J Physiol Heart Circ Physiol. 2014 Dec 1;307(11):H1655-66.

123. Sabelis LW, Senden PJ, Fijnheer R, de Groot PG, Huisveld IA, Mosterd WL, et al. Endothelial markers in chronic heart failure: training normalizes exercise-induced $\mathrm{vWF}$ release. Eur J Clin Invest. 2004 Sep;34(9):583-9.

124. de Meirelles LR, Matsuura C, Resende Ade C, Salgado AA, Pereira NR, Coscarelli PG, et al. Chronic exercise leads to antiaggregant, antioxidant and anti-inflammatory effects in heart failure patients. Eur J Prev Cardiol. 2014 Oct;21(10):1225-32. 
125. Senden PJ, Sabelis LW, Zonderland ML, Hulzebos EH, Bol E, Mosterd WL. The effect of physical training on workload, upper leg muscle function and muscle areas in patients with chronic heart failure. International Journal of Cardiology. 2005;100(2):293-300.

126. Dracup K, Evangelista LS, Hamilton MA, Erickson V, Hage A, Moriguchi J, et al. Effects of a home-based exercise program on clinical outcomes in heart failure. American Heart Journal. 2007;154(5):877-83.

127. Jonsdottir S, Andersen KK, Sigurosson AF, Sigurosson SB. The effect of physical training in chronic heart failure. Eur J Heart Fail. 2006 Jan;8(1):97-101.

128. Bouchla A, Karatzanos E, Dimopoulos S, Tasoulis A, Agapitou V, Diakos N, et al. The addition of strength training to aerobic interval training: effects on muscle strength and body composition in CHF patients. J Cardiopulm Rehabil Prev. 2011 Jan-Feb;31(1):4751.

129. Anagnostakou V, Chatzimichail K, Dimopoulos S, Karatzanos E, Papazachou O, Tasoulis A, et al. Effects of Interval Cycle Training With or Without Strength Training on Vascular Reactivity in Heart Failure Patients. Journal of Cardiac Failure. 2011;17(7):585-91.

130. Georgantas A, Dimopoulos S, Tasoulis A, Karatzanos E, Pantsios C, Agapitou V, et al. Beneficial Effects of Combined Exercise Training on Early Recovery Cardiopulmonary Exercise Testing Indices in Patients With Chronic Heart Failure. Journal of Cardiopulmonary Rehabilitation and Prevention. 2014;34(6):378-85.

131. Santos JM, Kowatsch I, Tsutsui JM, Negrao CE, Canavesi N, Carvalho Frimm C, et al. Effects of exercise training on myocardial blood flow reserve in patients with heart failure and left ventricular systolic dysfunction. Am J Cardiol. 2010 Jan 15;105(2):2438.

132. Chrysohoou C, Angelis A, Tsitsinakis G, Spetsioti S, Nasis I, Tsiachris D, et al. Cardiovascular effects of high-intensity interval aerobic training combined with strength exercise in patients with chronic heart failure. A randomized phase III clinical trial. International Journal of Cardiology. 2015;179:269-74. 
133. Keast ML, Slovinec D'Angelo ME, Nelson CR, Turcotte SE, McDonnell LA, Nadler RE, et al. Randomized trial of Nordic walking in patients with moderate to severe heart failure. Can J Cardiol. 2013 Nov;29(11):1470-6.

134. de Mello Franco FG, Santos AC, Rondon MUP, Trombetta IC, Strunz C, Braga AMW, et al. Effects of home-based exercise training on neurovascular control in patients with heart failure. European Journal of Heart Failure. 2006;8(8):851-5.

135. Higgins JPT, Green S, Cochrane Collaboration. Cochrane handbook for systematic reviews of interventions. Chichester, England ; Hoboken, NJ: Wiley-Blackwell; 2008.

136. Shiwa SRea. PEDro: a base de dados de evidências em fisioterapia. Fisioter mov (Impr) [online]. 2011;24(3):10.

137. Verhagen AP, de Vet HC, de Bie RA, Kessels AG, Boers M, Bouter LM, et al. The Delphi list: a criteria list for quality assessment of randomized clinical trials for conducting systematic reviews developed by Delphi consensus. J Clin Epidemiol. 1998 Dec;51(12):1235-41.

138. Aslanger E, Assous B, Bihry N, Beauvais F, Logeart D, Cohen-Solal A. Effects of Cardiopulmonary Exercise Rehabilitation on Left Ventricular Mechanical Efficiency and Ventricular-Arterial Coupling in Patients With Systolic Heart Failure. J Am Heart Assoc. 2015;4(10).

139. Caminiti G, Volterrani M, Marazzi G, Cerrito A, Massaro R, Sposato B, et al. Hydrotherapy added to endurance training versus endurance training alone in elderly patients with chronic heart failure: a randomized pilot study. Int J Cardiol. 2011 Apr $14 ; 148(2): 199-203$.

140. Cheetham C, Green D, Collis J, Dembo L, O'Driscoll G. Effect of aerobic and resistance exercise on central hemodynamic responses in severe chronic heart failure. J Appl Physiol (1985). 2002 Jul;93(1):175-80.

141. Delagardelle C, Feiereisen P, Autier P, Shita R, Krecke R, Beissel J. Strength/endurance training versus endurance training in congestive heart failure. Med Sci Sports Exerc. 2002 Dec;34(12):1868-72. 
142. Edelmann F, Gelbrich G, Dungen HD, Frohling S, Wachter R, Stahrenberg R, et al. Exercise training improves exercise capacity and diastolic function in patients with heart failure with preserved ejection fraction: results of the Ex-DHF (Exercise training in Diastolic Heart Failure) pilot study. J Am Coll Cardiol. 2011 Oct 18;58(17):1780-91.

143. Gary RA, Cress ME, Higgins MK, Smith AL, Dunbar SB. Combined aerobic and resistance exercise program improves task performance in patients with heart failure. Arch Phys Med Rehabil. 2011 Sep;92(9):1371-81.

144. Gary RA, Cress ME, Higgins MK, Smith AL, Dunbar SB. A combined aerobic and resistance exercise program improves physical functional performance in patients with heart failure: a pilot study. J Cardiovasc Nurs. 2012 Sep-Oct;27(5):418-30.

145. Jankowska EA, Witkowski T, Ponikowska B, Reczuch K, Borodulin-Nadzieja L, Anker $\mathrm{SD}$, et al. Excessive ventilation during early phase of exercise: a new predictor of poor long-term outcome in patients with chronic heart failure. Eur J Heart Fail. 2007 Oct;9(10):1024-31.

146. Kemps HM, de Vries WR, Schmikli SL, Zonderland ML, Hoogeveen AR, Thijssen EJ, et al. Assessment of the effects of physical training in patients with chronic heart failure: the utility of effort-independent exercise variables. Eur J Appl Physiol. 2010 Feb;108(3):469-76.

147. Miche E, Roelleke E, Wirtz U, Zoller B, Tietz M, Huerst M, et al. Combined endurance and muscle strength training in female and male patients with chronic heart failure. Clin Res Cardiol. 2008 Sep;97(9):615-22.

148. Savage PA, Shaw AO, Miller MS, VanBuren P, LeWinter MM, Ades PA, et al. Effect of resistance training on physical disability in chronic heart failure. Med Sci Sports Exerc. 2011 Aug;43(8):1379-86.

149. Tyni-Lenne R, Gordon A, Jansson E, Bermann G, Sylven C. Skeletal muscle endurance training improves peripheral oxidative capacity, exercise tolerance, and health-related quality of life in women with chronic congestive heart failure secondary to either ischemic cardiomyopathy or idiopathic dilated cardiomyopathy. Am J Cardiol. 1997 Oct 15;80(8):1025-9. 
150. Coats AJ, Adamopoulos S, Radaelli A, McCance A, Meyer TE, Bernardi L, et al. Controlled trial of physical training in chronic heart failure. Exercise performance, hemodynamics, ventilation, and autonomic function. Circulation. 1992 Jun;85(6):211931.

151. Larsen AI, Aarsland T, Kristiansen M, Haugland A, Dickstein K. Assessing the effect of exercise training in men with heart failure; comparison of maximal, submaximal and endurance exercise protocols. Eur Heart J. 2001 Apr;22(8):684-92.

152. Karapolat H, Demir E, Bozkaya YT, Eyigor S, Nalbantgil S, Durmaz B, et al. Comparison of hospital-based versus home-based exercise training in patients with heart failure: effects on functional capacity, quality of life, psychological symptoms, and hemodynamic parameters. Clin Res Cardiol. 2009 Oct;98(10):635-42.

153. Hambrecht R, Fiehn E, Weigl C, Gielen S, Hamann C, Kaiser R, et al. Regular physical exercise corrects endothelial dysfunction and improves exercise capacity in patients with chronic heart failure. Circulation. 1998 Dec 15;98(24):2709-15.

154. Cowie A, Thow MK, Granat MH, Mitchell SL. Effects of home versus hospital-based exercise training in chronic heart failure. Int J Cardiol. 2012 Jul 12;158(2):296-8.

155. Mentz RJ, Bittner V, Schulte PJ, Fleg JL, Pina IL, Keteyian SJ, et al. Race, exercise training, and outcomes in chronic heart failure: findings from Heart Failure - a Controlled Trial Investigating Outcomes in Exercise TraiNing (HF-ACTION). Am Heart J. 2013 Sep;166(3):488-95.

156. Ahmad T, Fiuzat M, Mark DB, Neely B, Neely M, Kraus WE, et al. The effects of exercise on cardiovascular biomarkers in patients with chronic heart failure. Am Heart J. 2014 Feb;167(2):193-202 e1.

157. Owen A, Croucher L. Effect of an exercise programme for elderly patients with heart failure. Eur J Heart Fail. 2000 Mar;2(1):65-70.

158. Besson D, Joussain C, Gremeaux V, Morisset C, Laurent Y, Casillas JM, et al. Eccentric training in chronic heart failure: feasibility and functional effects. Results of a comparative study. Ann Phys Rehabil Med. 2013 Feb;56(1):30-40. 
159. Koufaki P, Mercer TH, George KP, Nolan J. Low-volume high-intensity interval training vs continuous aerobic cycling in patients with chronic heart failure: a pragmatic randomised clinical trial of feasibility and effectiveness. J Rehabil Med. 2014 Apr;46(4):348-56.

160. Nishi I, Noguchi T, Iwanaga Y, Furuichi S, Aihara N, Takaki H, et al. Effects of exercise training in patients with chronic heart failure and advanced left ventricular systolic dysfunction receiving beta-blockers. Circ J. 2011;75(7):1649-55.

161. Belardinelli R, Georgiou D, Cianci G, Purcaro A. 10-year exercise training in chronic heart failure: a randomized controlled trial. J Am Coll Cardiol. 2012 Oct 16;60(16):1521-8.

162. Taylor A. Physiological response to a short period of exercise training in patients with chronic heart failure. Physiother Res Int. 1999;4(4):237-49.

163. Kitzman DW, Brubaker PH, Herrington DM, Morgan TM, Stewart KP, Hundley WG, et al. Effect of endurance exercise training on endothelial function and arterial stiffness in older patients with heart failure and preserved ejection fraction: a randomized, controlled, single-blind trial. J Am Coll Cardiol. 2013 Aug 13;62(7):584-92.

164. Kitzman DW, Brubaker PH, Morgan TM, Stewart KP, Little WC. Exercise training in older patients with heart failure and preserved ejection fraction: a randomized, controlled, single-blind trial. Circ Heart Fail. 2010 Nov;3(6):659-67.

165. Smart NA, Haluska B, Jeffriess L, Leung D. Exercise training in heart failure with preserved systolic function: a randomized controlled trial of the effects on cardiac function and functional capacity. Congest Heart Fail. 2012 Nov-Dec;18(6):295-301.

166. Chen Z, Dunson DB. Random effects selection in linear mixed models. Biometrics. 2003 Dec;59(4):762-9.

167. Lilliefors HW. On the Kolmogorov-Smirnov test for normality with mean and variance unknown. Journal of the American Statistical Association. 1967;62(318):4.

168. Snedecor GW. Cochran W.G. Statistical methods. 7th ed: Ames: The Iowa State University Press; 1980. 
169. Groehs RV, Toschi-Dias E, Antunes-Correa LM, Trevizan PF, Rondon MU, Oliveira P, et al. Exercise training prevents the deterioration in the arterial baroreflex control of sympathetic nerve activity in chronic heart failure patients. Am J Physiol Heart Circ Physiol. 2015 May 1;308(9):H1096-102.

170. Williams AD, Carey MF, Selig S, Hayes A, Krum H, Patterson J, et al. Circuit Resistance Training in Chronic Heart Failure Improves Skeletal Muscle Mitochondrial ATP Production Rate-A Randomized Controlled Trial. Journal of Cardiac Failure. 2007;13(2):79-85.

171. Craenenbroeck EM, Hoymans VY, Beckers PJ, Possemiers NM, Wuyts K, Paelinck BP, et al. Exercise training improves function of circulating angiogenic cells in patients with chronic heart failure. Basic Research in Cardiology. 2010;105(5):665-76.

172. Giannuzzi P, Temporelli PL, Corra U, Tavazzi L. Antiremodeling effect of long-term exercise training in patients with stable chronic heart failure: results of the Exercise in Left Ventricular Dysfunction and Chronic Heart Failure (ELVD-CHF) Trial. Circulation. 2003 Aug 5;108(5):554-9.

173. Guazzi M, Vitelli A, Arena R. The effect of exercise training on plasma NT-pro-BNP levels and its correlation with improved exercise ventilatory efficiency in patients with heart failure. International Journal of Cardiology. 2012;158(2):290-1.

174. Klocek M, Kubinyi A, Bacior B, Kawecka-Jaszcz K. Effect of physical training on quality of life and oxygen consumption in patients with congestive heart failure. International Journal of Cardiology. 2005;103(3):323-9.

175. Lenk K, Erbs S, Hollriegel R, Beck E, Linke A, Gielen S, et al. Exercise training leads to a reduction of elevated myostatin levels in patients with chronic heart failure. Eur $\mathbf{J}$ Prev Cardiol. 2012 Jun;19(3):404-11.

176. Mandic S, Myers J, Selig SE, Levinger I. Resistance versus aerobic exercise training in chronic heart failure. Curr Heart Fail Rep. 2012 Mar;9(1):57-64.

177. Dieberg G, Ismail H, Giallauria F, Smart NA. Clinical outcomes and cardiovascular responses to exercise training in heart failure patients with preserved ejection fraction: a systematic review and meta-analysis. J Appl Physiol (1985). 2015 Sep 15;119(6):72633. 
178. Lavie CJ, Arena R, Swift DL, Johannsen NM, Sui X, Lee DC, et al. Exercise and the cardiovascular system: clinical science and cardiovascular outcomes. Circ Res. 2015 Jul $3 ; 117(2): 207-19$.

179. Kamiya K. MT, Matsunaga, A., Miida, K., Ogura, M.N., Kimura, M., Noda, C., Ymaoka-tojo, M., Inomata, T., Izumi, T. Decreased Strength of quadriceps increases the risk of mortality in patients with Chronic Heart Failure. Circulation. 2010;122(Suppl 21).

180. Magnusson G, Gordon A, Kaijser L, Sylven C, Isberg B, Karpakka J, et al. High intensity knee extensor training, in patients with chronic heart failure. Major skeletal muscle improvement. Eur Heart J. 1996 Jul;17(7):1048-55.

181. Cattadori G, Agostoni P, Corra U, Di Lenarda A, Sinagra G, Veglia F, et al. Severe heart failure prognosis evaluation for transplant selection in the era of beta-blockers: role of peak oxygen consumption. Int J Cardiol. 2013 Oct 12;168(5):5078-81.

182. de Morton NA. The PEDro scale is a valid measure of the methodological quality of clinical trials: a demographic study. Aust J Physiother. 2009;55(2):129-33.

183. Macedo LG, Elkins MR, Maher CG, Moseley AM, Herbert RD, Sherrington C. There was evidence of convergent and construct validity of Physiotherapy Evidence Database quality scale for physiotherapy trials. J Clin Epidemiol. 2010 Aug;63(8):920-5. 


\section{ANEXOS}

ANEXO A: Manuscrito

$O$ presente manuscrito, redigido nas normas da Revista "The Jornal of the American Medical Association - JAMA" (Anexo B) foi submetido e aguarda parecer da revista.

\section{Resistance Exercise Enhances the Effect of Peak Oxygen Uptake without Worsening} Cardiac Function in Patient with Heart Failure: A Systematic Review and Meta-Analysis

Francisco V. Santos, PT, MSc, ${ }^{\text {a,b }}$ Gaspar R. Chiappa, PT, ScD, ${ }^{\text {a }}$ Sergio Henrique Rodolpho Ramalho, MD, MBA ${ }^{\mathrm{a}, \mathrm{c}}$ Alexandra Correa Gervazoni Balbuena de Lima, MD,

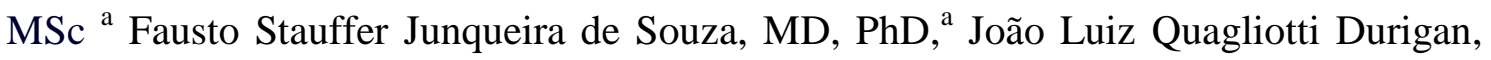

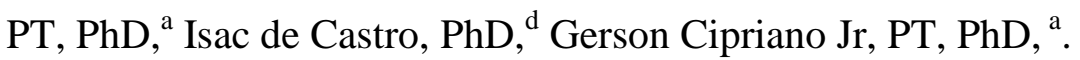

${ }^{a}$ Health and Technologies in Health Sciences Program, University of Brasilia, Brazil. ${ }^{\mathrm{b}}$ Cancer Institute of Sao Paulo, Sao Paulo; ${ }^{c}$ Sarah Network of Rehabilitation Hospitals, Brasilia; ${ }^{\mathrm{d}}$ Department of Medicine, Division of Molecular Medicine, University of Sao Paulo School of Medicine, Brazil

\section{Address for correspondence:}

Gerson Cipriano Jr, PT, PhD

Health and Technologies in Health Sciences Program - University of Brasilia

Address: Centro Metropolitano, Conjunto A - Lote 01 - Ceilândia

Brasília, DF, Brazil

ZIP CODE: 72220-900;

Tel/Fax: +55 6133760252

E-mail: cipriano@unb.br 


\begin{abstract}
IMPORTANCE Late scientific literature showed that resistance exercise improves peak oxygen uptake $\left(\mathrm{VO}_{2}\right.$ peak), similarly to aerobic exercise and its effect on cardiac remodeling was controversial. Meanwhile, current state of art indicates significant changes in both outcomes.
\end{abstract}

OBJECTIVE To compare the effect of exercise training on $\mathrm{VO}_{2}$ peak, left ventricular ejection fraction (LVEF) and left ventricular end diastolic volume (LVEDV) in heart failure patients.

DATA SOURCES AND STUDY SELECTION MEDLINE, EMBASE, Cochrane Library and CINAHL, AMEDEO and PEDro databases were searched from January 1990 to March 2016.

DATA EXTRACTION AND SYNTHESIS Two reviewers independently extracted study characteristics and exercise type and vascular outcome data.

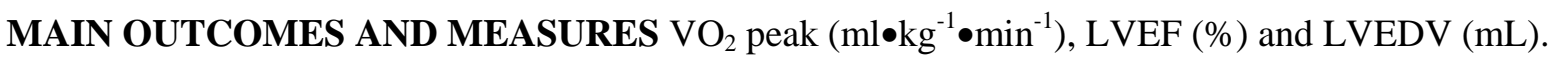

RESULTS From 4919 articles retrieved, 59 RCTs (n=5046 patients) were included. From resistance exercise articles (5 studies) resulted in a higher increase of $\mathrm{VO}_{2}$ peak $(P<0.00001$; with $3.57 \mathrm{ml} \bullet \mathrm{kg}$ ${ }^{1} \cdot \min ^{-1}\left(95 \%\right.$ confidence interval [CI] 2.45 to $\left.4.68 ; \mathrm{I}^{2}=0 \%\right)$. Also, aerobic exercise (28 studies) was associated with an increase of $2.63 \mathrm{ml} \bullet \mathrm{kg}^{-1} \bullet \mathrm{min}^{-1}\left(95 \% \mathrm{CI}, 1.96\right.$ to $\left.3.29 ; \mathrm{I}^{2}=58 \%\right)$. In addition, those with combined (aerobic and resistance) exercise (13 studies) evidence $2.48 \mathrm{ml} \bullet \mathrm{kg}^{-1} \bullet \mathrm{min}^{-1}$ increase ( $95 \%$ CI, 0.88 to $4.09 ; \mathrm{I}^{2}=69 \%$ ) in $\mathrm{VO}_{2}$ compared to control group. The comparison between combined and aerobic exercise alone, resistance exercise compared to aerobic exercise alone, we verify similar effects on $\mathrm{VO}_{2}$ peak $\left(P=0.84\right.$ and 1.00 respectively; $\left.\mathrm{I}^{2}=0 \%\right)$. To cardiac remodeling, aerobic exercise (16 studies) was associated with higher gain in LVEF $\left(P<0.00001 ; \mathrm{I}^{2}=17 \%\right)$, with an increase of $3.15 \%$ (CI, 1.87 to $4.44 ; \mathrm{I}^{2}, 17 \%$ ), whereas resistance exercise alone and combined exercise were similar, compared with control participants. Interestingly, combined (aerobic and resistance) exercise was similar to aerobic exercise effects on LVEF. Subgroup analysis for LVEDV demonstrate that aerobic exercise reduces $-10.21 \mathrm{ml}$ significantly (CI, -17.64 to $-2.77 ; \mathrm{I}^{2}, 0 \%$ ), while combined and resistance exercise showed no effect compared with control participants.

CONCLUSIONS AND RELEVANCE The resistance exercise results in a higher gain on $\mathrm{VO}_{2}$ peak, and induces not deleterious effects on cardiac function in heart failure patients.

Key words: Ventricular Remodeling; Performance; Exercise capacity. 


\section{INTRODUCTION}

The structural and functional consequences which follow an acute or a chronic insult to the myocardium in the heart failure (HF) disease, may trigger several compensatory mechanisms, such as gene expression, sympathetic stimulation, neurohumoral activity ${ }^{1-4}$, and clinically presents with exercise intolerance as one of its hallmarks. HF mortality rates remain high ${ }^{5}$, regardless of current therapeutic management strategies.

Studies have showed that exercise is a safe and effective intervention to improve oxygen uptake $\left(\mathrm{VO}_{2}\right.$ peak) in heart failure patients ${ }^{6}$. This response is linked to the favorable change in cardiovascular and skeletal muscle function ${ }^{7}$.

In this way, different studies reported the effectiveness of exercise on clinical consequences of left ventricle remodeling and exercise capacity, which can impact on HF prognosis ${ }^{8-12}$. This benefit has been confirmed only with aerobic exercise, through attenuation of sympathovagal dysfunction leading to an improved peripheral vasodilatation response ${ }^{4,12,13}$. Moreover, previous meta-analysis by Haykowsky et al ${ }^{4}$ have reported that combined and resistance exercise improved upper extremity muscle strength compared to the aerobic exercise while the change in $\mathrm{VO}_{2}$ peak and lower extremity strength were not different between aerobic, combined and resistance exercise alone. Also, authors reported that effects of aerobic exercise on ventricular remodeling do not occur when combined with resistance exercise due to excessive increase in left ventricular afterload caused by resistance exercise ${ }^{4}$. In contrast, recently studies ${ }^{7,14,15}$ have showed that addition of resistance exercise present similar effect compared to combined and aerobic exercise, without causing any damage to the left ventricular ejection fraction. However,

the literature is quite divergent on its effects. Furthermore, previous studies did not performed statistical comparisons between combined versus aerobic exercise and resistance versus aerobic exercise. In addition, it is unclear whether resistance exercise might have greater

effects on cardiac remodeling based on peripheral muscle tropisms improvement ${ }^{11,16-18}$. To clarify this question, we conducted a comprehensive overview of the effects from combined exercise or resistance exercise alone on cardiac remodeling and functional capacity in patients with systolic heart failure. We hypothesized that resistance exercise can lead positive benefits in functional capacity without causing deleterious effects on cardiac function of patients with heart failure. 


\section{METHODS}

\section{Search Strategy}

We conducted a systematic review and meta-analysis in compliance with the recommendations and criteria described in the Preferred Reporting Items for Systematic Reviews and Meta-Analyses (PRISMA) and Cochrane Handbook ${ }^{19}$. Protocol was registered in the PROSPERO database (www.crd.york.ac.uk/prospero/) under number: CRD42014013857.

\section{Sources of Data}

Potential studies were identified by a sensitive strategy. The systematic review was performed in the following databases: MEDLINE (Ovid) (1950 to March 2016); EMBASE (1974 to 2016), The Cochrane and CINAHL (1981 to 2016); Amedeo (1997 to March 2016) and PEDro (1929 to March 2016). The search strategy involved the crosschecking of keywords selected based on the Medical Subjects Headings (Mesh) - United States National Library of Medicine and free terms for key words (intervention + population), with filters to limit the search to clinical trials (Phases I-IV), controlled clinical trials, multicenter studies, randomized controlled trials, pragmatic clinical trials and systematic reviews. There was no language restriction. The following keywords were used for $i$ ) intervention: "Resistance exercise"[Mesh] OR "Muscle Contraction"[Mesh] OR "Muscle Strength"[Mesh] OR "Muscle Strenght Dynamometer"[Mesh] OR "Exercise"[Mesh] OR "Exercise Therapy"[Mesh] OR Exercise Tolerance"[Mesh] OR "Exercise Test"[Mesh] OR "Physical Education and Training" [Mesh] OR "Physical and Rehabilitation Medicine" [Mesh] OR "Physical Fitness" [Mesh] OR "Physical Exertion" [Mesh] OR "Physical Endurance" [Mesh]; ii) outcomes: "Ventricular Remodeling”[Mesh]OR "Myocardium"[Mesh] OR "Myocardial Contraction"[Mesh] OR “Atrial Remodeling”[Mesh] OR "Myocytes, Cardiac"[Mesh] OR "Exercise Tolerance"[Mesh]; and iii) Population studied: "Cardiomyopathies" [Mesh] OR "Heart Failure" [Mesh] OR "Cardiomegaly"[Mesh]. The studies were selected in accordance to Cochrane handbook ${ }^{19}$. Authors initially assessed title and abstract (type of study design, description of population and information on interventions) for eligibility. After the selection of potentially relevant studies, the full-text versions were analyzed for methodological quality by two researchers independently. 


\section{Types of Studies and Participants}

The following criteria were adopted for the selection of the studies: Randomized Clinical Trials (RCTs) with or without a cross-over strategy; interventions involving physical exercises based on The Cochrane Review Handbook ${ }^{19}$; and a comparison group submitted to aerobic exercise, resistance exercise and combined exercise (aerobic and resistance exercise), with control group or between intervention group. The population consisted of adult individuals with a diagnosis of systolic heart failure (based on clinical findings and objective indices, such as ejection fraction $<45 \%$ and functional classes I to IV) aged 45 to 64 years (middle-age). Studies with specific populations were excluded.

\section{Types of Interventions and Outcomes}

We considered resistance exercise alone, aerobic exercise alone or a combination of both interventions accomplished at hospital, outpatient or home based settings. We considered interventions with the following parameters: 1) frequency: 2 - 4 days per week; 2) duration: at least 8 - 26 weeks; 3$)$ intensity: 50-90\% of maximum heart rate $\left(\mathrm{HR}_{\max }\right)$ or $50-80 \%$ of $\mathrm{VO}_{2}$ for aerobic exercise and 40-80\% of one maximum repetition (1-MR) for resistance exercise. The clinical outcomes of the studies must be evaluated at least one of the following: Peak Oxygen Uptake $\left(\mathrm{VO}_{2}\right.$ peak, $\left.\mathrm{ml} \bullet \mathrm{kg}^{-1} \bullet \mathrm{min}^{-1}\right)$, Left Ventricular Ejection Fraction (LVEF, \%) and Left Ventricular end Diastolic Volume (LVEDV, mL).

\section{Data Extraction}

All relevant data regarding the inclusion criteria (type of study, population, interventions [including type of exercise, intensity, frequency, duration and modality], comparison and outcomes), risk of bias (randomization, blinding and presence of a control group) and results were extracted from all selected studies. A single researcher performed the extraction procedure and a second researcher scrutinized it. Any disagreements were resolved by consensus.

\section{Quality (Risk of Bias) and Publication Bias Assessment}

One researcher evaluated quality and risk of bias independently, using the PEDro scale ${ }^{20}$ based on the Delphi list developed by Verhagen et al. ${ }^{21}$. A second researcher examined. This scale includes the following items to be evaluated: eligibility criteria, randomization, allocation concealment, similarity in baseline data, blinding of subjects, blinding of therapists, 
blinding of evaluators, adequate follow up, intention-to-treat analysis, statistical analysis among groups and the use of measures.

\section{Data Analyses}

Relative changes in $\mathrm{VO}_{2}$ and absolute changes in LVEF and LVEVD were reported as differences between arithmetic means before and after interventions. Data from intention-totreat analyses were entered whenever available in included RCTs. Pooled-effect estimates were obtained by comparing the least squares mean percentage change from base line to the end of the study for each group, and were expressed as the weighted mean difference (WMD) between groups. Calculations were performed using a random-effects model. Tests for subgroup differences based on random-effects models may be regarded as preferable to those based on fixed-effect models, due to the high risk of false-positive results when comparing subgroups in a fixed-effect model ${ }^{19}$. Four comparisons were made with each group being compared with a no intervention (control) group: aerobic exercise training, resistance exercise training, combined aerobic/resistance exercise training, and control. An $\boldsymbol{\alpha}$ value $=.05$ was considered statistically significant.

Publication bias was assessed using a contour-enhanced funnel plot of each trial's effect size against the standard error. Funnel plot asymmetry was evaluated by Begg and Egger tests. Statistical heterogeneity of the treatment effect among studies was assessed using Cochran Q test, a threshold $P$ value $<0.1$ was considered statistically significant, and the inconsistency $\mathrm{I}^{2}$ test in which values greater than $50 \%$ were considered indicative of high heterogeneity ${ }^{19}$. The heterogeneity between included studies was explored. First, we reanalyze the meta-analyses removing each study at a time to check if a particular study was explaining heterogeneity. Second, we performed sensitivity analyses to evaluate subgroups of studies most likely to yield valid estimates of the intervention based on preexistent relevant clinical information. All analyses were conducted using Review Manager Version 5.0.

\section{RESULTS}

\section{Selection and Evaluation of Studies}

The initial search identified 4.919 studies on aerobic exercise and resistance exercise (either alone or in combination with aerobic exercise) involving patients with systolic heart failure. Two duplicates were removed $(n=4917)$. After title and abstract analysis, we excluded 4.827 studies ineligible based on inclusion criteria (Figure 1). Thirty one studies were not eligible 
after entire text analysis: 15 studies regarding resistance exercise alone or combined exercise 22-36, and 16 studies regarding aerobic exercise ${ }^{36-51}$ were excluded to a) absence of comparative group, b) absence of analyzed outcomes, c) protocol not in accordance to the inclusion criteria, d) absence of data outcome in mean and standard deviation, e) transversal studies, and f) heart failure with preserved ejection fraction (Table 1).

The present systematic review and meta-analysis included a total of 59 studies: 29 involving resistance exercise alone and/or combined exercise (Table 2) and 31 involving aerobic exercise (Table 3). One study ${ }^{11}$ were included in all comparisons, and another study ${ }^{37}$ were included in aerobic and combined comparisons. In one study ${ }^{38}$, the data was described in median and interquartile range and not in mean and standard deviation. Thus, for converting a good estimate of mean and standard deviation of sample was used the following methodology: Through the median values and interquartile ranges the percentile values were estimated from 5 to $95 \%$, for every $5 \%$, by proportional estimate. Using the estimated values, fourth order polynomial equations was obtained with good linearity $\left(r^{2}>0.9\right)$. The four polynomial equations (one for each sample) were obtained according to each sample size, as described in the original article. Finally, with the projection of the individual those values average and the standard deviation values were calculate ${ }^{39-41}$.

\section{Studies Included in Systematic Review}

Publication date ranged from 1992 to 2015, involving a total of 5.046 patients, $3.939(78,1 \%)$ male gender and mean age was $58.2 \pm 7.99$ years. Heart failure patients were clinically stable, with New York Heart Association functional classes between I and IV. LVEF range was from $20-45 \%$. Mean training frequency for resistance exercise alone and combined exercise was $3.0 \pm 0.49$ days per week, with a mean duration of $49.8 \pm 16.7$ min per session and mean protocol duration of $17.8 \pm 4.9$ weeks. The mean frequency of aerobic exercise was $4.0 \pm 1.76$ times per week, with a mean duration of $44.9 \pm 14.9$ minutes per session and mean protocol duration of $17.8 \pm 8.6$ weeks. The intensity of aerobic exercise ranged from $50-80 \%$ of $\mathrm{VO}_{2}$, $40-90 \%$ of $\mathrm{HR}_{\max }$ or $40-80 \%$ of $\mathrm{HRR}$. The intensity of resistance exercise ranged from $30-$ $90 \%$ of 1 MR (Table 2). Heterogeneity among the studies was low $\left(\mathrm{I}^{2}<50 \%\right)$, except for comparative analysis between aerobic and combined with control group ( $\mathrm{I}^{2}=58 \%$ and $69 \%$, respectively) in $\mathrm{VO}_{2}$ peak outcome. 
Combined exercise was compared with: aerobic exercise in eight studies ${ }^{10,11,37,42-46}$; control group in fourteen studies ${ }^{11,47-59}$; and resistance exercise alone in one study ${ }^{11}$. Resistance exercise alone was compared with: aerobic exercise in three studies ${ }^{11,60,61}$; control group in eight 11,16-18,61-64. Thirty-two studies compared aerobic exercise alone to a control group, $8,9,11,37,38,65-91$. The analysis of quality using the PEDro scale demonstrated scores ranging from 4 to 7 points for both resistances exercise alone and combined exercise, as well as aerobic exercise. The level of agreement between the reviewers, which was calculated using the Kappa coefficient, was 0.95 (95\% CI: 0.88 to 1.0 ).

\section{Exercise and Peak Oxygen Consumption $\left(\mathrm{VO}_{2}\right.$ peak)}

The Exercise was associated with a significant improvement of the $\mathrm{VO}_{2}$ peak when data of all studies was pooled (46 studies, $\mathrm{n}=4.296$ patients, weighted mean difference [WMD] $=2.70$ $\mathrm{ml} \bullet \mathrm{kg}^{-1} \bullet \mathrm{min}^{-1}, 95 \% \mathrm{CI}: 2.11$ to $3.28 \mathrm{ml} \bullet \mathrm{kg}^{-1} \bullet \mathrm{min}^{-1}, \mathrm{I}^{2}=65 \%$ ) (Figure 2a). Furthermore, the isolated resistance exercise was associated with higher gain $\mathrm{VO}_{2}$ peak $(5$ studies, $\mathrm{n}=124$ patients, WMD $=3.57 \mathrm{ml} \bullet \mathrm{kg}^{-1} \bullet \mathrm{min}^{-1}, 95 \% \mathrm{CI}: 2.45$ to $4.68 \mathrm{ml} \bullet \mathrm{kg}^{-1} \bullet \mathrm{min}^{-1}, \mathrm{I}^{2}=0 \%$ ) in relation to aerobic (28 studies, $\mathrm{n}=3.584$ patients, WMD $=2.86 \mathrm{ml} \bullet \mathrm{kg}^{-1} \bullet \mathrm{min}^{-1}, 95 \%$ CI: 2.37 to $3.35 \mathrm{ml} \bullet \mathrm{kg}^{-1} \bullet \mathrm{min}^{-1}, \mathrm{I}^{2}=2 \%$ ) and combined exercise aerobic (13 studies, $\mathrm{n}=588$ patients, $\mathrm{WMD}=2.48 \mathrm{ml} \bullet \mathrm{kg}^{-1} \bullet \mathrm{min}^{-1}, 95 \% \mathrm{CI}: 0.88$ to $4.09 \mathrm{ml} \bullet \mathrm{kg}^{-1} \bullet \mathrm{min}^{-1}, \mathrm{I}^{2}=69 \%$ ). The results of the analysis for comparisons between resistance and combined exercise both with aerobic exercise were inconclusive (Resistance: 03 studies, $\mathrm{n}=75$ patients, $\mathrm{WMD}=0.12 \mathrm{ml} \bullet \mathrm{kg}^{-}$ ${ }^{1} \bullet \mathrm{min}^{-1}, 95 \% \mathrm{CI}$ : -1.22 to $1.45 \mathrm{ml} \bullet \mathrm{kg}^{-1} \bullet \mathrm{min}^{-1}, \mathrm{I}^{2}=0 \% /$ Combined: 08 studies, $\mathrm{n}=283$ patients, WMD $=0.69 \mathrm{ml} \bullet \mathrm{kg}^{-1} \bullet \mathrm{min}^{-1}, 95 \% \mathrm{CI}:-0.87$ to $2.25 \mathrm{ml} \bullet \mathrm{kg}^{-1} \bullet \mathrm{min}^{-1}, \mathrm{I}^{2}=0 \%$ ) (Figure 2b). One trial comparing combined exercise and resistance exercise alone had also unsatisfactory results $\left(\mathrm{n}=30, \mathrm{WMD}=-0.60 \mathrm{ml} \bullet \mathrm{kg}^{-1} \bullet \mathrm{min}^{-1}, 95 \% \mathrm{CI}:-3.82\right.$ to $2.62 \mathrm{ml} \bullet \mathrm{kg}^{-}$ $\left.{ }^{1} \bullet \min ^{-1}\right)$.

\section{Exercise and Left Ventricular Ejection Fraction (LVEF)}

The analysis of the studies comparing exercise with control group demonstrated favorable effects on exercise for the outcome LVEF (32 studies, $\mathrm{n}=1.373$ patients, $\mathrm{WMD}=2.33 \%$, 95\% CI: 1.20 to $3.47 \%, \mathrm{I}^{2}=26 \%$ ) (Figure $3 \mathrm{a}$ ). However, resistance exercise both isolated as combined not demonstrated improvement in LVEF (Resistance: 04 studies, $\mathrm{n}=86$ patients, $\mathrm{WMD}=1.91 \%, 95 \% \mathrm{CI}:-3.71$ to $7.53 \%, \mathrm{I}^{2}=23 \%$ / Combined: 11 studies, $\mathrm{n}=468$ patients, $\mathrm{WMD}=0.02 \%, 95 \% \mathrm{CI}:-1.47$ to $1.52 \%, \mathrm{I}^{2}=0 \%$, while the analysis of aerobic exercise 
showed improvement this outcome (17 studies, $\mathrm{n}=819$ patients, $\mathrm{WMD}=3.15 \%, 95 \% \mathrm{CI}$ : 1.87 to $4.44 \%, \mathrm{I}^{2}=17 \%$ ). Additionally, studies testing combined exercise with aerobic exercise were also inconclusive (03 studies, $\mathrm{n}=78$ patients, $\mathrm{WMD}=0.06 \%, 95 \% \mathrm{CI}:-4.14$ to $4.27 \%, \mathrm{I}^{2}=0 \%$ ) (Figure $3 \mathrm{~b}$ ). There was only one study in comparisons between resistance exercise with aerobic and combined exercise $(n=20, \mathrm{WMD}=-3.00,95 \%$ CI: -9.92 to $3.92 \%$ and $\mathrm{n}=30$ patients, $\mathrm{WMD}=-3.00,95 \% \mathrm{CI}:-4.65$ to $10.65 \%$, respectively).

\section{Exercise and Left Ventricular End Diastolic Volume (LVEDV)}

Despite the fact of aerobic exercise have led an improvement in LVEDV (08 studies, $n=478$ patients, WMD $=-10.21 \mathrm{~mL} 95 \% \mathrm{CI}:-17.64$ to $2.77 \mathrm{~mL}$ ) (Figure 4), the effects of combined and strength exercise were unsatisfactory (Combined: 04 studies, $\mathrm{n}=239$ patients, WMD $=$ $1,98 \mathrm{~mL} 95 \% \mathrm{CI}:-3.14$ to $7.09 \mathrm{~mL} /$ Resistance: 02 studies, $\mathrm{n}=46$ patients, $\mathrm{WMD}=-7.93$ $\mathrm{mL} 95 \% \mathrm{CI}$ : -49.82 to $33.97 \mathrm{~mL}$ ). Overall, exercise was not associated with a significant improvement in EF when data from all trials were pooled (14 studies, $n=763$ patients, WMD $=-2.42 \mathrm{~mL} 95 \% \mathrm{CI}:-6.88$ to $2.04 \mathrm{~mL})$. Only one study evaluated the effects in LVEDV, but data were unclear $(\mathrm{n}=30, \mathrm{WMD}=-6.0 \mathrm{~mL} 95 \% \mathrm{CI}:-51.74$ to $39.74 \mathrm{~mL})$. One trial comparing combined exercise and resistance exercise alone had inconclusive results $(n=30$, $\mathrm{WMD}=-7.0 \mathrm{~mL}$. $95 \% \mathrm{CI}:-67.28$ to $53.28 \mathrm{~mL}$ ) as well as the comparison between resistance exercise alone versus aerobic exercise $(n=30, \mathrm{WMD}=1.0 \mathrm{~mL}, 95 \% \mathrm{CI}$ : -49.92 to 51.92 $\mathrm{mL})$.

\section{DISCUSSION}

The present meta-analysis supports current and robust evidence that resistance exercise training in heart failure patients administered alone or in combination with aerobic exercise, offers greater benefits in cardiopulmonary capacity without causing deleterious effects on cardiac function. Moreover, even with the inclusion of more recent studies (post Haykowsky et al), resistance exercise training - alone or combined - had no influence on ventricular remodeling variables. These findings adds relevant information to previously published metaanalysis over this topic ${ }^{4}$.

In this study we reanalyzed more recent studies that assessed aerobic exercise training effects on the three clinical interest outcomes (VO $\mathrm{V}_{2}$ peak, LVEF and LVEDV), to compare with those obtained with resistance exercise. We found that aerobic exercise produced benefits in all 
three clinical outcomes. These results corroborate meta-analysis provided to the outcomes of ventricular remodeling ${ }^{13}$ and $\mathrm{VO}_{2}$ peak ${ }^{92}$. A recent meta-analysis considering preserved systolic function heart failure patients published by Dieberg et al. demonstrated a similar effect to our results of aerobic exercise on $\mathrm{VO}_{2}$ peak ${ }^{93}$. Also, Lavie et al in review study reported similar effects of $\mathrm{VO}_{2}$ peak in $\mathrm{HF}$ patients with preserved and reduced ejection fraction, with improvements in $\mathrm{VO}_{2}$ peak of $>16 \%$ after aerobic exercise ${ }^{94}$.

\section{Effects of Resistance Exercise Alone}

The increase in muscle mass and strength provided by resistance exercise can also positively influence $\mathrm{VO}_{2}$ peak. This finding is clinically relevant for patients with heart failure, in whom muscle mass has emerge as an independent mortality predictor ${ }^{95}$ hence, the mechanism of exercise intolerance in patients with heart failure is related to abnormalities in skeletal muscles in addition to the cardiac dysfunction itself ${ }^{94}$. In the present study, resistance exercise training revealed comparable results to aerobic exercise regarding cardiopulmonary capacity. Nonetheless, $\mathrm{VO}_{2}$ peak increased significantly with resistance exercise training alone versus control group. In a recent study, Feiereisen et al. demonstrated that resistance exercise significantly increased peripheral muscle strength in comparison to aerobic exercise and to a control group. Moreover, the reduction in muscle mass in the control group led to a significant reduction in $\mathrm{VO}_{2}$ peak ${ }^{11}$. Moreover, the decrease in neuro-hormonal activity induced by resistance exercise can directly contribute to improved exercise capacity in these patients ${ }^{51,96}$. These findings indicate the importance of increasing muscle mass and strength as an important component to improve exercise performance in patients with heart failure.

The present study shows that resistance exercise alone resulted in neutral effects on LVEF and on LVEDV. Nevertheless, these results do not nullify the effects of resistance exercise to the central hemodynamics of these HF patients. First because safety is a permanent concern in this treatment modality and no deleterious effects in remodeling were observed ${ }^{11,16,31}$. Second, there is an important role of resistance exercise on cardiac remodeling mechanism with peripheral modifications, such as increased of capillarisation and oxidative capacity 97 lowering peripheral vascular resistance preventing deterioration of hemodynamic function and attenuating left ventricular afterload ${ }^{17,37,61,62,96}$. Additionally, an increase in LVEF caused by use of antiremodeling drugs in the control group, it seems to be a confounding factor with the comparative analysis of resistance exercise training effects in heart failure patients ${ }^{11,16}$. 
This systematic review provides relevant information for two reasons. First, this study adds evidence with more recent studies for outcomes $\mathrm{VO}_{2}$ peak, LVEF and LVEDV comparing resistance exercise modality versus control group in systolic heart failure patients. Second, this is the first meta-analysis to demonstrate significant improvement in $\mathrm{VO}_{2}$ with resistance exercise alone, updating the results presented in previous meta-analysis with fewer studies ${ }^{4,12}$.

\section{Effects of Combined Exercise}

Combined and aerobic exercise alone achieved a similar absolute effect regarding $\mathrm{VO}_{2}$ peak and LVEF. Only one study demonstrated analogous effect for these two interventions regarding LVEDV ${ }^{98}$. This exercise modality did not demonstrate additional effects on LVEF and LVEDV in comparison to the control group or resistance exercise alone. Previous metaanalysis by Haykowsky et al. ${ }^{4}$ found that positive effects of aerobic exercise on these variables cannot be sustained with the addition of resistance exercise, justifying this effect by a worsening ventricular performance caused by an excessive pressure overload and stress on the ventricular wall mediated by resistance exercise. However, several recent studies have demonstrated a change in this paradigm. Currently it is believed that the addition of resistance exercise to aerobic exercise does not affects cardiovascular function negatively in patients with systolic heart failure, in any of the cardiac remodeling variables, such as preload, afterload and ventricular ejection fraction. Besides, they showed improved endothelial response to exercise and vascular resistance after exercise. ${ }^{10,11,25,37,43,47-50,54}$.

This is the first meta-analysis to demonstrated the favorable effect of combined resistance exercise on functional capacity based on $\mathrm{VO}_{2}$ peak in patients with systolic heart failure- The previous meta-analysis failed to demonstrate this effect ${ }^{4,12}$. As demonstrated in the current study, combined exercise modality is capable to modify exercise performance in such patients by increasing $\mathrm{VO}_{2}$ peak by a mean of $2.48 \mathrm{ml} \bullet \mathrm{kg}^{-1} \bullet \mathrm{min}^{-1}$. According to current survival strata of systolic heart failure patients by levels of $\mathrm{VO}_{2}$ peak $\left(<8 \mathrm{ml} \bullet \mathrm{kg}^{-1} \bullet \mathrm{min}^{-1}, 8\right.$ to $10 \mathrm{ml} \bullet \mathrm{kg}^{-}$ ${ }^{1} \cdot \mathrm{min}^{-1}$ and $>10 \mathrm{ml} \bullet \mathrm{kg}^{-1} \bullet \mathrm{min}^{-1}$ ) ${ }^{99}$, that magnitude of increment may eventually help improving prognosis in these patients specially in heart transplant waiting list. Thus, the inclusion of combined exercise in cardiac rehabilitation programs is directly related to improvements in cardiorespiratory capacity in HF patients with reduced ejection fraction. Remarkably, comparatively analyzing this modality with aerobic exercise alone, the effects on this variable were similar. 
The main purpose to include resistance exercise in rehabilitation programs in patients with heart failure is certainly the reversion or attenuation of the peripheral vascular and skeletal muscle dysfunction secondary to the syndrome. Furthermore, other effect of training with combined strategy described in literature is an increase in sub-maximum endurance in comparison to aerobic exercise alone ${ }^{10,11}$. The latter has only slight effects on these dysfunctions 24 .

The findings of the present meta-analysis regarding combined exercise are in agreement with previous studies, showing the effectiveness of this exercise modality on either the improvement or the prevention of a worsening in $\mathrm{VO}_{2}$ peak in patients with heart failure and these results are directly related to the adherence of patients to rehabilitation program ${ }^{37}$.

\section{Strengths and Limitations}

An high heterogeneity was identified in the meta-analyses, especially in the aerobic exercise training with an inclusion of HF-Action study $\left(\mathrm{I}^{2}=58 \%\right)$. Similarly, we also observed a moderate heterogeneity in the EC compared to the $\mathrm{CG}\left(\mathrm{I}^{2}=69 \%\right)$. This was due mainly to the presence of two studies with unfavorable results by treatment group. To address this, we have performed subgroup analyses. Also, we excluded clinical trials $(\mathrm{n}=2)$ with older patients. It resulted in a better homogeneity among the included studies $\left(\mathrm{I}^{2}<50 \%\right)$ in all proposed analyzes. The general quality of the studies was low (mean score $=5.62$, from 0 to 10 ), reflecting increased risk of bias in some studies. The quality of the included studies in this meta-analysis was performed using PEDro scale. This scale has been tested and confirmed in

previous studies, demonstrating its ability to evaluate the quality of clinical trials ${ }^{100,101}$. The quality of the included studies may have contributed to the heterogeneity for some of our analyses.

\section{CONCLUSIONS}

The most compelling finding from our data is that resistance exercise, either alone or combined with aerobic exercise is an effective treatment modality for HF patients with reduced ejection fraction with positive impact on $\mathrm{VO}_{2}$ peak. This study shows that resistance exercise presents itself as an effective option to minimize the effects on cardiac remodeling mechanism, as well as an excellent risk-benefit ratio of this type of exercise, since the absence of adverse effects of this type is clearly overwhelmed for its benefits in these patients. 
Funding Sources: This study was supported by grants from CNPq and CAPES

Conflict of Interest Disclosures: None

\section{REFERENCES}

1. Ferraz AS BE, Meneghelo RS, Umeda II, Salvarani N, Guimarães GV, Piegas LS. High sensitive C-reactive protein is reduced by exercise training in chronic heart failure patients. A prospective randomized controlled study. Circulation. 2004;17(suppl):793794.

2. Clavell AL BJ. Cardiovascular reflex and humoral control od the circulation. In: JG M, ed. Mayo Clinic Cardiology Review. 2nd ed. Philadelphia2000:21-26.

3. Krankel N, Adams V, Gielen S, et al. Differential gene expression in skeletal muscle after induction of heart failure: impact of cytokines on protein phosphatase $2 \mathrm{~A}$ expression. Mol Genet Metab. Sep-Oct 2003;80(1-2):262-271.

4. Haykowsky MJ, Liang Y, Pechter D, Jones LW, McAlister FA, Clark AM. A metaanalysis of the effect of exercise training on left ventricular remodeling in heart failure patients: the benefit depends on the type of training performed. J Am Coll Cardiol. Jun 19 2007;49(24):2329-2336.

5. Bui AL, Horwich TB, Fonarow GC. Epidemiology and risk profile of heart failure. Nat Rev Cardiol. Jan 2011;8(1):30-41.

6. van der Meer S, Zwerink M, van Brussel $M$, van der Valk P, Wajon E, van der Palen J. Effect of outpatient exercise training programmes in patients with chronic heart failure: a systematic review. European Journal of Preventive Cardiology. 2011;19(4):795-803.

7. Mandic S, Tymchak W, Kim D, et al. Effects of aerobic or aerobic and resistance training on cardiorespiratory and skeletal muscle function in heart failure: a randomized controlled pilot trial. Clinical Rehabilitation. 2009;23(3):207-216.

8. Belardinelli R, Georgiou D, Cianci G, Purcaro A. Randomized, controlled trial of longterm moderate exercise training in chronic heart failure: effects on functional capacity, quality of life, and clinical outcome. Circulation. Mar 9 1999;99(9):1173-1182.

9. Alves AJ, Ribeiro F, Goldhammer E, et al. Exercise training improves diastolic function in heart failure patients. Med Sci Sports Exerc. May 2012;44(5):776-785.

10. Beckers PJ, Denollet J, Possemiers NM, Wuyts FL, Vrints CJ, Conraads VM. Combined endurance-resistance training vs. endurance training in patients with chronic 
heart failure: a prospective randomized study. Eur Heart J. Aug 2008;29(15):18581866.

11. Feiereisen $P$, Delagardelle C, Vaillant M, Lasar Y, Beissel J. Is strength training the more efficient training modality in chronic heart failure? Med Sci Sports Exerc. Nov 2007;39(11):1910-1917.

12. Hwang C-L, Chien C-L, Wu Y-T. Resistance training increases 6-minute walk distance in people with chronic heart failure: a systematic review. Journal of Physiotherapy. 2010;56(2):87-96.

13. Chen YM, Li ZB, Zhu M, Cao YM. Effects of exercise training on left ventricular remodelling in heart failure patients: an updated meta-analysis of randomised controlled trials. Int J Clin Pract. Aug 2012;66(8):782-791.

14. Feiereisen P, Delagardelle C, Vaillant M, Lasar Y, Beissel J. Is Strength Training the More Efficient Training Modality in Chronic Heart Failure? Medicine \& Science in Sports \& Exercise. 2007;39(11):1910-1917.

15. Laoutaris ID, Adamopoulos S, Manginas A, et al. Benefits of combined aerobic/resistance/inspiratory training in patients with chronic heart failure. A complete exercise model? A prospective randomised study. International Journal of Cardiology. 2013;167(5):1967-1972.

16. Koch M, Douard H, Broustet JP. The benefit of graded physical exercise in chronic heart failure. Chest. May 1992;101(5 Suppl):231S-235S.

17. Levinger I, Bronks R, Cody DV, Linton I, Davie A. The effect of resistance training on left ventricular function and structure of patients with chronic heart failure. Int $J$ Cardiol. Nov 2 2005;105(2):159-163.

18. Palevo G, Keteyian SJ, Kang M, Caputo JL. Resistance Exercise Training Improves Heart Function and Physical Fitness in Stable Patients With Heart Failure. Journal of Cardiopulmonary Rehabilitation and Prevention. 2009;29(5):294-298.

19. Higgins JPT, Green S, Cochrane Collaboration. Cochrane handbook for systematic reviews of interventions. Chichester, England; Hoboken, NJ: Wiley-Blackwell; 2008.

20. Shiwa SRea. PEDro: a base de dados de evidências em fisioterapia. Fisioter. mov. (Impr.) [online]. 2011;24(3):10.

21. Verhagen AP, de Vet HC, de Bie RA, et al. The Delphi list: a criteria list for quality assessment of randomized clinical trials for conducting systematic reviews developed by Delphi consensus. J Clin Epidemiol. Dec 1998;51(12):1235-1241. 
22. Caminiti G, Volterrani M, Marazzi G, et al. Hydrotherapy added to endurance training versus endurance training alone in elderly patients with chronic heart failure: a randomized pilot study. Int J Cardiol. Apr 14 2011;148(2):199-203.

23. Cheetham C, Green D, Collis J, Dembo L, O'Driscoll G. Effect of aerobic and resistance exercise on central hemodynamic responses in severe chronic heart failure. J Appl Physiol (1985). Jul 2002;93(1):175-180.

24. Delagardelle C, Feiereisen P, Autier P, Shita R, Krecke R, Beissel J. Strength/endurance training versus endurance training in congestive heart failure. Med Sci Sports Exerc. Dec 2002;34(12):1868-1872.

25. Edelmann F, Gelbrich G, Dungen HD, et al. Exercise training improves exercise capacity and diastolic function in patients with heart failure with preserved ejection fraction: results of the Ex-DHF (Exercise training in Diastolic Heart Failure) pilot study. J Am Coll Cardiol. Oct 18 2011;58(17):1780-1791.

26. Gary RA, Cress ME, Higgins MK, Smith AL, Dunbar SB. Combined aerobic and resistance exercise program improves task performance in patients with heart failure. Arch Phys Med Rehabil. Sep 2011;92(9):1371-1381.

27. Aslanger E, Assous B, Bihry N, Beauvais F, Logeart D, Cohen-Solal A. Effects of Cardiopulmonary Exercise Rehabilitation on Left Ventricular Mechanical Efficiency and Ventricular-Arterial Coupling in Patients With Systolic Heart Failure. J Am Heart Assoc. 2015;4(10).

28. Gary RA, Cress ME, Higgins MK, Smith AL, Dunbar SB. A combined aerobic and resistance exercise program improves physical functional performance in patients with heart failure: a pilot study. J Cardiovasc Nurs. Sep-Oct 2012;27(5):418-430.

29. Jankowska EA, Witkowski T, Ponikowska B, et al. Excessive ventilation during early phase of exercise: a new predictor of poor long-term outcome in patients with chronic heart failure. Eur J Heart Fail. Oct 2007;9(10):1024-1031.

30. Kemps HM, de Vries WR, Schmikli SL, et al. Assessment of the effects of physical training in patients with chronic heart failure: the utility of effort-independent exercise variables. Eur J Appl Physiol. Feb 2010;108(3):469-476.

31. Maiorana A, O'Driscoll G, Cheetham $\mathrm{C}$, et al. Combined aerobic and resistance exercise training improves functional capacity and strength in CHF. J Appl Physiol (1985). May 2000;88(5):1565-1570. 
32. Miche E, Roelleke E, Wirtz U, et al. Combined endurance and muscle strength training in female and male patients with chronic heart failure. Clin Res Cardiol. Sep 2008;97(9):615-622.

33. Myers J, Prakash M, Froelicher V, Do D, Partington S, Atwood JE. Exercise capacity and mortality among men referred for exercise testing. $N$ Engl J Med. Mar 14 2002;346(11):793-801.

34. Owen A, Croucher L. Effect of an exercise programme for elderly patients with heart failure. Eur J Heart Fail. Mar 2000;2(1):65-70.

35. Savage PA, Shaw AO, Miller MS, et al. Effect of resistance training on physical disability in chronic heart failure. Med Sci Sports Exerc. Aug 2011;43(8):1379-1386.

36. Tyni-Lenne R, Gordon A, Jansson E, Bermann G, Sylven C. Skeletal muscle endurance training improves peripheral oxidative capacity, exercise tolerance, and health-related quality of life in women with chronic congestive heart failure secondary to either ischemic cardiomyopathy or idiopathic dilated cardiomyopathy. Am J Cardiol. Oct 15 1997;80(8):1025-1029.

37. Mandic S, Tymchak W, Kim D, et al. Effects of aerobic or aerobic and resistance training on cardiorespiratory and skeletal muscle function in heart failure: a randomized controlled pilot trial. Clin Rehabil. Mar 2009;23(3):207-216.

38. O'Connor CM, Whellan DJ, Lee KL, et al. Efficacy and safety of exercise training in patients with chronic heart failure: HF-ACTION randomized controlled trial. JAMA. Apr 8 2009;301(14):1439-1450.

39. Chen Z, Dunson DB. Random effects selection in linear mixed models. Biometrics. Dec 2003;59(4):762-769.

40. LILLIEFORS HW. On the Kolmogorov-Smirnov test for normality with mean and variance unknown. Journal of the American Statistical Association. 1967;62(318):4.

41. SNEDECOR GW. COCHRAN, W.G. Statistical methods. 7th ed: Ames: The Iowa State University Press; 1980.

42. Anagnostakou V, Chatzimichail $\mathrm{K}$, Dimopoulos $\mathrm{S}$, et al. Effects of interval cycle training with or without strength training on vascular reactivity in heart failure patients. J Card Fail. Jul 2011;17(7):585-591.

43. Laoutaris ID, Adamopoulos S, Manginas A, et al. Benefits of combined aerobic/resistance/inspiratory training in patients with chronic heart failure. A complete exercise model? A prospective randomised study. Int $J$ Cardiol. Sep 1 2013;167(5):1967-1972. 
44. Keast ML, Slovinec D'Angelo ME, Nelson CR, et al. Randomized trial of Nordic walking in patients with moderate to severe heart failure. Can $J$ Cardiol. Nov 2013;29(11):1470-1476.

45. Bouchla A, Karatzanos E, Dimopoulos S, et al. The addition of strength training to aerobic interval training: effects on muscle strength and body composition in $\mathrm{CHF}$ patients. J Cardiopulm Rehabil Prev. Jan-Feb 2011;31(1):47-51.

46. Georgantas A, Dimopoulos S, Tasoulis A, et al. Beneficial Effects of Combined Exercise Training on Early Recovery Cardiopulmonary Exercise Testing Indices in Patients With Chronic Heart Failure. Journal of Cardiopulmonary Rehabilitation and Prevention. 2014;34(6):378-385.

47. Roveda F, Middlekauff HR, Rondon MU, et al. The effects of exercise training on sympathetic neural activation in advanced heart failure: a randomized controlled trial. $J$ Am Coll Cardiol. Sep 3 2003;42(5):854-860.

48. Stolen KQ, Kemppainen J, Ukkonen H, et al. Exercise training improves biventricular oxidative metabolism and left ventricular efficiency in patients with dilated cardiomyopathy. J Am Coll Cardiol. Feb 5 2003;41(3):460-467.

49. Sabelis LW, Senden PJ, Fijnheer R, et al. Endothelial markers in chronic heart failure: training normalizes exercise-induced $\mathrm{vWF}$ release. Eur $J$ Clin Invest. Sep 2004;34(9):583-589.

50. Jonsdottir S, Andersen KK, Sigurosson AF, Sigurosson SB. The effect of physical training in chronic heart failure. Eur J Heart Fail. Jan 2006;8(1):97-101.

51. Antunes-Correa LM, Nobre TS, Groehs RV, et al. Molecular basis for the improvement in muscle metaboreflex and mechanoreflex control in exercise-trained humans with chronic heart failure. Am J Physiol Heart Circ Physiol. Dec 1 2014;307(11):H16551666.

52. Chrysohoou C, Angelis A, Tsitsinakis G, et al. Cardiovascular effects of high-intensity interval aerobic training combined with strength exercise in patients with chronic heart failure. A randomized phase III clinical trial. Int J Cardiol. Jan 20 2015;179:269-274.

53. Groehs RV, Toschi-Dias E, Antunes-Correa LM, et al. Exercise training prevents the deterioration in the arterial baroreflex control of sympathetic nerve activity in chronic heart failure patients. Am J Physiol Heart Circ Physiol. May 1 2015;308(9):H10961102. 
54. McKelvie RS, Teo KK, Roberts R, et al. Effects of exercise training in patients with heart failure: the Exercise Rehabilitation Trial (EXERT). Am Heart J. Jul 2002;144(1):23-30.

55. de Meirelles LR, Matsuura C, Resende Ade C, et al. Chronic exercise leads to antiaggregant, antioxidant and anti-inflammatory effects in heart failure patients. Eur $J$ Prev Cardiol. Oct 2014;21(10):1225-1232.

56. Santos JM, Kowatsch I, Tsutsui JM, et al. Effects of exercise training on myocardial blood flow reserve in patients with heart failure and left ventricular systolic dysfunction. Am J Cardiol. Jan 15 2010;105(2):243-248.

57. de Mello Franco FG, Santos AC, Rondon MUP, et al. Effects of home-based exercise training on neurovascular control in patients with heart failure. European Journal of Heart Failure. 2006;8(8):851-855.

58. Dracup K, Evangelista LS, Hamilton MA, et al. Effects of a home-based exercise program on clinical outcomes in heart failure. American Heart Journal. 2007;154(5):877-883.

59. Senden PJ, Sabelis LW, Zonderland ML, Hulzebos EH, Bol E, Mosterd WL. The effect of physical training on workload, upper leg muscle function and muscle areas in patients with chronic heart failure. International Journal of Cardiology. 2005;100(2):293-300.

60. Jakovljevic DG, Donovan G, Nunan D, et al. The effect of aerobic versus resistance exercise training on peak cardiac power output and physical functional capacity in patients with chronic heart failure. Int J Cardiol. Dec 3 2010;145(3):526-528.

61. Maiorana AJ, Naylor LH, Exterkate A, et al. The impact of exercise training on conduit artery wall thickness and remodeling in chronic heart failure patients. Hypertension. Jan 2011;57(1):56-62.

62. Selig S, Carey M, Menzies D, et al. Moderate-intensity resistance exercise training in patients with chronic heart failure improves strength, endurance, heart rate variability, and forearm blood flow*1. Journal of Cardiac Failure. 2004;10(1):21-30.

63. Williams AD, Carey MF, Selig S, et al. Circuit Resistance Training in Chronic Heart Failure Improves Skeletal Muscle Mitochondrial ATP Production Rate-A Randomized Controlled Trial. Journal of Cardiac Failure. 2007;13(2):79-85.

64. Tyni-Lenne R, Dencker K, Gordon A, Jansson E, Sylven C. Comprehensive local muscle training increases aerobic working capacity and quality of life and decreases 
neurohormonal activation in patients with chronic heart failure. Eur J Heart Fail. Jan 2001;3(1):47-52.

65. Belardinelli R, Georgiou D, Cianci G, Purcaro A. Effects of exercise training on left ventricular filling at rest and during exercise in patients with ischemic cardiomyopathy and severe left ventricular systolic dysfunction. Am Heart J. Jul 1996;132(1 Pt 1):61-70.

66. Belardinelli R, Georgiou D, Scocco V, Barstow TJ, Purcaro A. Low intensity exercise training in patients with chronic heart failure. J Am Coll Cardiol. Oct 1995;26(4):975982.

67. Chrysohoou C, Tsitsinakis G, Vogiatzis I, et al. High intensity, interval exercise improves quality of life of patients with chronic heart failure: a randomized controlled trial. Qjm. Jan 2014;107(1):25-32.

68. Van Craenenbroeck EM, Hoymans VY, Beckers PJ, et al. Exercise training improves function of circulating angiogenic cells in patients with chronic heart failure. Basic Res Cardiol. Sep 2010;105(5):665-676.

69. Erbs S, Hollriegel R, Linke A, et al. Exercise training in patients with advanced chronic heart failure (NYHA IIIb) promotes restoration of peripheral vasomotor function, induction of endogenous regeneration, and improvement of left ventricular function. Circ Heart Fail. Jul 2010;3(4):486-494.

70. Giannuzzi P, Temporelli PL, Corra U, Tavazzi L. Antiremodeling effect of long-term exercise training in patients with stable chronic heart failure: results of the Exercise in Left Ventricular Dysfunction and Chronic Heart Failure (ELVD-CHF) Trial. Circulation. Aug 5 2003;108(5):554-559.

71. Guazzi M, Vitelli A, Arena R. The effect of exercise training on plasma NT-pro-BNP levels and its correlation with improved exercise ventilatory efficiency in patients with heart failure. Int J Cardiol. Jul 12 2012;158(2):290-291.

72. Hambrecht R, Gielen S, Linke A, et al. Effects of exercise training on left ventricular function and peripheral resistance in patients with chronic heart failure: A randomized trial. JAMA. Jun 21 2000;283(23):3095-3101.

73. Huang SC, Wong MK, Lin PJ, et al. Modified high-intensity interval training increases peak cardiac power output in patients with heart failure. Eur J Appl Physiol. Sep 2014;114(9):1853-1862.

74. Kiilavuori K, Sovijarvi A, Naveri H, Ikonen T, Leinonen H. Effect of physical training on exercise capacity and gas exchange in patients with chronic heart failure. Chest. Oct 1996;110(4):985-991. 
75. Klecha A, Kawecka-Jaszcz K, Bacior B, et al. Physical training in patients with chronic heart failure of ischemic origin: effect on exercise capacity and left ventricular remodeling. Eur J Cardiovasc Prev Rehabil. Feb 2007;14(1):85-91.

76. Klocek M, Kubinyi A, Bacior B, Kawecka-Jaszcz K. Effect of physical training on quality of life and oxygen consumption in patients with congestive heart failure. Int $J$ Cardiol. Sep 1 2005;103(3):323-329.

77. Lenk K, Erbs S, Hollriegel R, et al. Exercise training leads to a reduction of elevated myostatin levels in patients with chronic heart failure. Eur J Prev Cardiol. Jun 2012;19(3):404-411.

78. Myers J, Gademan M, Brunner K, Kottman W, Boesch C, Dubach P. Effects of highintensity training on indices of ventilatory efficiency in chronic heart failure. $J$ Cardiopulm Rehabil Prev. Jan-Feb 2012;32(1):9-16.

79. Myers J, Wagner D, Schertler T, et al. Effects of exercise training on left ventricular volumes and function in patients with nonischemic cardiomyopathy: application of magnetic resonance myocardial tagging. Am Heart J. Oct 2002;144(4):719-725.

80. Passino C, Severino S, Poletti R, et al. Aerobic training decreases B-type natriuretic peptide expression and adrenergic activation in patients with heart failure. J Am Coll Cardiol. May 2 2006;47(9):1835-1839.

81. Sandri M, Kozarez I, Adams V, et al. Age-related effects of exercise training on diastolic function in heart failure with reduced ejection fraction: the Leipzig Exercise Intervention in Chronic Heart Failure and Aging (LEICA) Diastolic Dysfunction Study. Eur Heart J. Jul 2012;33(14):1758-1768.

82. Wielenga RP, Huisveld IA, Bol E, et al. Safety and effects of physical training in chronic heart failure. Results of the Chronic Heart Failure and Graded Exercise study (CHANGE). Eur Heart J. Jun 1999;20(12):872-879.

83. Corvera-Tindel T, Doering LV, Woo MA, Khan S, Dracup K. Effects of a home walking exercise program on functional status and symptoms in heart failure. American Heart Journal. 2004;147(2):339-346.

84. Koukouvou G, Kouidi E, Iacovides A, Konstantinidou E, Kaprinis G, Deligiannis A. Quality of life, psychological and physiological changes following exercise training in patients with chronic heart failure. Journal of Rehabilitation Medicine. 2004;36(1):3641. 
85. Malfatto G, Branzi G, Osculati G, et al. Improvement in Left Ventricular Diastolic Stiffness Induced by Physical Training in Patients With Dilated Cardiomyopathy. Journal of Cardiac Failure. 2009;15(4):327-333.

86. van den Berg-Emons R, Balk A, Bussmann H, Stam H. Does aerobic training lead to a more active lifestyle and improved quality of life in patients with chronic heart failure? European Journal of Heart Failure. 2004;6(1):95-100.

87. Gademan MG, Swenne CA, Verwey HF, et al. Exercise training increases oxygen uptake efficiency slope in chronic heart failure. Eur J Cardiovasc Prev Rehabil. Apr 2008;15(2):140-144.

88. Mueller L, Myers J, Kottman W, et al. Exercise capacity, physical activity patterns and outcomes six years after cardiac rehabilitation in patients with heart failure. Clin Rehabil. Oct 2007;21(10):923-931.

89. Sturm B, Quittan M, Wiesinger GF, Stanek B, Frey B, Pacher R. Moderate-intensity exercise training with elements of step aerobics in patients with severe chronic heart failure. Arch Phys Med Rehabil. Jul 1999;80(7):746-750.

90. Willenheimer R, Erhardt L, Cline C, Rydberg E, Israelsson B. Exercise training in heart failure improves quality of life and exercise capacity. Eur Heart J. May 1998;19(5):774-781.

91. Keteyian SJ, Brawner CA, Schairer JR, et al. Effects of exercise training on chronotropic incompetence in patients with heart failure. Am Heart J. Aug 1999;138(2 Pt 1):233-240.

92. van der Meer S, Zwerink M, van Brussel M, van der Valk P, Wajon E, van der Palen J. Effect of outpatient exercise training programmes in patients with chronic heart failure: a systematic review. Eur J Prev Cardiol. Aug 2012;19(4):795-803.

93. Dieberg G, Ismail H, Giallauria F, Smart NA. Clinical outcomes and cardiovascular responses to exercise training in heart failure patients with preserved ejection fraction: a systematic review and meta-analysis. J Appl Physiol (1985). Sep 15 2015;119(6):726733.

94. Lavie CJ, Arena R, Swift DL, et al. Exercise and the cardiovascular system: clinical science and cardiovascular outcomes. Circ Res. Jul 3 2015;117(2):207-219.

95. Kamiya KM, T.; Matsunaga, A.; Miida, K.; Ogura, M.N.; Kimura, M.; Noda, C.; Ymaoka-Tojo, M.; Inomata, T.; Izumi, T. . Decreased Strength of Quadriceps Increases the Risk of Mortality in Patients with Chronic Heart Failure. Circulation. 2010;122(A12709). 
96. Kishi T. Heart failure as an autonomic nervous system dysfunction. Journal of Cardiology. 2012;59(2):117-122.

97. Magnusson G, Gordon A, Kaijser L, et al. High intensity knee extensor training, in patients with chronic heart failure. Major skeletal muscle improvement. Eur Heart J. Jul 1996;17(7):1048-1055.

98. Ahmad T, Fiuzat M, Mark DB, et al. The effects of exercise on cardiovascular biomarkers in patients with chronic heart failure. Am Heart J. Feb 2014;167(2):193-202 e191.

99. Cattadori G, Agostoni P, Corra U, et al. Severe heart failure prognosis evaluation for transplant selection in the era of beta-blockers: role of peak oxygen consumption. Int $J$ Cardiol. Oct 12 2013;168(5):5078-5081.

100. de Morton NA. The PEDro scale is a valid measure of the methodological quality of clinical trials: a demographic study. Aust J Physiother. 2009;55(2):129-133.

101. Macedo LG, Elkins MR, Maher CG, Moseley AM, Herbert RD, Sherrington C. There was evidence of convergent and construct validity of Physiotherapy Evidence Database quality scale for physiotherapy trials. J Clin Epidemiol. Aug 2010;63(8):920-925. 
ANEXO B: Normas da revista "The Journal of the American of Medical Association"

\section{Manuscript Submission}

All manuscripts must be submitted online via the JAMA online manuscript submission and review system. At the time of submission, complete contact information (affiliation, postal/mail address, email address, telephone and fax numbers) for the corresponding author is required. First and last names, email addresses, and institutional affiliations of all coauthors are also required. After the manuscript is submitted, the corresponding author will receive an acknowledgment confirming receipt and a manuscript number. Authors will be able to track the status of their manuscripts via the online system. After manuscript submission, all authors of papers under consideration for publication will be sent a link to the Authorship Form to complete and submit (see sample Authorship Form). See Manuscript Checklist, Manuscript Preparation and Submission Requirements, and other details in these instructions for additional requirements.

\section{Cover Letter}

Include a cover letter and complete contact information for the corresponding author (affiliation, postal/mail address, email address, and telephone number) and whether the authors have published or submitted any related papers from the same study (see Duplicate/Previous Publication or Submission).

\section{Manuscript Style}

Manuscripts should be prepared in accordance with the AMA Manual of Style, 10th edition, 1 and/or the ICMJE Recommendations for the Conduct, Reporting, Editing, and Publication of Scholarly Work in Medical Journals.

\section{Manuscript Components}

Include a title page, abstract, text, references, and as appropriate, figure legends, tables, and figures. Start each of these sections on a new page, numbered consecutively, beginning with the title page. 


\title{
Recommended File Sizes
}

We recommend individual file sizes of no more than $500 \mathrm{kB}$ and not exceeding $1 \mathrm{MB}$, with the total size for all files not exceeding $5 \mathrm{MB}$ (not including any video files).

\section{Manuscript File Formats}

For submission and review, please submit the manuscript as a Word document. Do not submit your manuscript in PDF format. Use 10-, 11-, or 12-point font size, double-space text, and leave right margins unjustified (ragged).

\section{Title Page}

The title page should include a word count for text only (eg, not including abstract, acknowledgment, or references) and the full names, highest academic degrees, and affiliations of all authors. If an author's affiliation has changed since the work was done, the new affiliation also should be listed.

\section{Title}

Titles should be concise, specific, and informative and should contain the key points of the work. Please limit the length of titles to 150 characters for reports of research and other major articles and 100 characters for Editorials, Viewpoints, Commentaries, and Letters. For scientific manuscripts, overly general titles are not desirable and questions and declarative sentences should be avoided. For reports of clinical trials, meta-analyses, and systematic reviews, include the type of study as a subtitle (eg, A Randomized Clinical Trial, A Metaanalysis, A Systematic Review). For reports of other types of research, do not include study type or design in the title or subtitle.

\begin{abstract}
s
Include a structured abstract of no more than 350 words for reports of original data, reviews, and meta-analyses. Abstracts should be prepared in JAMA style-see instructions for preparing abstracts below. For other major manuscripts, include an unstructured abstract of no more than 200 words that summarizes the objective, main points, and conclusions of the article. Abstracts are not required for Editorials, Viewpoints, and some special features.
\end{abstract}


All reports of original data, systematic reviews, and meta-analyses should be submitted with structured abstracts as described below. No information should be reported in the abstract that does not appear in the text of the manuscript.

\section{Abstracts for Meta-analyses and The Rational Clinical Examination:}

Manuscripts reporting the results of meta-analyses should include an abstract of no more than 350 words using the headings listed below. The text of the manuscript should also include a section describing the methods used for data sources, study selection, data extraction, and data synthesis. Each heading should be followed by a brief description:

Importance: A sentence or 2 explaining the importance of the review question.

Objective: State the precise primary objective of the review. Indicate whether the review emphasizes factors such as cause, diagnosis, prognosis, therapy, or prevention and include information about the specific population, intervention, exposure, and tests or outcomes that are being reviewed.

Data Sources: Succinctly summarize data sources, including years searched. The search should include the most current information possible, ideally with the search being conducted within several months before the date of manuscript submission. Potential sources include computerized databases and published indexes, registries, abstract booklets, conference proceedings, references identified from bibliographies of pertinent articles and books, experts or research institutions active in the field, and companies or manufacturers of tests or agents being reviewed. If a bibliographic database is used, state the exact indexing terms used for article retrieval, including any constraints (for example, English language or human study participants). If abstract space does not permit this level of detail, summarize sources in the abstract including databases and years searched, and place the remainder of the information in the Methods section.

Study Selection: Describe inclusion and exclusion criteria used to select studies for detailed review from among studies identified as relevant to the topic. Details of selection should include particular populations, interventions, outcomes, or methodological designs. The method used to apply these criteria should be specified (for example, blinded review, consensus, multiple reviewers). State the proportion of initially identified studies that met selection criteria. 
Data Extraction and Synthesis: Describe guidelines used for abstracting data and assessing data quality and validity (such as criteria for causal inference). The method by which the guidelines were applied should be stated (for example, independent extraction by multiple observers).

Main Outcome(s) and Measure(s): Indicate the primary study outcome(s) and measurement(s) as planned before data collection began. If the manuscript does not report the main planned outcomes of a study, this fact should be stated and the reason indicated. State clearly if the hypothesis being tested was formulated during or after data collection. Explain outcomes or measurement unfamiliar to a general medical readership.

Results: State the main quantitative results of the review, including baseline characteristics and final included/analyzed studies and/or sample(s). Include the number of studies and patients/participants included in the analysis. Include absolute risks whenever possible (such as increase/decrease or absolute differences between groups), along with confidence intervals (for example, 95\%) or $P$ values. Meta-analyses should state the major outcomes that were pooled and include odds ratios or effect sizes and, if possible, sensitivity analyses. Numerical results should be accompanied by confidence intervals, if applicable, and exact levels of statistical significance. Evaluations of screening and diagnostic tests should include sensitivity, specificity, likelihood ratios, receiver operating characteristic curves, and predictive values. Assessments of prognosis should summarize survival characteristics and related variables. Major identified sources of variation between studies should be stated, including differences in treatment protocols, co-interventions, confounders, outcome measures, length of follow-up, and dropout rates.

Conclusions and Relevance: The conclusions and their applications (clinical or otherwise) should be clearly stated, limiting interpretation to the domain of the review.

\section{Tables and Figures}

Restrict tables and figures to those needed to explain and support the argument of the article and to report all outcomes identified in the Methods section. Number each table and figure and provide a descriptive title for each. Every table and figure should have an in-text citation. Verify that data are consistently reported across text, tables, figures, and supplementary material. See also Tables and Figures. 
Frequency data should be reported as "No. (\%)," not as percentages alone (exception, sample sizes exceeding $\sim 10,000$ ). Whenever possible, proportions and percentages should be accompanied by the actual numerator and denominator from which they were derived. This is particularly important when the sample size is less than 100. Do not use decimal places (ie, $\mathrm{xx} \%$, not $\mathrm{xx} \cdot \mathrm{xx} \%)$ if the sample size is less than 100. Tables that include results from multivariable regression models should focus on the primary results. Provide the unadjusted and adjusted results for the primary exposure(s) or comparison(s) of interest. If a more detailed description of the model is required, consider providing the additional unadjusted and adjusted results in supplementary tables. Tables have a minimum of 2 columns. Comparisons must read across the table columns. Do not duplicate data in figures and tables. For all primary outcomes noted in the Methods section, exact values with measures of uncertainty should be reported in the text or in a table and in the Abstract, and not only represented graphically in figures. Pie charts and 3-D graphs should not be used and should be revised to alternative graph types.

Bar graphs should be used to present frequency data only (ie, numbers and rates). Avoid stacked bar charts and consider alternative formats (eg, tables or splitting bar segments into side-by-side bars) except for comparisons of distributions of ordinal data.

Summary data (eg, means, odds ratios) should be reported using data markers for point estimates, not bars, and should include error bars indicating measures of uncertainty (eg, SDs, 95\% CIs). Actual values (not log-transformed values) of relative data (for example, odds ratios, hazard ratios) should be plotted on log scales.

For survival plots, include the number at risk for each group included in the analysis at intervals along the $\mathrm{x}$-axis scale. For any figures in which color is used, be sure that colors are distinguishable. All symbols, indicators, line styles, and colors in statistical graphs should be defined in a key or in the figure legend. Axes in statistical graphs must have labels. Units of measure must be provided for continuous data.

Note: all figures are recreated by journal graphics experts according to reporting standards using The JAMA Network style guide and color palette. 


\section{Units of Measure}

Laboratory values are expressed using conventional units of measure, with relevant System International (SI) conversion factors expressed secondarily (in parentheses) only at first mention. Articles that contain numerous conversion factors may list them together in a paragraph at the end of the Methods section. In tables and figures, a conversion factor to SI should be presented in the footnote or legend. The metric system is preferred for the expression of length, area, mass, and volume. For more details, see the Units of Measure conversion table on the website for the AMA Manual of Style..$^{1}$

\section{Names of Drugs, Devices, and Other Products}

Use nonproprietary names of drugs, devices, and other products, unless the specific trade name of a drug is essential to the discussion.

\section{Gene Names, Symbols, and Accession Numbers}

Authors describing genes or related structures in a manuscript should include the names and official symbols provided by the US National Center for Biotechnology Information (NCBI) or the HUGO Gene Nomenclature Committee. Before submission of a research manuscript reporting on large genomic data sets (eg, protein or DNA sequences), the data sets should be deposited in a publicly available database, such as NCBI's GenBank, and a complete accession number (and version number if appropriate) must be provided in the Methods section or Acknowledgment of the manuscript.

\section{Reproduced Material}

$J A M A$ does not republish text, tables, figures, or other material from other publishers, except under rare circumstances. Please delete any such material and replace with originals.

\section{References}

Authors are responsible for the accuracy and completeness of their references and for correct text citation. Number references in the order they appear in the text; do not alphabetize. In text, tables, and legends, identify references with superscript Arabic numerals. When listing references, follow AMA style and abbreviate names of journals according to the journals list in PubMed. List all authors and/or editors up to 6; if more than 6, list the first 3 followed by 
"et al." Note: Journal references should include the issue number in parentheses after the volume number.

Examples of reference style:

1. Youngster I, Russell GH, Pindar C, Ziv-Baran T, Sauk J, Hohmann EL. Oral, capsulized, frozen fecal microbiota transplantation for relapsing Clostridium difficile infection. JAMA. 2014;312(17):1772-1778.

2. Murray CJL. Maximizing antiretroviral therapy in developing countries: the dual challenge of efficiency and quality [published online December 1, 2014]. JAMA. doi:10.1001/jama.2014.16376.

3. Centers for Medicare \& Medicaid Services. CMS proposals to implement certain disclosure provisions of the Affordable Care Act. http://www.cms.gov/apps/media/press/factsheet.asp?Counter=4221. Accessed January 30, 2012.

4. McPhee SJ, Winker MA, Rabow MW, Pantilat SZ, Markowitz AJ, eds. Care at the Close of Life: Evidence and Experience. New York, NY: McGraw Hill Medical; 2011.

\section{Tables}

Number all tables in the order of their citation in the text. Include a title for each table (a brief phrase, preferably no longer than 10 to 15 words). Include all tables at the end of the manuscript file. Refer to Categories of Articles because there may be a limit on the number of tables for the type of manuscript. If a table must be continued, repeat the title on the second page, followed by “(continued)."

\section{Figures}

Number all figures (graphs, charts, photographs, and illustrations) in the order of their citation in the text. Include a title for each figure (a brief phrase, preferably no longer than 10 to 15 words). For initial manuscript submissions, figures must be of sufficient quality for editorial assessment and peer review. If the manuscript is accepted, authors will be asked to provide figures that meet the Guidelines for Figures in Accepted Manuscripts. Graphs, charts, titles, and legends in accepted manuscripts will be re-created or edited according to JAMA style and standards prior to publication. All illustrations of accepted manuscripts will be redrawn by 
JAMA medical illustrators. Online-only figures will not be edited or re-created (see OnlineOnly Material).

\section{Image Integrity}

Preparation of scientific images (clinical images, radiographic images, micrographs, gels, etc) for publication must preserve the integrity of the image data. Digital adjustments of brightness, contrast, or color applied uniformly to an entire image are permissible as long as these adjustments do not selectively highlight, misrepresent, obscure, or eliminate specific elements in the original figure, including the background. Selective adjustments applied to individual elements in an image are not permissible. Individual elements may not be moved within an image field, deleted, or inserted from another image. Cropping may be used for efficient image display but must not misrepresent or alter interpretation of the image by selectively eliminating relevant visual information. Juxtaposition of elements from different parts of a single image or from different images, as in a composite, must be clearly indicated by the addition of dividing lines, borders, and/or panel labels.

When inappropriate image adjustments are detected by the JAMA staff, authors will be asked for an explanation and will be requested to submit the image as originally captured prior to any adjustment, cropping, or labeling. Authors may be asked to resubmit the image prepared in accordance with the above standards.

\section{Acceptable Figure File Size}

To reduce the time that it takes to upload files to the JAMA submission site and for reviewers to download files from the site, we recommend that the file size of figures be compressed before uploading them. This can be done by using compression software or by decreasing the resolution of individual files.

\section{Acceptable Figure File Formats}

At submission, the following file formats are acceptable: AI, BMP, DOC, EMF, EPS, JPG, PDF, PPT, PSD, TIF, WMF, or XLS. Figures may be embedded at the end of the manuscript text file or loaded as separate files for submission purposes. 


\section{Figure Titles and Legends (Captions)}

At the end of the manuscript, include a title for each figure. The figure title should be a brief descriptive phrase, preferably no longer than 10 to 15 words. A figure legend can be used for a brief explanation of the figure or markers if needed (preferred maximum length, 40 words) and expansion of abbreviations. For photomicrographs, include the type of specimen, original magnification or a scale bar, and stain in the legend. For gross pathology specimens, label any rulers with unit of measure. Digitally enhanced images must be clearly identified in the figure legends as enhanced or manipulated, eg, computed tomographic scans, magnetic resonance images, photographs, photomicrographs, x-ray films.

\section{Figures with Labels, Arrows, or Other Markers}

Photographs, clinical images, photomicrographs, gel electrophoresis, and the like that include labels, arrows, or other markers must be submitted in 2 versions: one version with the markers and one without. Provide an explanation for all labels, arrows, or other markers in the figure legend. The Figure field in the File Description tab of the manuscript submission form allows for uploading of 2 versions of the same figure.

\section{Number of Figures}

Refer to Categories of Articles as there may be a limit on the number of figures for the type of manuscript.

\section{Online-Only Supplements and Multimedia}

Authors may submit supporting material to accompany their article for online-only publication when there is insufficient space to include the material in the print article. This material should be important to the understanding and interpretation of the report and should not repeat material in the print article. The amount of online-only material should be limited and justified. Online-only material should be original and not previously published.

Online-only material will undergo editorial and peer review with the main manuscript. If the manuscript is accepted for publication and if the online-only material is deemed appropriate for publication by the editors, it will be posted online at the time of publication of the article 
as additional material provided by the authors. This material will not be edited or formatted; thus, authors are responsible for the accuracy and presentation of all such material.

Online-only material should be submitted in a single Word document with pages numbered consecutively. Each element included in the online-only material should be cited in the text of the main manuscript (eg, eTable in the Supplement) and numbered in order of citation in the text (eg, eTable 1, eTable 2, eFigure 1, eFigure 2, eMethods). The first page of the onlineonly document should list the number and title of each element included in the document.

\section{Online-Only Text}

Online-only text should be set in Times New Roman font, 10 point in size, and single-spaced. The main heading of the online-only text should be in 12 point and boldface; subheadings should be in 10 point and boldface.

\section{Online-Only References}

All references cited within the online-only document must be included in a separate reference section, including those that also were cited in the main manuscript. They should be formatted just as in the main manuscript and numbered and cited consecutively in the online-only material.

\section{Online-Only Tables}

Online-only tables should be inserted in the document and numbered consecutively according to the order of citation as eTable 1, eTable 2 , etc. The text and data in online tables should be Arial font, 10 point in size, and single-spaced. The table title should be set in Arial font, 12 point, and bold. Headings within tables should be set in 10 point and bold. Table footnotes should be set in 8 point and single-spaced. See also instructions for Tables above. If a table runs on to subsequent pages, repeat the column headers at the top of each page. Wide tables may be presented using a landscape orientation.

\section{Online-Only Figures}

Online-only figures should be inserted in the document and numbered consecutively according to the order of citation as eFigure 1, eFigure 2, etc. Figure titles should be set in Arial font, 12 point, bold, and single-spaced. Text within figures should be set as Arial font, 
10 point. Figure legends should be set in 8 point and single-spaced. Graphs and diagrams should be exported directly out of the software application used to create them in a vector file format, such as .wmf, and then inserted into the Word document. Image file formats such as .jpg, .tif, and .gif are generally not suitable for graphs. Photographs, including all radiological images, should be prepared as .jpg (highest option) or .tif (uncompressed) files at a resolution of 300 dpi and width of 3-5 inches, but the resolution of photographic files with an original resolution <300 dpi should not be increased digitally to achieve a 300-dpi resolution. Photographs should be inserted in the document with the "Link to File" button turned off. Wide figures may be presented using a landscape orientation. 
ANEXO C: Parecer consubstanciado do CEP da Faculdade de Medicina da Universidade de São Paulo - FMUSP

\section{FACULDADE DE MEDICINA DA UNIVERSIDADE DE SÃO PAULO - FMUSP}

\section{PARECER CONSUBSTANCIADO DO CEP}

\section{DADOS DO PROJETO DE PESQUISA}

Título da Pesquisa: ANÁLISE DO IMPACTO DA VENTILAÇÃO MECÃNICA NÃO INVASIVA EM PACIENTES COM CÂNCER

Pesquisador: Gerson Cipriano Junior

Área Temática:

Versão: 2

CAAE: 47167815.4 .0000 .0065

Instituição Proponente: FUNDACAO FACULDADE DE MEDICINA

Patrocinador Principal: Financiamento Próprio

DADOS DO PARECER

Número do Parecer: 1.222 .069

\section{Apresentação do Projeto:}

Projeto bem fundamentado, relevante na área de Fisioterapia Respiratória, viável e sem impecilho ético.

\section{Objetivo da Pesquisa:}

Verificar o impacto do uso da VMNI nos desfechos clínicos de pacientes oncológicos clínicos e cirúrgicos.

\section{Avaliação dos Riscos e Benefícios:}

As informações no que dizem respeito à elaboração de um perfil destes pacientes que podem ou não se beneficiar desta modalidade de assistência ventilatória podem ser de importância na potencialização dos efeitos positivos, já descritos na literatura. Adicionalmente, uma análise comparativa entre pacientes clínicos e cirúrgicos pode ser útil para esclarecermos fatores que podem ser específicos ou inerentes a cada tipo de paciente dando informações importantes ao meio científico na condução terapêutica desta população. Por fim, acreditamos que um melhor conhecimento do impacto da VMNI nesta população pode contribuir para a melhor utilização desta intervenção neste subgrupo, trazendo beneficios a estes pacientes no entendimento mais aprofundado de seu desdobramento.

Endereço: DOUTOR ARNALDO $25121^{\circ}$ andar sala 36
Bairro: PACAEMBU
UF: SP Município: SAO PAULO
Telefone: (11)3893-4401
CEP: $01.246-903$ 
Comentários e Considerações sobre a Pesquisa:

Metodologia pertinente para responder a pergunta levantada na pesquisa. Projeto viável.

Pendências respondidas de forma satisfatória.

Considerações sobre os Termos de apresentação obrigatória:

Todas as pendências foram esclarecidas de forma satisfatória:

1. Documento faltante de Coparticipação da Universidade de Brasília

Resposta: Documento em anexo

2. Pesquisa com finalidade de mestrado - onde? Já que não é citado nenhum departamento da FMUSP ou o local a ser executada.

Resposta: A presente pesquisa a ser realizada no ICESP tem a finalidade de Mestrado que está sendo realizado na Universidade de Brasília, através do Programa de Pós-graduação em Ciências e Tecnologias, no qual o aluno Francisco Valdez Santos de Oliveira Lima está devidamente matriculado, estando o mesmo também vinculado ao ICESP.

3. A Universidade de Brasília é colocada como instituição coparticipante - qual a participação?

Resposta: A Universidade de Brasilia participa através do Programa de Pós-graduação em Ciências e Tecnologias, no qual o aluno acima citado encontra-se vinculado, com todo o apoio acadêmico necessário e orientação nas etapas de realização do projeto de pesquisa em questão.

4. Documento do ICESP dando permissão para pesquisa, já que a folha de rosto foi assinada em nome desta instituição.

Resposta: Documento de permissão em anexo

5. Esclarecer a origem do Orientador e a relação deste com o ICESP

Resposta: O referido orientador é Professor do Curso de Fisioterapia da Faculdade de

Ceilândia - UnB. É também Coordenador do Programa de Pós-graduação em Ciências e

Tecnologias dessa Universidade e Orientador do aluno e pesquisador citado acima. Desta

forma, a relação com o ICESP se dá de forma indireta, a partir do pesquisador Francisco

Valdez Santos de Oliveira Lima, que possui vínculo direto com o ICESP, como 
Contnuaçăo do Parecer. 1.222.069

Fisioterapeuta desta instituição.

Recomendações:

Aprovação.

Conclusões ou Pendências e Lista de Inadequações:

Sem pendências.

Consideraçôes Finais a critério do CEP:

Este parecer foi elaborado baseado nos documentos abaixo relacionados:

\begin{tabular}{|c|c|c|c|c|}
\hline Tipo Documento & Arquivo & Postagem & Autor & Situação \\
\hline Outros & Carta_UnB.pdf & $\begin{array}{c}28 / 08 / 2015 \\
08: 10: 00\end{array}$ & $\begin{array}{l}\text { Gerson Cipriano } \\
\text { Junior }\end{array}$ & Aceito \\
\hline Outros & Esclarecimentos_pendencias_CEP.pdf & $\begin{array}{c}28 / 08 / 2015 \\
08: 11: 35\end{array}$ & $\begin{array}{l}\text { Gerson Cipriano } \\
\text { Junior }\end{array}$ & Aceito \\
\hline $\begin{array}{l}\text { Projeto Detalhado / } \\
\text { Brochura } \\
\text { Investigador }\end{array}$ & Projeto.pdf & $\begin{array}{c}28 / 08 / 2015 \\
08: 02: 57\end{array}$ & $\begin{array}{l}\text { Gerson Cipriano } \\
\text { Junior }\end{array}$ & Aceito \\
\hline Outros & Cadastro_HC.pdf & $\begin{array}{c}28 / 08 / 2015 \\
08: 04: 45\end{array}$ & $\begin{array}{l}\text { Gerson Cipriano } \\
\text { Junior }\end{array}$ & Aceito \\
\hline Outros & Carta_permissao.pdf & $\begin{array}{c}28 / 08 / 2015 \\
08: 08: 31\end{array}$ & $\begin{array}{l}\text { Gerson Cipriano } \\
\text { Junior }\end{array}$ & Aceito \\
\hline Folha de Rosto & FOLHA_DE_ROSTO_FINAL.pdf & $\begin{array}{c}28 / 08 / 2015 \\
08: 14: 11 \\
\end{array}$ & $\begin{array}{l}\text { Gerson Cipriano } \\
\text { Junior }\end{array}$ & Aceito \\
\hline $\begin{array}{l}\text { Informações Básicas } \\
\text { do Projeto }\end{array}$ & $\begin{array}{l}\text { PB_INFORMAÇÓES_BÁSICAS_DO_P } \\
\text { ROJETO 545997.pdf }\end{array}$ & $\begin{array}{c}28 / 08 / 2015 \\
08: 14: 58 \\
\end{array}$ & & Aceito \\
\hline
\end{tabular}

Situação do Parecer:

Aprovado

Necessita Apreciação da CONEP:

Não

SAO PAULO, 10 de Setembro de 2015

Assinado por:

Maria Aparecida Azevedo Koike Folgueira

(Coordenador) 
ANEXO D: Parecer consubstanciado do CEP da Universidade Federal de São Paulo / Hospital São Paulo

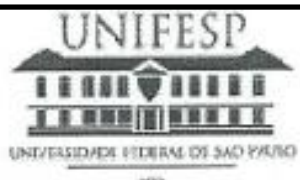

ros

\section{Universidade fodoral de STro Paub \\ Escole Paudists do Monoricino}

Comits on Ethice arn Pescovise

Hospear S 80 Paulo

Såo Paulo, 15 de fevereiro de 2008

CEP N $N^{\circ}$ : $1521 / 07$

IImo(a) Sria

Pesquisador(a): RAQUEL CRISTINA KOYAMA

Disciplina/Departamento: Cirurgia Cardiovascular/Cirurgia

Pesquisadores associados: Gerson Cipriano Junior, Cristie Gregorini, Amanda Amatti Marques, Enio Buffolo (orientador)

Parecer Consubstanciado do Comitê de Ética em Pesquisa da
Universidade Federal de São Paulo/Hospital Săo Paulo

TITULO DO ESTUDO: Efeito agudo da aplicaçăo de exercicio resistido após cirurgia de revascularização do miocárdio em ambiente hospitalar : $2^{\mathrm{a}}$ via do parecer emitida em 15/08/2015

CARACTERISTICA PRINCIPAL DO ESTUDO: Interveção terapêutica năo medicamentosa - fisioterapia RISCOS ADICIONAIS PARA O PACIENTE: Risco minimo, desconforto minimo, sem procedimento invasivo OBJETIVO DO ESTUDO: Verificar o comportamento cardiovascular durante a realizaçāo de exercicios resistidos na fase hospitalar da reabilitaçĕo cardiaca

RESUMO: Este estudo pretende verificar alteraç5es hemodinâmicas agudas durante a realizaçăodo teste de esforço máximo (1RM) e exercicios com cargas relativas (\%RM) durante a recuperaçäo hospitalar após cirurgia cardiaca, para verificar sua segurança e permitir sua utilização nesta fase. Este é um estudo coorte prospectivo, realizado no periodo de recuperaçāo hospitalar com individuos após cirurgia de revascularizaçăo do miocárdio, na enfermaria do setor de cirurgia cardiaca no Hospital Săo Paulo. Participaräo pacientes no $4^{\circ}$ dia pós-operatório de revascularização do miocárdio. 0 procedimento consistirá das seguintes etapas: 1- avaliaçäo pos-operatória; 2- teste de força máxima (1RM); 3-prescriçăo de cargas de 40,60 e $80 \%$ de $1 \mathrm{RM}$. Serão colhidas as seguintes variáveis: pressão arterial, freqüencia cardiaca, duplo produto, saturaçäo periférica de oxigênio, frequêencia respiratória e eletrocardiograma, escala de percepçăo do esforço aplicada para membros inferiores e para o esforço físico geral. O protocolo será interrompido na presença de sinais e sintornas que representem intoleráncia ao exercicio. Após 24 horas de aplicaçáo do protocolo, o paciente será reavaliado para verificar possiveis sinais de exercicio excessivo

FUNDAMENTOS E RACIONAL: Vários estudos têm avaliado o efeito do treinamento rasistido e teste de força máxima (1RM) em pacientes com insuficiência cardiaca congestiva, incluindo pacients em classe funcional III e IV e fraçäo de ejeçăo de até $20 \%$, mostarndo segurança na sua aplicaçăo,s em alteraçōes clinicas e hemodinămicas. Este estudo visa avaliar as respostas cardiovasculares agudas causadas por exercicios resistidos aplicados na fase hospitalar após cirurgia cardiaca.

MATERIAL E METODO: Estão descritos os procedimentos, sendo a realizaçăo dos exercicios monitorada durante todo o tempo.

TCLE: Adequado, contemplando a resoluçăb 196/96

DETALHAMENTO FINANCEIRO: Sem financiamento externo

CRONOGRAMA DO ESTUDO: 6 meses

PRIMEIROS RELATÓRIOS PARCIAIS PREVISTOS PARA : 09/02/2009 e 04/02/2010

$O$ Comite de Ética em Pesquisa da Universidade Federal de São Paulo/Hospital São Paulo ANALISOU e APROVOU o projeto de pesquisa referenciado.

1. Comunicar toda e qualquer alteraçāo do projeto e termo de consentimento livre e esclarecido. Nestas circunstảncias a inclusấo de pacientes deve ser temporariamente interrompida até a resposta do Comité, após análise das mudanças propostas.

2. Comunicar imediatamente ao Comitê qualquer evento adverso ocorrido durante o desenvolvimento do estudo. 3. Os dados individuais de todas as etapas da pesquisa devern ser mantidos em local seguro por 5 anos para possivel auditoria dos órgâos competentes.

Atenciosamente,

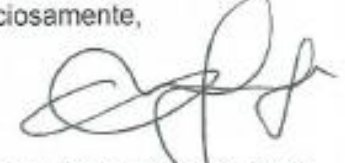

Prof. Dr. Miguel Rodelto Jorge

Coordenador do Comitê de Etica em Pesquisa da

Universidade Federal de São Paulo/Hospital Săo Paulo 


\section{APÊNDICE}

Apêndice A: Contribuições Científicas Durante O Programa

\section{TRABALHOS EM ANDAMENTO}

Título: "Análise do impacto da ventilação mecânica não invasiva em pacientes com Câncer". Número de parecer CEP: 1.222.069 (Anexo C)

Delineamento do Estudo: Trata-se de um estudo de Coorte retrospectivo para análise do impacto da ventilação não invasiva em pacientes com diagnóstico de neoplasia maligna. A coleta de dados consiste em análise de banco de dados eletrônico.

Objetivos: Verificar o impacto da ventilação mecânica não invasiva nos desfechos clínicos de pacientes oncológicos clínicos e cirúrgicos

Este projeto foi inicialmente cogitado para ser finalizado e utilizado para defesa do mestrado. Entretanto, em virtude de ser um trabalho bastante extenso não seria possível a sua finalização em tempo hábil. Desta forma, o referido trabalho será tema de minha dissertação de Doutorado, havendo, portanto, tempo suficiente para o seu término dentro do prazo estipulado. Atualmente, estamos em fase de coleta de dados no Instituto do Câncer do Estado de São Paulo (ICESP), com um total de 150 (cento e cinquenta) pacientes já coletados até o momento, sendo previsto um total de 560 pacientes com base no cálculo amostral previamente realizado na confecção do projeto.

\section{ARTIGOS SUBMETIDOS}

1. Vieira, L. Cipriano, G. Jr. Chiappa, A.M.G. Cipriano, G.F.B. Vieira, P.J.C. Zago, J.G. Castilhos, M. Santos, F.V. Chiappa, G.R. Combined effect of neuromuscular electrical stimulation on mobilization decreases duration of mechanical Ventilation: A randomized controlled trial. Submetido para a Revista "Physiotherapy Theory and Practice".

\section{ABSTRACT}

Background: Early mobilization can be employed to minimize the duration of intensive care. However, the effect of the combination of an early mobilization protocol associated neuromuscular electrical stimulation (NMES) has not been tested. The aim of the present 
study was to assess the efficacy of NMES, active mobilization (AM), and combined therapy $(\mathrm{NMES}+\mathrm{AM})$ on duration of mechanical ventilation in critically ill patients. Methods: The participants in this randomized, double-blind trial were prospectively recruited within 24 hours following admission to the intensive care unit of a tertiary hospital from March 2012 to April 2014. Computer-generated permuted block randomization was used to assign the patients to NMES, AM, NMES+AM and usual care (control group). The main endpoint was duration of mechanical ventilation. Clinical characteristics were also evaluated and intention to treat analysis was employed. Results: One hundred forty-four patients were assessed for eligibility to participate in the trial, 51 of whom were enrolled and randomly allocated to the four groups: 11 patients in the NMES group, 13 in the AM group, 12 in the NMES+AM group and 15 in the control group. Duration of mechanical ventilation was significantly shorter in the combined therapy group (median: 7.2 days; IQR: 5.7 to 8.7 days; $p=0.033$ ) in comparison to the control group, NMES or AM alone. Conclusions: Combined therapy consisting of NMES combined with active exercises proved to be a safe, well tolerated method that resulted in shorter duration of mechanical ventilation in comparison to standard care or isolated therapy (NMES or AM alone). Key words: Eletrostimulation, exercise, intensive care unit, patients

\section{ARTIGOS EM CONFECÇÃO}

1. Wolpat, A. Silva, F.M.F. Tochetto, M. Santos, F.V. Freitas, A.T. Grandi, T. Rodrigues, L. Paiva, V. Cipriano, G. Jr. Chiappa, A.M.G. Zago, J.G. Chiappa, G.R. Inspiratory muscle weakness as a determinant for the performance during six-minute walk test in patients with obstructive pulmonary disease. Artigo em fase de revisão final. Contribuição na confecção do artigo.

2. Santos, F.V. Chiappa, G.R. Cipriano, G. Jr. Analysis of acute hemodynamic responses during resistance exercise in postoperative cardiovascular surgery. Artigo em fase final de confecção como autor principal do artigo. 